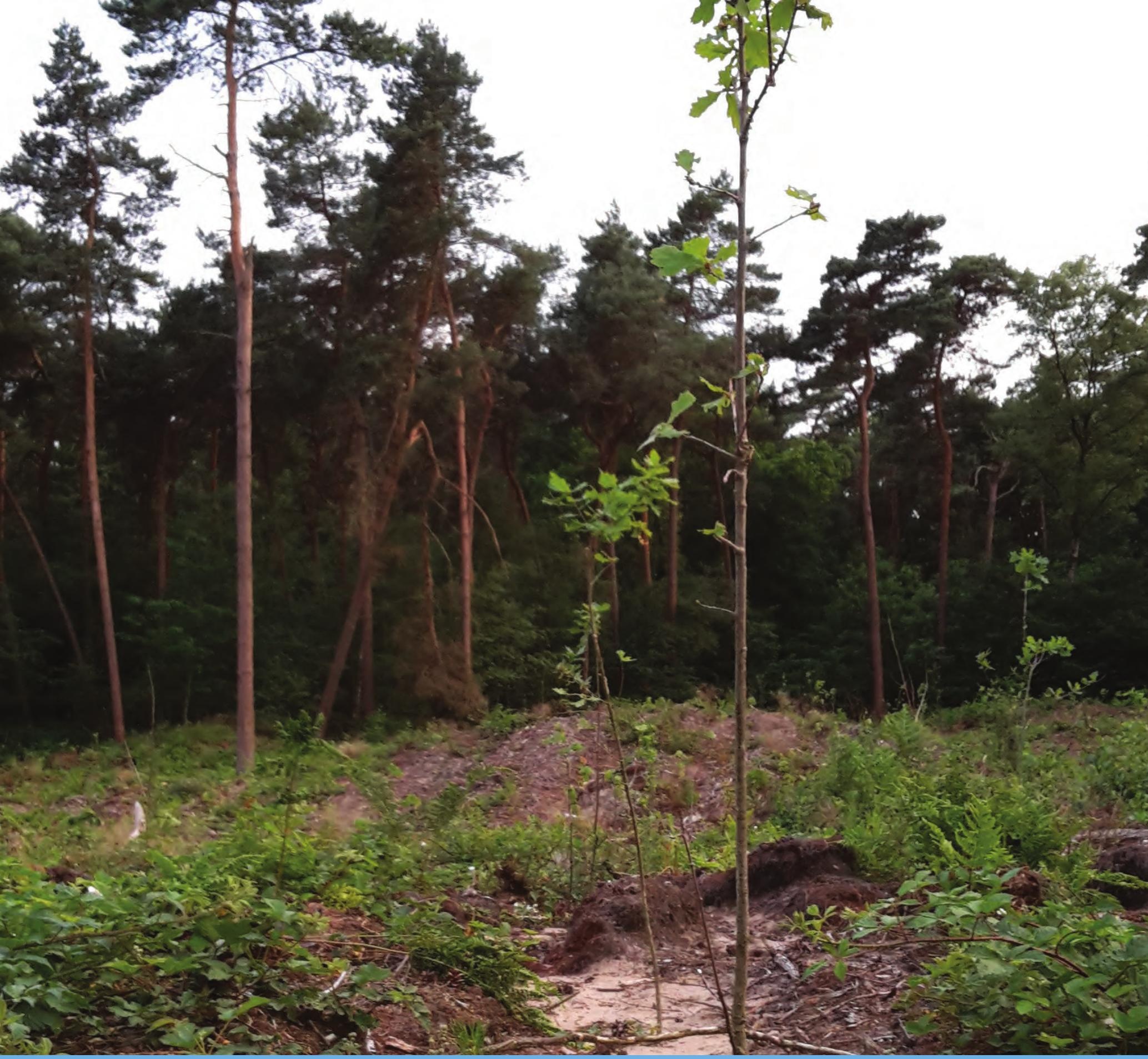

Effects of the EU-LULUCF regulation on the use of biomass for bio-energy

G.J. Nabuurs, E.J.M.M. Arets, J.-P. Lesschen and M.J. Schelhaas

WAGENINGEN

UNIVERSITY \& RESEARCH 



\section{Effects of the EU-LULUCF regulation on the use of biomass for bio-energy}

G.J. Nabuurs, E.J.M.M. Arets, J.-P. Lesschen and M.J. Schelhaas 
Nabuurs, G.J., E.J.M.M. Arets, J.-P. Lesschen and M.J. Schelhaas, 2018. Effects of the EU-LULUCF regulation on the use of biomass for bio-energy. Wageningen, Wageningen Environmental Research, Report 2886. 68 pp.; 27 fig.; 2 tab.; 33 ref.

Keywords: LULUCF, bio-energy, biomass, European forests

This project was carried out in the framework of the Renewable Energy Programme of the Netherlands Enterprise Agency, financed by the Ministry of Economic Affairs and Climate.

Contact: Kees.Kwant@RVO.nl

The pdf file is free of charge and can be downloaded at https://doi.org/10.18174/449788 or via the website www.wur.nl/environmental-research (scroll down to Publications - Wageningen Environmental Research reports). Wageningen Environmental Research does not deliver printed versions of the Wageningen Environmental Research reports.

(c) 2018 Wageningen Environmental Research (an institute under the auspices of the Stichting Wageningen Research), P.O. Box 47, 6700 AA Wageningen, The Netherlands,

T +31 (0) 3174807 00, www.wur.nl/environmental-research. Wageningen Environmental Research is part of Wageningen University \& Research.

- Acquisition, duplication and transmission of this publication is permitted with clear acknowledgement of the source.

- Acquisition, duplication and transmission is not permitted for commercial purposes and/or monetary gain.

- Acquisition, duplication and transmission is not permitted of any parts of this publication for which the copyrights clearly rest with other parties and/or are reserved.

Wageningen Environmental Research assumes no liability for any losses resulting from the use of the research results or recommendations in this report.

Wageningen Environmental Research Report 2886 | ISSN 1566-7197

Photo cover: G.J. Nabuurs 


\section{Contents}

$\begin{array}{ll}\text { Acknowledgements } & 5\end{array}$

$\begin{array}{ll}\text { Summary } & 7\end{array}$

1

$\begin{array}{ll}\text { Background } & 9\end{array}$

The Concept of capturing a forest carbon balance in reporting and accounting

3.1 Reporting vs accounting of the forest carbon balance 11

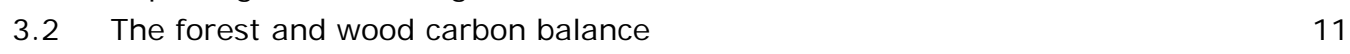

$\begin{array}{ll}\text { The reporting as mandatory for all countries } & 16\end{array}$

4.1 National Greenhouse Gas Reporting 16

$\begin{array}{lll}4.2 & \text { The LULUCF sector } & 17\end{array}$

$\begin{array}{lll}4.3 & \text { Forest Land } & 17\end{array}$

4.4 Cropland and Grassland $\quad 20$

$\begin{array}{lll}4.5 & \text { Inventory summary } & 20\end{array}$

$5 \quad$ The new EU LULUCF regulation and its room for interpretation (task 1) 22

5.1 The EU LULUCF regulation in more detail $\quad 22$

$\begin{array}{ll}5.2 & \text { LULUCF regulation accounting } \\ \end{array}$

5.2.1 Afforestation and deforestation $\quad 25$

5.2.2 Managed Forest land and harvest intensity $\quad 25$

5.2.3 Accounting of Harvested wood 26

5.2.4 National Forestry Accounting Plan 26

5.3 Accounting in relation to woody biomass use 26

$\begin{array}{ll}\text { 5.3.1 Compensation mechanism } & 28\end{array}$

6 Effects of the new LULUCF regulation on the production and use of biomass ( Task 2 )

6.1 Assessment of potential effect of LULUCF regulation on total wood harvest in Europe.

6.1.1 Methods 31

6.1.2 Simulations

6.1.3 Results 33

6.1.4 Constraints for increasing the harvest level in the Netherlands 36

6.2 Potential effects on agricultural biomass 37

6.3 Assessment of effects of straw use on soil carbon 38

6.4 Use of agricultural biomass for materials and biofuels 40

6.5 Indirect Land Use Change (ILUC) effects $\quad 41$

Effects of the LULUCF regulation on views and perceptions of (imported) biomass (Task 3)

7.1 Effects on import of biomass

7.2 Effects on the Action Plan Forest and Wood and the additional 100,000 ha in the Netherlands 
7.3 Does the new LULUCF regulation result in a change in accounting of the contribution of biomass to $\mathrm{CO}_{2}$ reductions?

7.4 Effects of the LULUCF regulation on application of biomass for energy in comparison to using it in materials or chemicals?

LULUCF regulation in relation to Dutch sustainability criteria and the RED (Task 4)

$\begin{array}{lll}8.1 & \text { Comparison of text in regulations } & 46\end{array}$

8.1.1 LULUCF regulation $\quad 46$

8.1.2 Renewable Energy Directive $\quad 47$

8.1.3 Comparison of the regulations 48

8.2 How Member States can show compliance with criteria 49

9 $\begin{array}{ll}\text { Conclusions } & 57\end{array}$

$\begin{array}{ll}\text { References } & 59\end{array}$

$\begin{array}{lll}\text { Annex } 1 & \text { Glossary } & 61\end{array}$

$\begin{array}{lll}\text { Annex } 2 & \text { Accounting principles for EU forests before } 2020 & 64\end{array}$ 


\section{Acknowledgements}

This study was carried out through a contract provided by the Dutch Executive agency 'RVO', contract 'Onderzoek naar mogelijke effecten van voorgenomen EU regelgeving t.a.v. Land Use, Land-Use Change and Forestry'.

The authors wish to thank the Advisory committee from RVO, Ministry Infrastructure and Environment and the Ministry of Agriculture, Nature Management and Food: Kees Kwant, Nico Bos, Wolter Elbersen, Sipke Castelein, Harry Vreuls, Elke van Thuijl, Martijn Root, Harry Vreuls, and Jose Muisers. 


\section{Summary}

In July 2016, the European Commission (EC) published a legislative proposal for incorporating greenhouse gas emissions and removals due to Land Use, Land Use Change and Forestry (LULUCF) into its 2030 Climate and Energy Framework. The Climate and Energy Framework aims at a total emission reduction of $40 \%$ by 2030 for all sectors together as part of the Paris Agreement (European commission 2016a: Regulation 479, UNFCCC 2015). With some revisions, the LULUCF regulation was adopted by Member States in December 2017. It regulates a 'no debit' target for LULUCF (Forests and Agricultural soils) against a Forest Reference Level and an accounting framework to handle any additional mitigation potential. EU Member States have negotiated with the Commission over the respective approach by which forests will contribute to their overall goals. This has led to the incorporation of a partial compensation mechanism in case a debit would arise because of higher harvesting. 'On 14 May 2018, the European Council adopted this Regulation 479 for the LULUCF sector under the Climate and Energy Framework. '

However, not only this regulation 479 was in development, but the Renewable Energy Directive (RED) was as well in the so-called winterpackage (COM(2016) 676). This regulates new targets for renewable energy as well as the criteria that the biomass derived bio-energy has to comply with. The criteria regulate e.g. protection of high conservation value sites, it regulates carbon debt and e.g. avoidance of soil degradation.

Both regulations will have an impact on the use of bio-energy in Netherlands and Europe, but the question is whether they are in line with each other and whether the LULUCF regulation may limit or hamper the RED.

This report answers above question and it was a support action towards RVO, the Dutch Executive Agency. Support consisted of explanation sessions on reporting, accounting issues plus many LULUCF reporting details (chapters 3,4 , and 5 ).

Chapter 6 then quantifies to what degree the LULUCF regulation may limit provision of woody and agricultural biomass, chapter 7 assesses how views on imported biomass may change under the LULUCF regulation, while chapter 8 looks in more detail at text of criteria in the regulations, whether they are in line and how monitoring requirements can be met. Chapter 9 then summarises the conclusions.

I mportant conclusion to make is that the LULUCF regulation does not change the manner in which harvested wood for bioenergy is accounted. If wood products are used to produce bioenergy the emissions which are the result of the burning of the wood are still reported and accounted at the time and in the country of harvesting. To prevent double counting of the emissions at the point of burning the wood for energy production, emissions are therefore counted as 0 , provided criteria of Sustainable Forest Management are met. This means the burning of the wood at the energy producer is still counted as carbon neutral. Related carbon emissions are accounted in the LULUCF regulation.

\section{Woody biomass provision}

The new LULUCF regulations projects the forest sink into the future under a Forest Reference Level (FRL) (comparable to Kyoto Commitment period 2). This continued projected sink will not be accounted as an achievement of the Paris goals. Only (small) changes in the sink compared to the FRL, will create debits or credits for the Paris goals and this sink is strongly impacted by harvesting level. The future harvest level thus has a great impact on the FRL, which MS have to set. The annual increment in the EU is $780 \mathrm{Mm} 3$, and this is potentially available but when projecting the current sink under the same harvesting intensity, the associated harvest is limited. 
We quantified this harvesting possibilities under the LULUCF regulation, provided a country does not want to generate debits. The simulations showed that the EU 26 as a whole may have a harvest increase from 420 million $\mathrm{m}^{3}$ in 2000-2009 to 560 million $\mathrm{m}^{3}$ in 2050, complying to harvest intensity criteria, without creating debits compared to Forest Reference Level. If we however set a cutoff to comply to a sustainability criteria as max $90 \%$ of increment to be harvested for each individual country, then the harvest can only increase to $\mathbf{4 9 3}$ million $\mathbf{~ m}^{\mathbf{3}} / \mathbf{y}$. The felling/increment ratio then becomes $80 \%$ for the EU26 as a whole, with values for individual countries ranging between $56 \%$ and $90 \%$. It also shows that the growth of the harvest is limited and can grow only by $20 \%$ to $560 \mathrm{Mm} 3$. In the Netherlands the present annual growth is $1 \mathrm{Mm} 3$. Simulations have shown that in the Netherlands the annual removal can grow from the present $1 \mathrm{Mm} 3$ to $2 \mathrm{Mm} 3$ in 2050 . So for the Netherlands the harvest could be doubled over the next decades within the constraints of the LULUCF regulation. 


\section{$1 \quad$ Background}

In July 2016, the European Commission (EC) published a legislative proposal for incorporating greenhouse gas emissions and removals due to Land Use, Land Use Change and Forestry (LULUCF) into its 2030 Climate and Energy Framework. The Climate and Energy Framework aims at a total emission reduction of $40 \%$ by 2030 for all sectors together as part of the Paris Agreement (European commission 2016a: Regulation 479, UNFCCC 2015). The LULUCF proposal regulates a 'no debit' target for LULUCF (Forests and Agricultural soils) and an accounting framework to handle any additional mitigation potential. EU Member States have negotiated with the Commission over the respective approach by which forests will contribute to their overall goals. This has led to the incorporation of a partial compensation mechanism in case a debit would arise because of higher harvesting. This is regulated further in many country specific clauses (EU Council 2017).

Already in the negotiations leading up to the Kyoto Protocol in 1997, concerns about the consequences of incorporating the existing forest sink in the climate targets had the policy outcome of imposing significant limits on the forest climate change mitigation role (Ellison et al. 2014). In particular, requirements related to direct human induced activities and separating managed from unmanaged lands have tried to deal with this. In practice 'caps', and 'forest (management) reference levels' (FMRL now called FRL) were introduced over time in the UNFCCC framework, and this set of rules has now evolved further within the new EU-level LULUCF proposal (EC 2016b). See chapter 3 and 6 for more details.

Setting such a forest management reference level may mean that any desired harvest increase for a bio-economy may be limited in the future. This, because after 2020 a substantial increase in harvest may lead to carbon debits, even though a sink still exists. Setting this FRL and any level of compensation of future debits has been a major obstacle in the discussions between Member States and the Commission.

Furthermore, the amount of carbon credits above the FRL has been capped at a maximum $3.5 \%$ of total GHG emissions of that Member State. For the different Member States this works out very differently, as those with a small economy quickly reach that cap. Others with a very large economy never reach that cap. With some revisions, the Member States and Commission agreed on the LULUCF regulation in December 2017. 'On 14 May 2018, the European Council adopted this Regulation 479 for the LULUCF sector under the Climate and Energy Framework. '

However, not only this regulation 479 was in development, but the Renewable Energy Directive (RED) was as well in the so-called winterpackage (COM(2016) 676). This regulates new targets for renewable energy as well as the criteria that the biomass derived energy has to comply with. The criteria regulate e.g. protection of high conservation value sites, it regulates carbon debt and e.g. avoidance of soil degradation.

Both regulations will have an impact on the use of bio-energy in Netherlands and Europe, but the question is whether they are in line with each other and whether the LULUCF regulation may limit or hamper the RED. 


\section{$2 \quad$ Aims and Methods}

The overall aim is to assess the consequences of the LULUCF regulation on the functioning of the RED and volumes of biomass becoming available to it. For this we review literature and use available tools as the European forest resource model EFISCEN.

Task 1 is to design alternative interpretations of the guidance for setting reference levels for the future sink under the LULUCF regulation for as far as still possible and to assess effects on land use, sinks and required monitoring.

Task 2 assesses the effects of the LULUCF regulation on the use of biomass.

Task 3 assesses how the LULUCF regulation may impact the view on imported biomass.

Task4 then reflects on how the LULUCF regulation relates to Dutch sustainability criteria and the RED. 


\section{The Concept of capturing a forest carbon balance in reporting and accounting}

\subsection{Reporting vs accounting of the forest carbon balance}

In order to understand the reasoning behind the proposed LULUCF regulation by the European Commission, we first have to understand the concept of reporting the Greenhouse Gas balance of the forest-wood value chain. Only then we can describe and understand the accounting. Reporting and accounting currently are two different steps.

The reporting follows as complete as possible the full dynamics of a large forest estate or (for UNFCCC) for a whole countries' dynamic forest managed system by following its carbon pools in forest biomass, soils, deadwood, litter and harvested products, as well as how long they are in use (thus including the moment they are being disposed of as bioenergy). The net of all changes of carbon stocks in these pools determines whether the system is a sink or a source of carbon dioxide $\left(\mathrm{CO}_{2}\right)$.

In the accounting step, which is currently under the Kyoto Protocol and in the future under the LULUCF regulation (EC/479/2016), it is determined how and which part of these emissions and removals are taken into consideration towards achieving the agreed climate targets.

\subsection{The forest and wood carbon balance}

The total mitigation impacts of the forest-wood products value chain may be larger for the whole society than what is reported, because fossil fuels are saved when using wood products and when producing bioenergy or if wood products substitute other materials that are associated with high energy use or carbon emissions. These potential emission reductions by using wood or agriculture biomass, however, are not considered under the LULUCF sector, but their impacts are implicit under other sectors as housing or energy sector.

\section{Wood in forests}

Forests impact net greenhouse gas (GHG) balances in two ways (see Figure 1, representing the full managed forest carbon cycle). First, they retrieve carbon dioxide from the atmosphere and sequester carbon in biomass, thus acting as a carbon sink. Subsequently part of this carbon is transferred into soils through litterfall, or into a variety of products through harvesting. Forest management activities such as improved silviculture, afforestation, reforestation and reduced deforestation (see glossary) increase net carbon sequestration in forests or conserve existing carbon stocks. In addition, carbon sequestration in long-lived wood products, wood structural frames for instance, delays carbon release into the atmosphere (sequestration lever in Figure 1). Moreover, wood products thus prolong the storage of carbon for decades or even centuries. However, of the total wood harvest, only a fraction ends up in long term storage. 


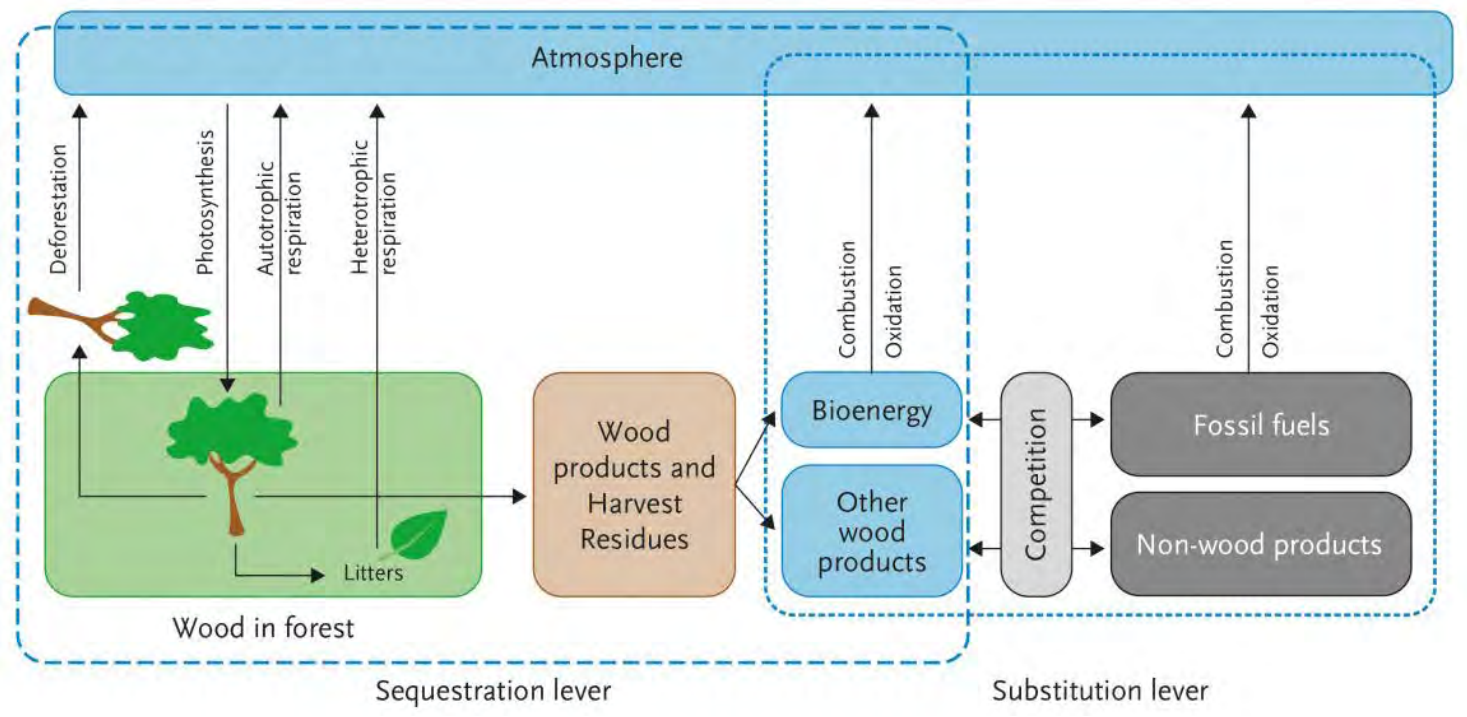

Figure 1 Conceptual flow diagram of carbon in a managed forest-wood products-energy chain (from Nabuurs et al. 2015).

\section{Substitution}

Second, fuelwood and bioenergy (e.g., woodpellets, pyrolysis oil and second generation biodiesel) can substitute fossil fuels, and timber products can substitute other more energy- and emissions-intensive materials like steel, aluminium and plastics. Emissions linked to wood product consumption are thus often lower than those created by the consumption of non-wood substitute products like steel and aluminium (Sathre and O'Connor 2010), provided they originate from sustainably managed forests. In this way, every ton of wood would avoid emissions in the order of 2 tonne of $\mathrm{CO}_{2}$ (Sathre and O'Connor 2010).

Wood product consumption (substituting for products coming from other materials for building, insulation, packing, furniture, etc.) consequently may enable a reduction in fossil energy emissions (substitution lever in Figure 1).

\section{Combined forest and substitution effects}

Forests and the use of forest products can therefore contribute to climate change mitigation by increasing sequestration and through substitution effects, via appropriate policies and measures. It is interesting and important to note that, although both effects represent potential contributions to climate change mitigation, they have different implications in terms of forest management and harvesting.

While the sequestration effect is maximized in the short term by a lower intensity of forest harvesting, enhanced use of the substitution effect implies an intensification of forest harvesting. In larger areas of forests, both mitigation options do not necessarily conflict with each other, as it is possible to balance carbon stocks in the forest biomass and (over larger areas) simultaneously use the biomass for wood products and fossil fuel and material substitution. At the regional and national level, it is possible and meaningful to combine both mitigation options.

\section{Scale effect}

The evaluation of forest-based climate change mitigation effects therefore requires careful consideration of scale and system boundaries as is visible in Figure 1. E.g. purely looking at the forest ecosystem a harvest would lead to $\mathrm{CO}_{2}$ losses. However, when the whole system is regarded, the balance will look very different.

When emissions are compared at the forest stand level, it is always beneficial to protect the stand and to maximize the carbon sink in the growing forest biomass. Any harvest activity leads to emissions of the $\mathrm{CO}_{2}$ that has been accumulated in the forest biomass, and only a fraction of the harvested carbon 
in the stemwood can substitute alternative materials, although new sawing and glue-ing techniques allow for small dimensions stemwood to be used in high-rise and high quality constructions.

A major challenge is that not all wood comes from sustainably managed sources. Increased harvest removals in an unsustainable manner e.g. in the tropics in primary forests (to generate bioenergy) will create a carbon debt that can take decades or even centuries to be compensated by new carbon sequestration in forest regeneration. To distinguish sustainable sources from unsustainable remains a challenge although certification with chain of custody has helped to guarantee the sources of wood.

At a stand scale, the annual fluctuations can be large (Figure 2). Due to management interventions, a stand that functions as a sink, can start to act as a source for a short period of time. In a larger forest regional level all the different forest age-classes occur simultaneously, and the carbon removal of the harvested forest stands is compensated by the carbon sequestration of the remaining growing stands. While time lags are dampened at the regional level, it is still possible that certain management interventions which result in long-term increases in carbon sequestration are followed by short-term net carbon release - for example in the case of salvage cutting of stands damaged by disturbances.

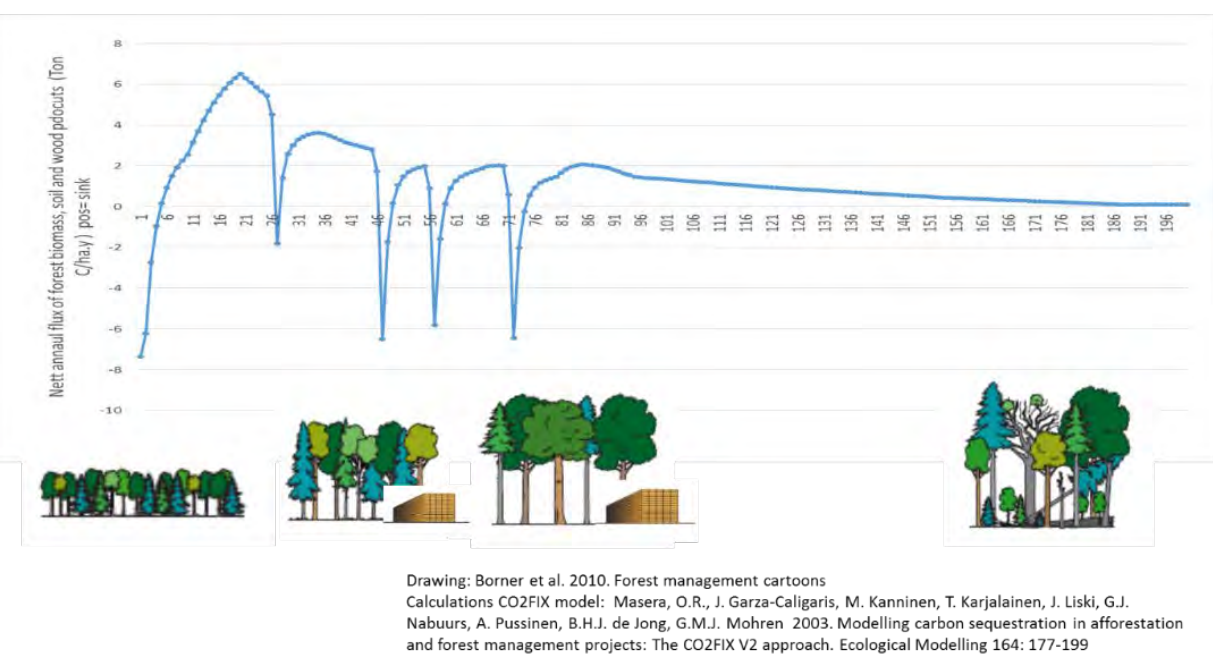

Figure 2 Net carbon flux of one forest stand over time (positive = sink, negative = source) for biomass, soil and wood products together. After the last thinning at year 70, it is decided to stop management and let natural dynamics take place. Eventually the sink then saturates, although a large stock is retained. When countries report for their total forest area, in principle they report the sum of all the stands' sink or source at that reporting year, summing the sink due to growth and sources due to harvesting. When a country accounts, it only sums those sinks and sources that are due to a management change, e.g. a set aside for nature conservation.

Due to the dynamic nature of forest growth cycles, a single forest carbon sink and source are not stable. However, over very large areas, this dampens out. In the EU, the forest carbon sink has been increasing over many decades and sTable for last 27 years (Figure 3), mostly because areas and increments have increased and harvesting has remained rather stable. Over the same time period, there has also been an increase in the area of forest reserves where forest management is not allowed. Figure 3 shows the rather sTable removals (negative sign), an annual storage of about $450,000 \mathrm{Gg} \mathrm{CO}_{2}$ /year in forest ecosystems, plus $\sim 50,000 \mathrm{Gg} \mathrm{CO}_{2} /$ year in wood products (this compensates $10 \%$ of European emissions). However such a growth cannot continue forever (see eg. Nabuurs et al. 2013), but sustainable forest management and harvesting is required to keep the vitality of forests. 


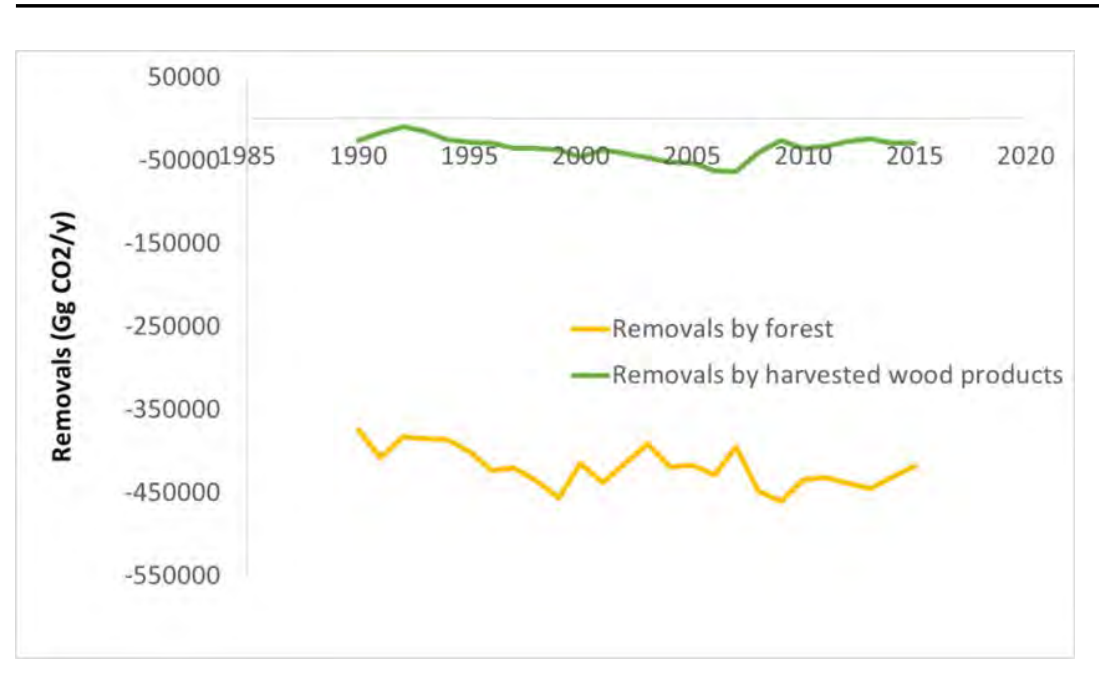

Figure 3 Role of European forests in terms of carbon sink in forest ('removals'; negative number meaning a sink), and in terms of carbon sink in wood products in use. Together these compensate roughly $10 \%$ of total EU emissions, see below. (country data submitted to UNFCCC http://di.unfccc.int/detailed_data_by_party).

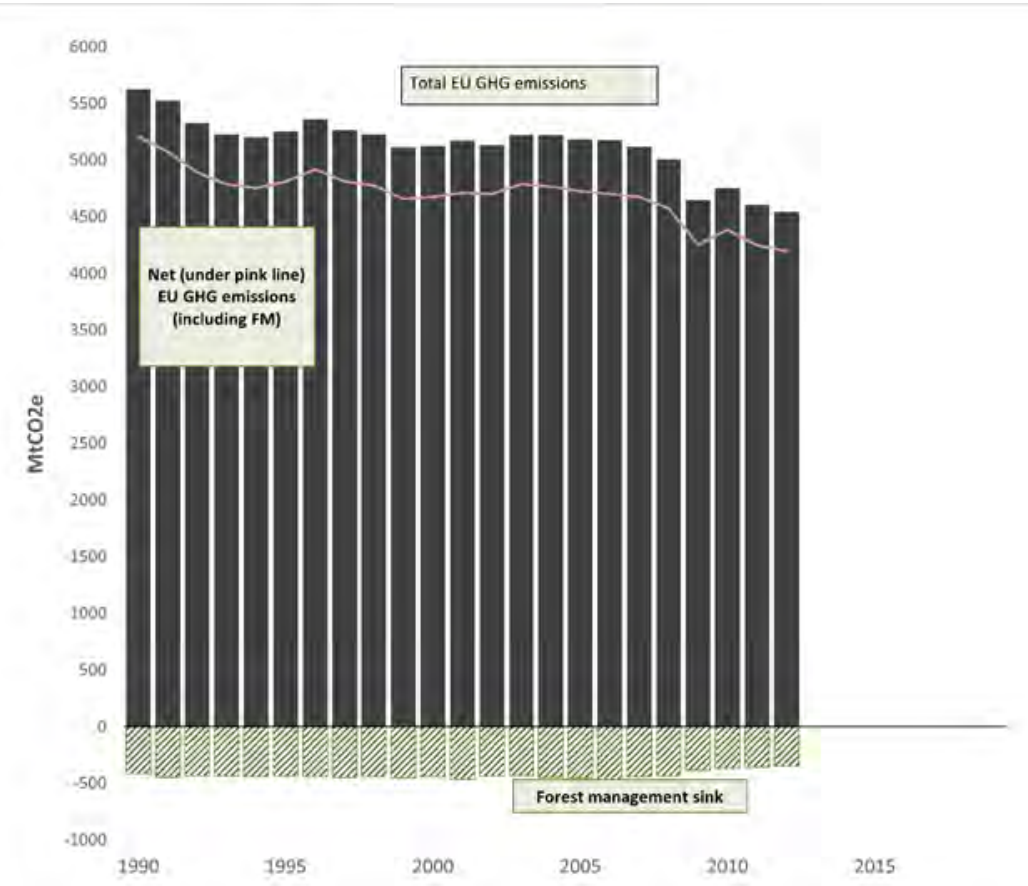

Figure 4 The size of the European forest biomass sink, in perspective to the total emissions from the EU. (sink displayed as negative, emissions as positive). Based on Ellison et al. (2014).

\section{System boundaries}

Equally important as scale effects are proper considerations of system boundaries. If the system boundary is limited to forest ecosystems, changes in carbon storage in wood products are not accounted for. More importantly, it is crucial to include other fuels and materials and their associated greenhouse gas emissions, because if the use of forests is limited to maximizing carbon in the forest biomass, fewer wood products can be harvested and consequently there will be an increasing demand to substitute wood products with fossil fuels and more energy-intensive materials. However, most often the effects of policies are only taken into account for their impacts on the forest biomass.

\section{Type of wood used for energy}

Which type of wood is used for energy generation also determines the total net emission reduction. Energy substitution based on the use of harvest residues results in a larger net positive climate change 
mitigation than the direct application of stemwood for energy purposes, because the residues would decompose relatively fast if they were left in the forest. However, in pellet production, only the lower quality stemwood can be used for wood market reasons. The higher quality is what the forest owner manages for and aims at because that will be sold at the highest price. Still, even when aiming at high quality sawlogs, large volumes of pre commercial thinning wood and low quality stemwood is produced anyway. This is sold at much lower prices to the pellet industry. Without such sales to the pellet industry, these low quality residues as they are called, would otherwise be burned in the field ${ }^{1}$.

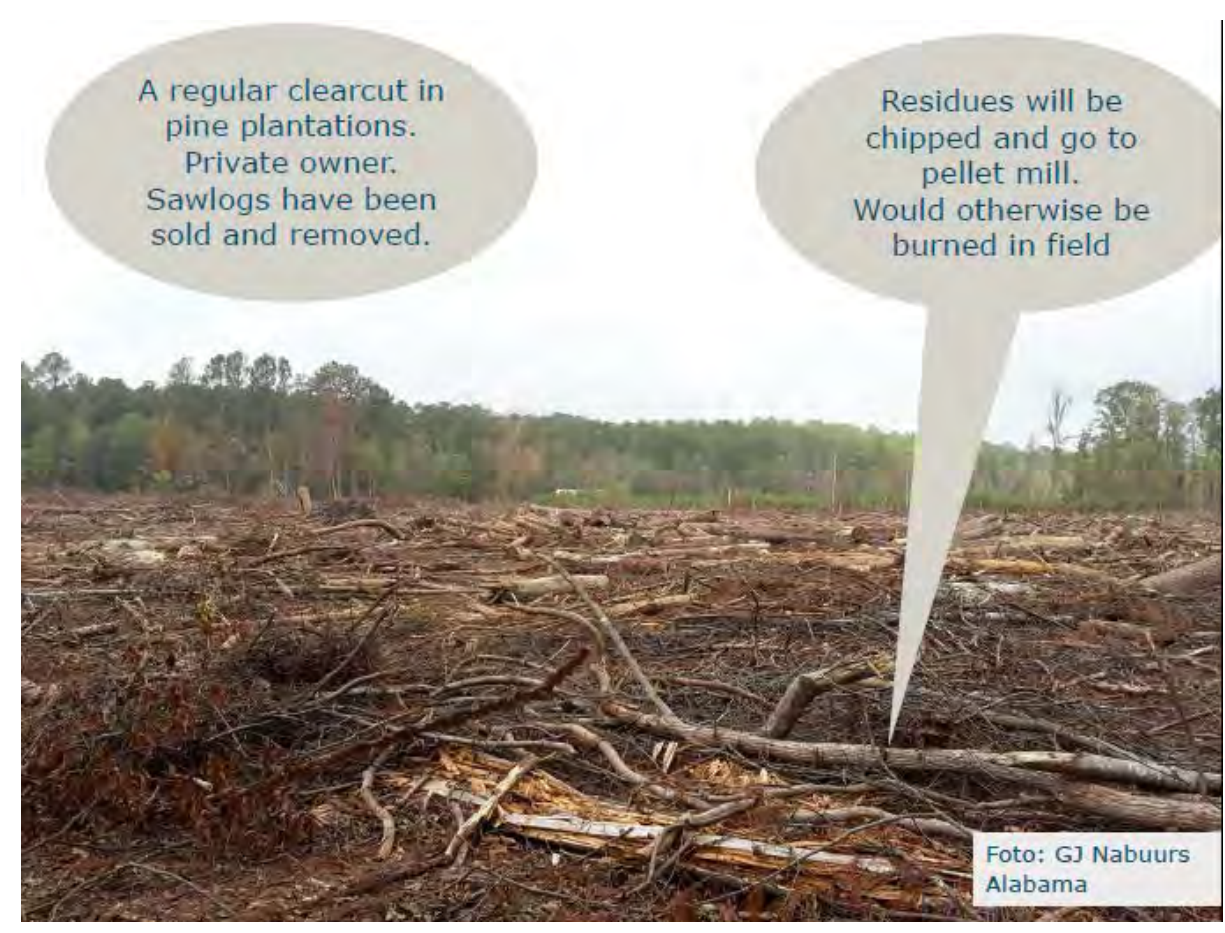

Figure 5 A regular clearcut in pine plantation in Alabama with residues after harvesting on the site. The sawlogs have been sold to sawmill. The residues will be chipped and sold to pellet mill.

However, to determine what is 'available', aspects such as cost efficiency, biodiversity issues, soil carbon and nutrient balances also need to be considered when extracting residues (Fingerman et al. 2017). Last, the conversion efficiency of woody biomass into energy products has to be taken into account as well. For example, using wood in a modern Combined Heat and Power plant may have a higher energy output efficiency and thus net avoided $\mathrm{CO} 2$, when compared to producing transport fuels from it.

\footnotetext{
${ }^{1}$ Eg. South Carolina Best Management Practices for Forestry and Mississippi's Best management practices for Forestry
} 


\section{$4 \quad$ The reporting as mandatory for all countries}

\subsection{National Greenhouse Gas Reporting}

How is all of the above reported by countries to the United Nations Framework Convention on Climate Change (UNFCCC)?

The UNFCCC is the overall international framework under which all Annex I countries report their greenhouse gas emissions and removals. This is done by distinguishing different sectors, i.e. the energy sector, the industrial processes and product use, waste sector, agriculture sector and the Land Use, Land Use Change and Forestry (LULUCF) sector. The results are annually reported in an inventory submissions to the UNFCCC, including a national inventory report (NIR) ${ }^{2}$ and common reporting format (CRF) ${ }^{3}$ (see Figure 5). The NIRs contain detailed descriptive and numerical information and the CRF tables contain all greenhouse gas (GHG) emissions and removals, implied emission factors and activity data. The LULUCF sector in the Netherlands constitutes a net source of emissions (also see Chapter 4.5 ) that in 2017 contributed 3.3\% to the total emissions (Figure 5).

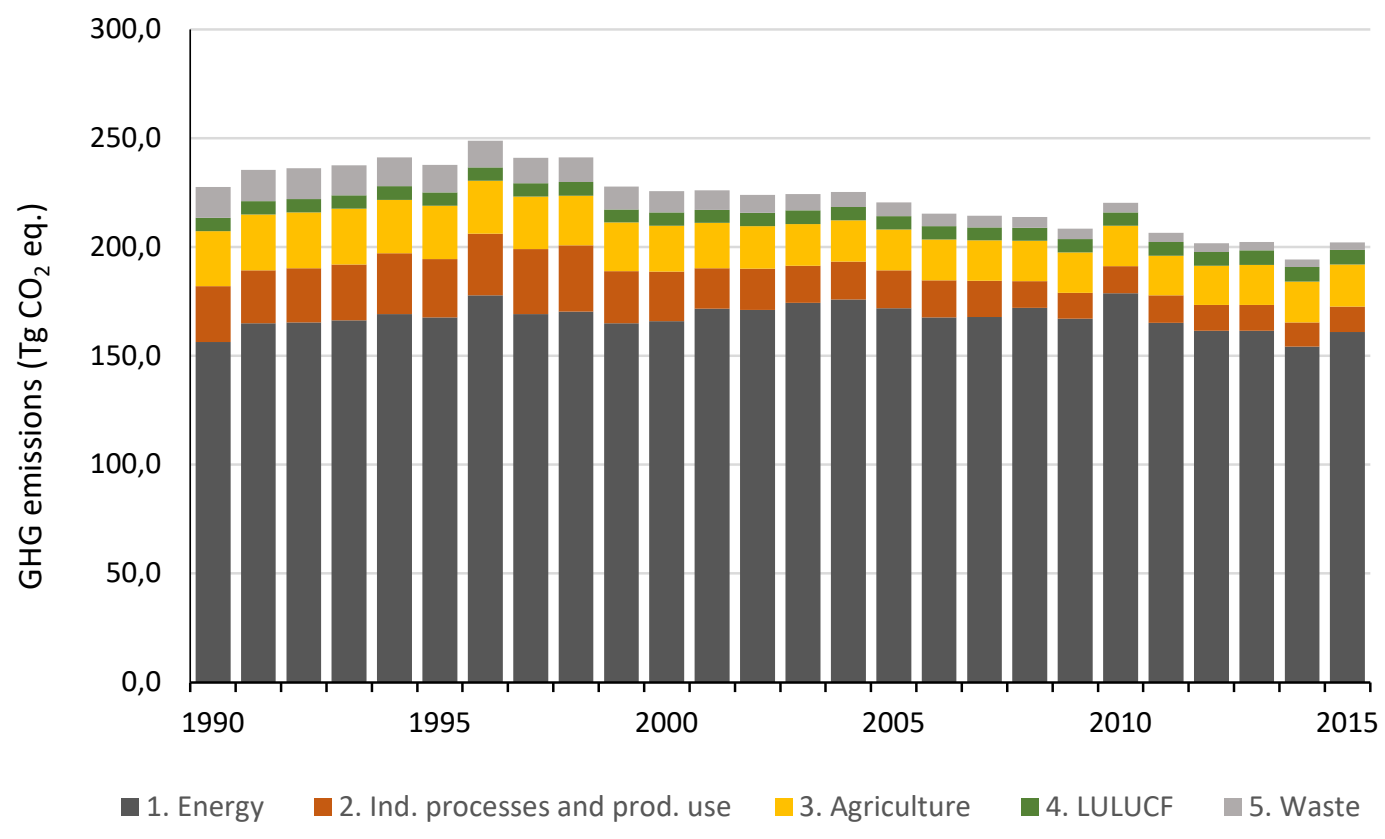

Figure 5 Emission trends in the Netherlands per source category (based on the Dutch NIR 2017)1.

\footnotetext{
2 Dutch NIR 2017 (Coenen et al. 2017):

http://unfccc.int/files/national_reports/annex_i_ghg_inventories/national_inventories_submissions/application/zip/nld2017-nir-14apr17.zip

3 Dutch CRF 2017:

http://unfccc.int/files/national_reports/annex_i_ghg_inventories/national_inventories_submissions/application/zip/nld2017-crf-14apr17.zip
} 


\subsection{The LULUCF sector}

The LULUCF sector distinguishes six main land use categories; Forest Land, Cropland, Grassland, Wetlands, Settlement and Other land. Each of these categories is divided in land remaining, e.g. Forest land remaining Forest land, and land converted to, e.g. land converted to Forest land. This latter is made up of the conversions of the other land use categories to the destination land-use, e.g. cropland converted to forest land, grassland converted to forest land, etc. After conversion land is reported under the land converted to sub-category for 20 years, after which it moves to the 'remaining' category. These 20 years are the default transition times needed to consider the stabilisation of carbon stock changes in mineral soils, and in the case of conversions to forests to cover the young forest stages with different growth characteristics from the more mature, or average forests in a country.

In the LULUCF land-use categories the following carbon stock pools are considered, living biomass (above and belowground), dead organic matter (litter and dead wood), mineral soils and organic soils. Changes in carbon stocks in these pools may result from sequestration in biomass, removal of biomass and dead organic matter due to land-use conversions and changing inputs into soils, disturbance of soils or, drainage of organic soils. The methods and approaches for LULUCF need to be in line with the various UNFCCC decisions and should follow the 2006 IPCC guidelines (IPCC 2006) and for the Netherlands are detailed in Arets et al. (2017).

\subsection{Forest Land}

This category includes a.o. emissions and sinks of $\mathrm{CO}_{2}$ caused by changes in forests. The category includes two sub-categories: 4A1 (Forest land remaining forest land) and 4A2 (Land converted to forest land). The first sub-category includes estimates of changes in the carbon stock from different carbon pools in the forest. The second sub-category includes estimates of the changes in land use from mainly agricultural areas to forest land since 1990 with a 20-year transition period, during which such transitions are reported under Land converted to Forest Land (Figure 6).

Also included in this section (under the heading 'Forest land converted to other land-use categories') are the descriptions related to the conversion of forest land to all other land-use categories (deforestation).

Methods employed in Dutch reporting system

Removals and emissions of $\mathrm{CO}_{2}$ from forestry and changes in woody biomass stock are estimated based on country-specific Tier 2 methodology. The approach chosen follows the 2006 IPCC Guidelines (IPCC, 2006) where a stock difference approach is suggested. The basic assumption is that the net flux can be derived from converting the change in growing stock volumes in the forest into carbon. Detailed descriptions of the methods used and Emission Factors can be found in the methodological background report for the LULUCF sector (Arets et al. 2017). The Netherlands' National System follows the carbon cycle of a managed forest and wood products system. Changes in the carbon stock are calculated for above-ground biomass, below-ground biomass and dead wood and litter in forests to a large degree based on data form national Forest inventory carried out in the Netherlands. 


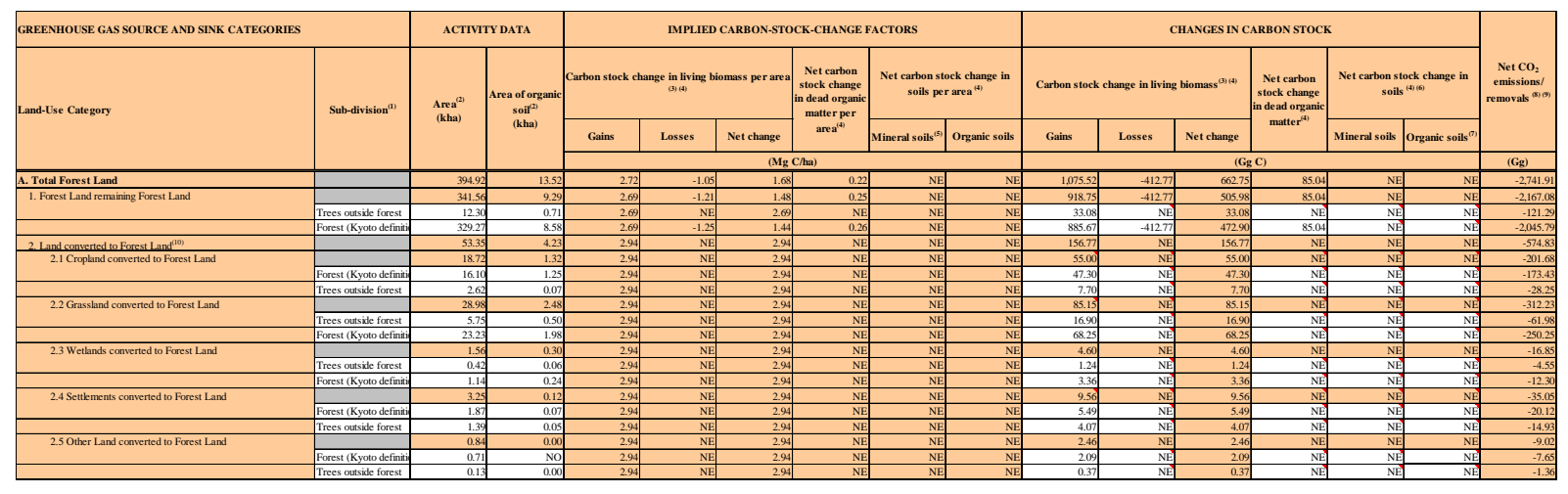

\begin{tabular}{|c|c|c|c|c|c|c|c|c|c|c|c|}
\hline \multirow[t]{4}{*}{ GREENHOUSE GAS SOURCE AND } & \multicolumn{3}{|c|}{ ACTIVITY DATA } & \multicolumn{7}{|c|}{ CHANGES IN CARBON STOCK AND NET $\mathrm{CO}_{2}$} & \multirow{3}{*}{$\begin{array}{c}{\mathrm{Net} \mathrm{CO}_{2}}_{\text {emissions/ }} \\
\text { removals } \\
\text { (4) (7) }\end{array}$} \\
\hline & \multirow{3}{*}{$\begin{array}{c}\text { Total } \\
\text { area }^{(2)} \\
(\mathbf{k h a})\end{array}$} & \multirow{3}{*}{\begin{tabular}{|c|} 
Area of \\
mineral \\
soil \\
(kha)
\end{tabular}} & \multirow{3}{*}{$\begin{array}{c}\text { Area of } \\
\text { organic } \\
\text { soil } \\
\text { (kha) }\end{array}$} & \multicolumn{3}{|c|}{\begin{tabular}{|c|}
$\begin{array}{c}\text { Carbon stock change in } \\
\text { living biomass }\end{array}$ \\
\end{tabular}} & \multirow{2}{*}{\begin{tabular}{|c|} 
Net \\
carbon \\
stock \\
change \\
in dead \\
wood $^{(4)}$ \\
\end{tabular}} & \multirow{2}{*}{$\begin{array}{c}\text { Net } \\
\text { carbon } \\
\text { stock } \\
\text { change } \\
\text { in } \\
\text { litter }^{(4)}\end{array}$} & \multicolumn{2}{|c|}{$\begin{array}{c}\text { Net carbon stock } \\
\text { change in soils }\end{array}$} & \\
\hline & & & & Gains & Losses & $\begin{array}{c}\text { Net } \\
\text { change }\end{array}$ & & & $\begin{array}{c}\text { Mineral } \\
\text { soils }\end{array}$ & $\begin{array}{c}\text { Organic } \\
\text { soils }\end{array}$ & \\
\hline & & & & \multicolumn{7}{|c|}{ (kt C) } & (kt) \\
\hline A. To & 98.62 & 73.53 & 25.09 & 43 & -345.18 & 24 & 79.40 & NO & -1.35 & -1.54 & -2437.44 \\
\hline 1. Forest land remaining for & 336.92 & 318.83 & 18.09 & 713.04 & -326.25 & 386.79 & 79.40 & $\mathrm{NO}$ & NO & $\mathrm{NO}$ & $-1 / 09.50$ \\
\hline 2. Land converted to forest land ${ }^{(8)}$ & 61.70 & 54.70 & 7.00 & 220.39 & -18.94 & 201.45 & $\mathrm{NO}$ & NO & -1.35 & -1.54 & -728.06 \\
\hline 2.1 Cropland converted to forest land & 12.83 & 10.80 & 2.03 & 46.68 & -3.49 & 43.20 & $\mathrm{NO}$ & $\mathrm{NO}$ & 3.74 & -0.46 & \\
\hline 2.2 Grassland converted to forest land & 33.72 & 29.96 & 3.76 & 120.38 & -15.45 & 104.93 & $\mathrm{NO}$ & $\mathrm{N}$ & -11.91 & -0.88 & -337 \\
\hline 2.3 Wetlands converted to forest land & 2.17 & 1.61 & 0.56 & 7.68 & $\mathrm{NO}$ & 7.68 & $\mathrm{NC}$ & $\mathrm{N}$ & 0. & $\mathrm{NO}$ & -28 . \\
\hline 2.4 Settlements converted to forest land & 11.61 & 10.96 & 0.65 & 40.83 & $\mathrm{NO}$ & 40.83 & $\mathrm{NO}$ & $\mathrm{NO}$ & 3.79 & -0.20 & -162.8 \\
\hline ( & 1.36 & 1.36 & 0.01 & 4.81 & $\mathrm{NO}$ & 4.81 & NO & NO & 2.93 & & \\
\hline
\end{tabular}

Figure 6 Example of a common reporting format (CRF) Table as used by countries to report GHG emissions and removals. Here the Table for Forest land remaining Forest land and all other land uses converted to Forest Land is shown from the Dutch 2017 inventory (columns with the implied emission factors, i.e. the carbon stock changes per unit area, were removed for readability). These tables are accompanied by background documents detailing the methods and data, i.e. Coenen et al. (2017), and Arets et al. (2017). Note, negative carbon stock changes relate to emissions and positive carbon stock changes relate to removals, while the negative values of $\mathrm{CO}_{2}$ emissions in the rightmost column indicate net removals (i.e. $\mathrm{CO}_{2}$ is removed from the atmosphere).

\section{National Forest I nventories}

Data on forests are based on three National Forest Inventories carried out during 1988- 1992 (HOSP data, Schoonderwoerd and Daamen 1999), 2000-2005 (MFV data, Daamen Daamen and Dirkse 2005; Dirkse et al. 2007) and in 2012-2013 (NBI6, Schelhaas Schelhaas et al. 2014). As these most accurately describe the state of Dutch forests, they were applied in the calculations for Forest land remaining forest land, Land converted to forest land and Forest land converted to other land use, representing the state of the forest at three moments in time; 1990 (HOSP), 2003 (MFV) and 2012 (NBI6). I nformation between 2013 and 2020 was based on projections using the EFISCEN model (see Arets et al., 2017).

With plot level data from the HOSP, MFV and NBI 6 changes in carbon stocks in living biomass in forests were calculated. In addition, changes in emission factors were assessed using several databases with tree biomass information, with allometric equations to calculate above-ground and below-ground biomass and with forest litter.

More detailed descriptions of the methods used and EFs can be found in Arets et al. (2017).

\section{Forest land remaining forest land}

The net change in carbon stocks for Forest Land remaining Forest Land is calculated as the difference in carbon contained in the forest between two points in time. Carbon in the forest is derived from the growing stock volume, making use of other forest traits routinely determined in forest inventories. With the three repeated measures from the NFI's the changes in biomass and carbon stocks are assessed for the periods 1990-2003 and 2003-2012. The annual changes during the years between 1990-2003 and 2003-2012 are determined using linear interpolation. There is an exception on this for 
forest land remaining forest land that was afforested between 20 and 30 years ago. These units of land are reported under FL-FL, but the calculation of carbon stock changes in these areas of forest still follows the approach for newly established forests(land converted to forest land).

For each plot that is measured during the forest inventories, information is available on the presence of the dominant tree species, standing stock (stem volumes) and the forest area it represents. Based on this information the following calculation steps are implemented (for more details see Arets et al., 2017):

1. Based on the growing stock information and biomass expansion functions (BCEF) for each plot in the NFI's total tree biomass per hectare is calculated. Tree biomass is calculated on the basis of growing stock information from the three forest inventories. For all plots in the NFI datasets, biomass is calculated using the dominant tree species group's specific BCEFs.

2. Weighted for the representative area of each of the NFI plots for each of the inventories the average growing stocks $\left(\mathrm{m}^{3} \mathrm{ha}^{-1}\right.$ ), average BCEF's (tonnes biomass $\mathrm{m}^{-3}$ ) and average root-toshoot ratios are calculated (Arets et al., 2017).

3. Based on the distribution of total biomass per hectare over coniferous and broadleaved plots (determined on the basis of the dominant tree species), the relative share of coniferous and broadleaved forest is determined.

4. The average growing stock, average BCEF's, average root-to-shoot ratios and shares of coniferous and broadleaved forests are linearly interpolated between the NFI's to estimate those parameters for all the intermediate years.

5. Combining for each year average growing stock, the average BCEF and root-to-shoot ratios the average aboveground and belowground biomasses (tonnes dry matter ha ${ }^{-1}$ ) are estimated for each year.

6. Using the relative share of coniferous and broadleaved forests and the differentiated T1 carbon fractions for conifers and broad-leaved species, above- and belowground biomass were converted to carbon.

7. Losses from wood harvesting are already included in the differences in carbons stocks between the three forest inventories, HOSP, MFV and NBI 6 (Figure 77). Therefore wood harvest (8) need to be included to calculate the gross carbon stock gains and losses (9).

For other pools like dead wood, harvested wood products and soils, comparable approaches are used, although based on other data. See for more info Arets et al., (2017).
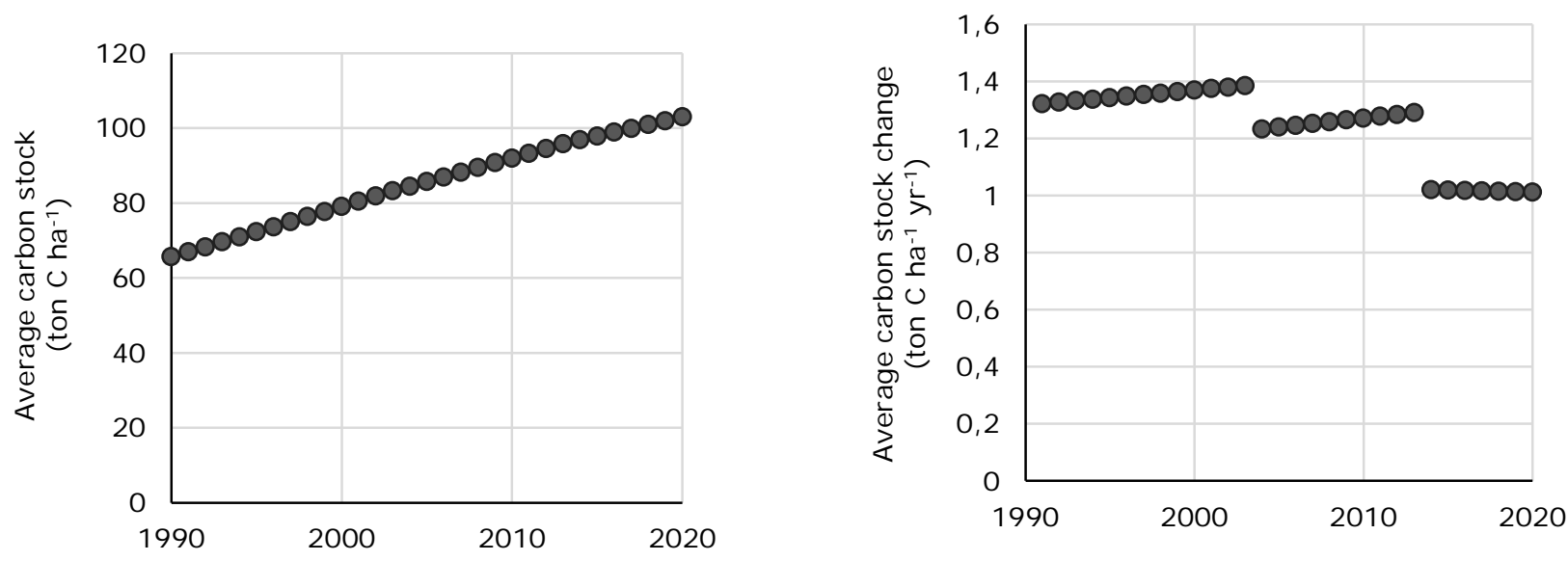

Figure 7 Average carbon stock development in Dutch forests over time (left) and net carbon stock changes in biomass in forest land remaining based on the stock differences in the Dutch NFI data (right). 


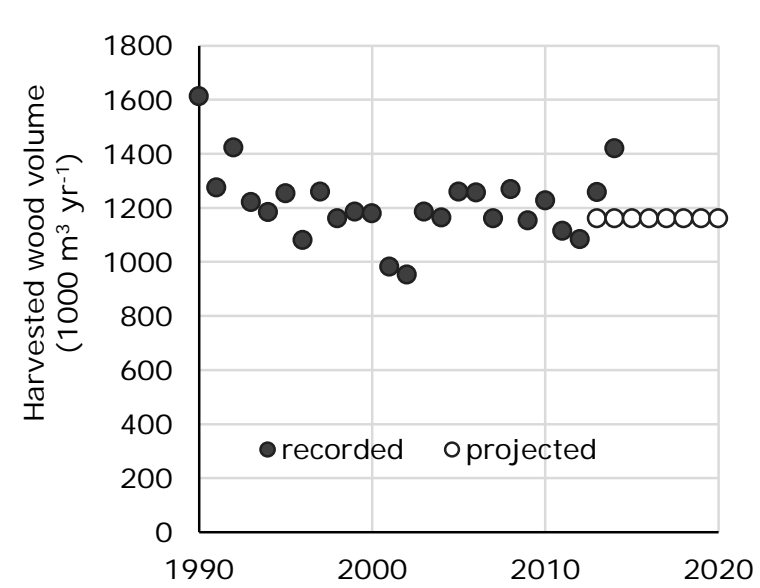

Figure 8 Harvested round wood volume (1000 $\left.\mathrm{m}^{3} \mathrm{yr}^{-1}\right)$ since 1990 in Netherlands.

Projected years are guestimates and can be used to set reference level.

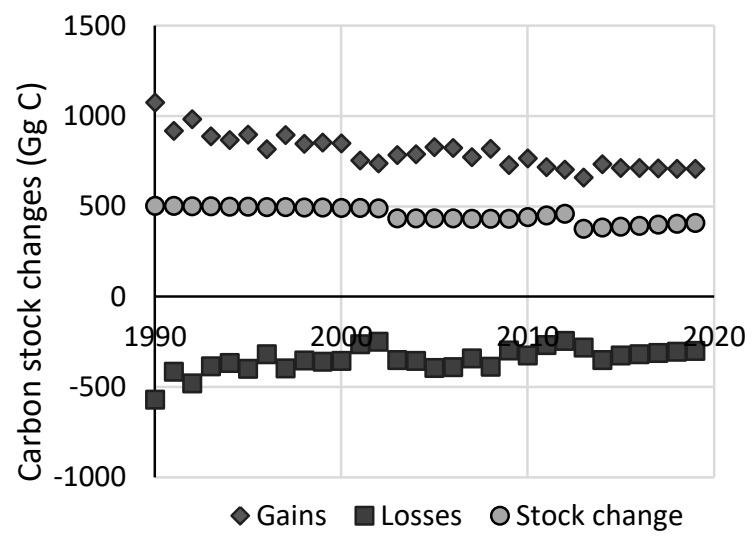

Figure 9 Carbon stock gains and losses in forest land remaining forest land combining net carbon stock changes from the NFI data with the (stock change, cf.) with the harvest statistics.

\subsection{Cropland and Grassland}

In cropland and grassland, the carbon pools in the soil are most relevant. Emissions from drainage of peat soils are the main emission sources for cropland and grassland. Mineral soils are a source of carbon for cropland (mainly as a result of carbon stock losses from conversion of grassland to cropland) and a sink for grassland (increasing carbon stock in all land use conversions to grassland).

For carbon stock changes in the biomass and dead organic matter carbon pool it is assumed that these are in equilibrium (increases are removed in the same year). Only in the first year of conversion to cropland or grassland a carbon stock is included. For this the IPCC default values are used (see Arets et al. 2017).

\subsection{Inventory summary}

In the Netherlands Forest land is a net sink (2434 kt CO 2 in 2015, see Table 1 ). However, mainly due to the strong emissions from drained peat soil under grassland and cropland the LULUCF sector in the Netherlands is a net source of emissions (6581 kt CO 2 in 2015, see Table 1). In contrast, in most European countries the LULUCF sector typically is a net $\mathrm{CO}_{2}$ sink, with the Netherlands and Denmark ${ }^{4}$ as two exceptions due to their high emissions from cultivated organic soil.

\footnotetext{
${ }^{4}$ http://unfccc.int/files/national_reports/annex_i_ghg_inventories/national_inventories_submissions/application/zip/dnm2017-nir-27may17.zip
} 
Table 1 Summary Table (CRF Table 4) of net $\mathrm{CO} 2$ emissions $\left(\mathrm{kt} \mathrm{CO}_{2}\right)$ and removals for the LULUCF categories in 1990, 1995, 2000, 2005, 2010 and 2015 as reported in the 2017 national inventory of the Netherlands (see Coenen et al. 2017 and Arets et al. 2017).

\begin{tabular}{|c|c|c|c|c|c|c|}
\hline \multirow{3}{*}{$\begin{array}{l}\text { GREENHOUSE GAS SOURCE } \\
\text { AND S INK CATEGORIES } \\
\text { Year }\end{array}$} & \multicolumn{6}{|c|}{ Net $\mathrm{CO}_{2}$ emissions/removals } \\
\hline & \multicolumn{6}{|c|}{ (kt) } \\
\hline & 1990 & 1995 & 2000 & 2005 & 2010 & 2015 \\
\hline 4. Total LULUCF & 6054 & 6181 & 5982 & 5895 & 6029 & 6581 \\
\hline A. Forest land & -1911 & -2033 & -2190 & -2140 & -2340 & -2434 \\
\hline 1. Forest land remaining forest land & -1949 & -1926 & -1900 & -1641 & -1684 & -1706 \\
\hline 2. Land converted to forest land & 38 & -107 & -290 & -499 & -656 & -728 \\
\hline B. Cropland & 1637 & 1798 & 1958 & 2099 & 2365 & 2667 \\
\hline 1. Cropland remaining cropland & 1468 & 1307 & 1147 & 1004 & 904 & 794 \\
\hline 2. Land converted to cropland & 169 & 490 & 811 & 1095 & 1461 & 1873 \\
\hline C. Grassland & 5483 & 5209 & 4935 & 4352 & 4307 & 4420 \\
\hline 1. Grassland remaining grassland & 5196 & 4971 & 4746 & 4486 & 4204 & 3961 \\
\hline 2. Land converted to grassland & 287 & 238 & 188 & -134 & 103 & 460 \\
\hline D. Wetlands ${ }^{(3)}$ & 88 & 66 & 45 & 49 & 60 & 64 \\
\hline 1. Wetlands remaining wetlands & $\mathrm{NO}$ & NO & $\mathrm{NO}$ & $\mathrm{NO}$ & $\mathrm{NO}$ & NO \\
\hline 2. Land converted to wetlands & 88 & 66 & 45 & 49 & 61 & 64 \\
\hline E. Settlements & 888 & 1025 & 1163 & 1373 & 1466 & 1650 \\
\hline 1. Settlements remaining settlements & 379 & 370 & 362 & 346 & 342 & 399 \\
\hline 2. Land converted to settlements & 510 & 655 & 801 & 1027 & 1125 & 1250 \\
\hline F. Other land ${ }^{(4)}$ & 26 & 51 & 75 & 91 & 109 & 126 \\
\hline \multicolumn{7}{|l|}{ 1. Other land remaining other land } \\
\hline 2. Land converted to other land & 26 & 51 & 75 & 91 & 109 & 126 \\
\hline G. Harvested wood products ${ }^{(5)}$ & -157 & 66 & -3 & 71 & 62 & 88 \\
\hline H. Other (please specify) & IE,NE,NO & IE,NE,NO & IE,NE,NO & IE,NE,NO & IE,NE,NO & IE,NE,NO \\
\hline
\end{tabular}




\section{The new EU LULUCF regulation and its room for interpretation (task 1 )}

\subsection{The EU LULUCF regulation in more detail}

Whereas the previous chapter was about the reporting of the LULUCF sector, the EU LULUCF regulation is about the accounting (see Chapter 3.2) of these emissions and removals. The EC LULUCF proposal of July 2016 (EC 2016) and adopted in Dec 2017 (WK 14966/2017 INIT) places forestry together with agricultural land- $\mathrm{CO}_{2}{ }^{5}$ (i.e. $\mathrm{CO}_{2}$ emissions and removals from Cropland and Grassland, see Figure 10) into one compartmentalized sectoral package (the LULUCF 'Pillar'), with limited flexibility and potential for exchange with other sectors. A no-debit rule applies for the combined LULUCF forestry and agricultural land- $\mathrm{CO}_{2}$, meaning that these quantities together should not result in net debits (i.e. create more emissions than in baseline years), and should ideally contribute to a continuously increasing sink.

Emissions from agricultural land may be compensated by change in the forest sink, but only above a forest reference level ( $=$ a baseline sink, FRL), and only up to a maximum 3.5\% of a country's total, economy-wide, base year emissions, in sum $160 \mathrm{Mt} \mathrm{CO} /$ year for the $\mathrm{EU}$ as a whole. However, due to high reference levels and/or small caps in individual Member States, many MS will be inadequately encouraged to achieve this potential (Ellison et al. 2014). The regulation further allows for a small exchange with the Effort Sharing Decision (ESD) sectors, which sets reduction targets for the transport and housing sectors, and non- $\mathrm{CO}_{2}$ emissions from agriculture. The exchange, however, is capped at $280 \mathrm{Mt} \mathrm{CO}_{2} / 10$ years and can only be achieved through specific activities such as afforestation and cropland management. Regarding forest land it states 'The LULUCF flexibility will enable member states to make limited use of net removals from certain land use, land use change and forestry. This will also include credits from managed forest land once the forest reference levels have been adopted under the LULUCF regulation and from wetlands when accounting for them becomes mandatory under that regulation'.

Because of the limited set of allowable measures, this maximum is not likely to be achieved either.

The range of earlier concerns toward including LULUCF in the climate targets was primarily related to uncertainty in reporting on the forest sink, opposition to using the forest sector as a tool for 'offsetting' industry-level emission reduction commitments, a strong interest in preserving 'environmental integrity', and questions regarding the relative permanence of forest-based carbon sequestration. Many or most of these (earlier) concerns hampered innovation in the LULUCF policy framework. However, many of these concerns have been sidelined by important changes since the early 1990s. Continuous increased growth in European forests over the last several decades (Pretzsch et al. 2014), as well as continuous improvement in forest inventory reporting practices since the initial UNFCCC reporting requirements were agreed, have helped to reduce concerns related to uncertainty and permanence.

\footnotetext{
5 Although the LULUCF sector also inlcudes some $\mathrm{N}_{2} \mathrm{O}$ and $\mathrm{CH}_{4}$ emissions associated mainly with biomass burning from wildifres and soil disturbance, the focus in this report is on the $\mathrm{CO}_{2}$ emissions related to changes in carbon stocks in biomass.
} 


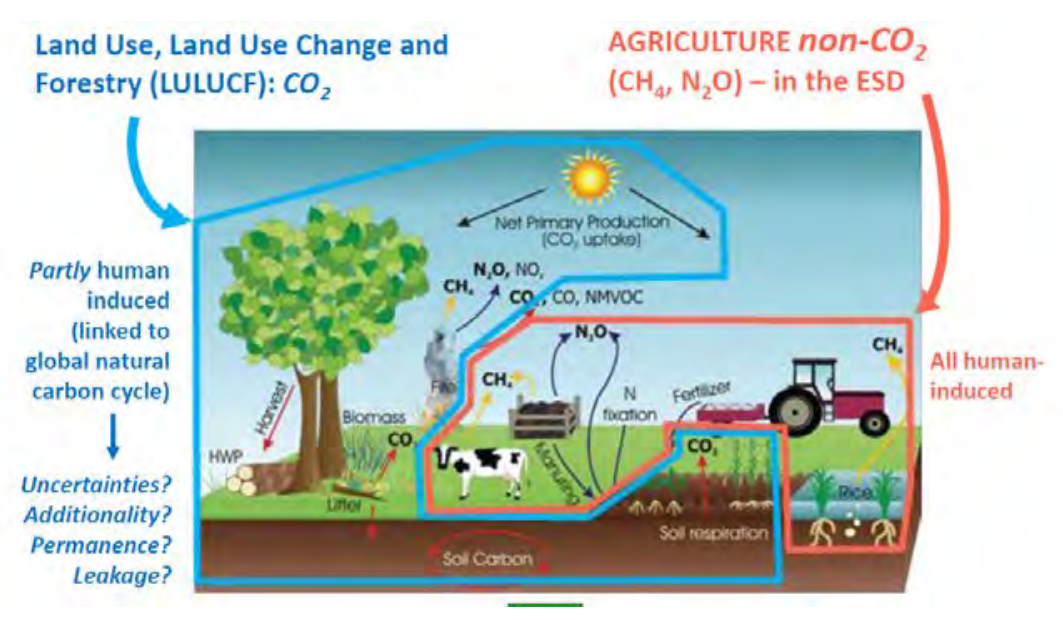

Figure 10 All land use related emissions and sinks are divided over two regulations: blue encircled is part of the LULUCF Regulation with only a 'no debit' target. The orange encircled is part of ESD (non-ETS) (source DG Clima).

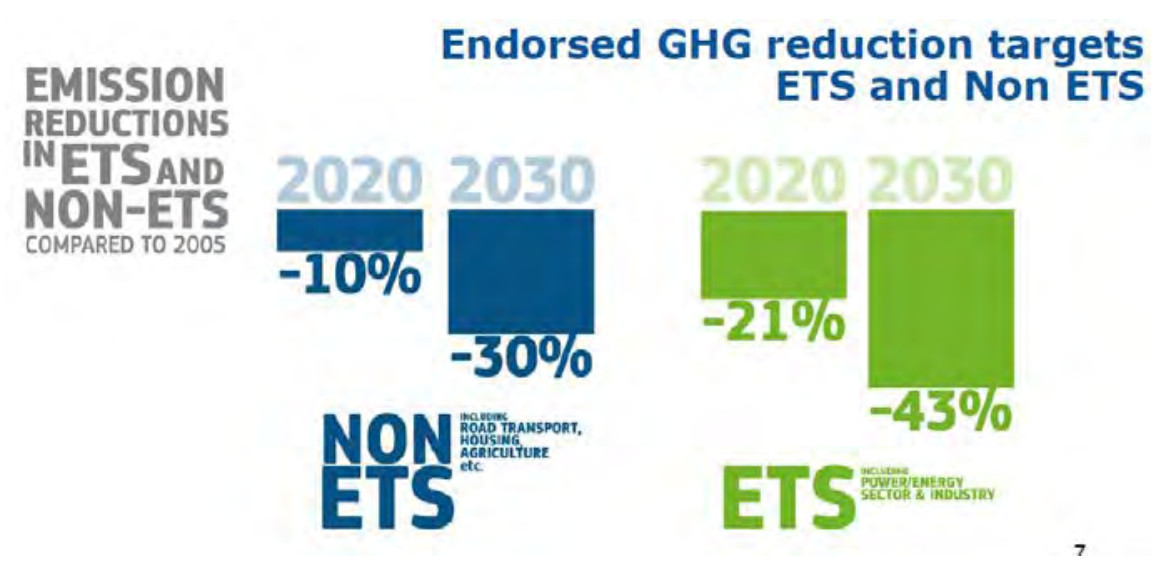

Figure 11 ETS with its -30\% emissions target (DG Clima).

To deal with the concerns regarding environmental integrity, the 2011 Durban inclusion of forests in the UNFCCC effectively turned a baseline sink into a forest sector commitment that has been added on top of the regular commitment framework. Under the current Kyoto Protocol accounting (see Annex II), this baseline sink is called the Forest Management Reference Level (FMRL) and must be achieved before any additional forest sector achievements can be counted. The structure of these rules essentially enforces the additive role of the forest contribution. Despite this raised ambition (existing commitment + the FMRL commitment) and the presence of additional emission reduction pathways, forests continue to play a marginal role in the climate policy framework.

As soon as Member States fail to achieve this baseline (the FMRL), they are debited for the shortfall even though the Forest is still a sink (and reported as such under the UNFCCC reporting (Chapter 3). For many Member States, this may represent a significant obstacle to their mitigation goals, in particular the increasing use of bioenergy. Although countries are likely permitted additional harvesting in their FMRL (management intensity) projections, this placement of constraints on how additional annual growth in European forests can be used may have unintended consequences. First, forest owners invest resources in productive forests. Perceived limits on the use of these productive resources (through the implementation of reference levels) may well create disincentives for future forest investments. Second, additional forest and forest resource use (rising harvesting levels as in the bio-economy case of Finland and Sweden) may in the short-term lead to a reduced sink. Even though these countries will likely continue to have a net sink, they will be debited for any shortfall. Finally, the difficulty in projecting future demand for bioenergy resources over longer periods of time is only likely to exacerbate these tensions. 


\subsection{LULUCF regulation accounting}

The proposed accounting under regulation 479/2016 largely follows the principles from the accounting under the Kyoto Protocol (KP) (see Annex II, Figure 12).

\begin{tabular}{|c|c|c|c|c|}
\hline UNFCCC & KP (CP2) & & 479/2016/EU & \\
\hline Reporting & Reporting & Accounting & Reporting & Accounting \\
\hline $\begin{array}{l}\text { Cropland }\left(\mathrm{CO}_{2}\right) \\
\text { Grassland }\left(\mathrm{CO}_{2}\right) \\
\text { Wetland } \\
\text { Settlements } \\
\text { Other }\end{array}$ & $\begin{array}{l}\text { GHG only from direct } \\
\text { human induced } \\
\text { activities } \\
\text { AR Aff/Reforestation } \\
\text { (D) Deforestation } \\
\text { FM Forest Management } \\
\frac{+ \text { HWP }}{\text { CM Cropland manag. }} \\
\text { GM Grazing land manag. } \\
\text { ND Wetland drain./rewet. } \\
\text { RV Revegetation }\end{array}$ & $\begin{array}{l}\text { Mandatory, gross- } \\
\text { net } \\
\text { Mandatory, ref level } \\
+ \text { cap }\end{array}$ & $\begin{array}{l}\text { GHG only from managed } \\
\text { land } \\
\text { activities } \\
\text { AR Afforested land } \\
\text { (D) Deforested land } \\
\text { FM Managed Forest Land } \\
\pm \text { HWP } \\
\text { CM Managed Cropland } \\
\text { GM Managed Grassland } \\
\text { WM Managed wetland }\end{array}$ & $\begin{array}{l}\text { - Mandatory, gross-net } \\
\text { J Mandatory, ref level } \\
\text { +cap (-compensation) }\end{array}$ \\
\hline
\end{tabular}

Figure 12 Overview of reporting under UNFCCC, reporting and accounting under KP (CP2) and the proposed accounting under 479/2016/EU.

An important difference is that KP reporting and accounting was activity based, while under 479/2016 it will more closely follow the UNFCCC land based approach. This means that the land-use classes and conversions between land-uses are based on the UNFCCC land categories. For instance afforested/reforested land is directly based on the UNFCCC sub-category 'land converted to forest land' and similarly deforestation is based on the UNFCCC subcategories Forest land converted to the other land categories, including the 20 year transition periods (with an option to apply a 30 years transition period for afforested land). Managed Forest Land (MFL) is made up of the UNFCCC land category 'Forest land remaining Forest land'.

This also implies that unlike under the definitions of KP, units of afforested land, after the transition period of 20 or 30 years will now be included under regularly managed forest land (MFL). It also means that reforestation after earlier deforestation will be included under afforested land, rather than remaining under deforestation as is now the case under KP. Also after the 20 years transition period units of Deforested land will move to the land-use activity they are in at that time (e.g. Managed Cropland or Managed Grassland).

Also under 479/2016 Managed Cropland and Managed grassland will become mandatory categories for accounting, while Cropland Management and Grazing land management under KP were voluntary activities for accounting. Accounting of these categories will be net-net compared to a base-period, 2005-2009. Emissions in the reporting year are compared to emissions in this base period. If emissions are reduced (or removals increased) compared to this period, this difference will generate credits, while in the opposite situation it will generate debits. 
What do gross-net, net-net and forest reference levels mean?

Here a simple example: Country A has a sink of 10 MT CO $\mathrm{CO}_{2}$ in 1990 and 13 MT $\mathrm{CO}_{2}$ in 2012. It projected that in $\mathbf{2 0 1 2}$, it would have a reduced sink of $8 \mathbf{M T} \mathbf{C O}_{2}$. (Thanks to FERN for the example):

- Under net-net accounting, it would account for the difference between 1990 and 2012, i.e. 3 MT $\mathrm{CO}_{2}$ of removals.

- Under gross-net accounting it would calculate the size of the sink in the year accounting takes place but not compare it to a base year. It would account for $13 \mathrm{MT} \mathrm{CO}_{2}$ of removals in 2012.

- Using a business as usual reference level, it would account for $5 \mathrm{MT} \mathrm{CO}_{2}$ removals, since the sink in 2012 was 5 MT CO 2 larger than the country projected it would be.

Source: Climate action Network http://www.caneurope.org/

\subsubsection{Afforestation and deforestation}

Although the base year for calculations of afforestation and deforestation changes, and hence the outcomes, the accounting rules are the same as under KP; gross-net accounting, so as long as units of land are within these categories all net emissions (or removals) on these units of land will be taken into consideration. In the year of deforestation the loss of carbon will be very large (all tree biomass will be assumed to contribute to the emissions) on deforested land, but during the other years of the 20 year transition period carbon stock changes will be more limited or gradual (like in soil). On units of afforested land the carbon stock in forest biomass will gradually built up until it reaches the carbon stock of the average Dutch forest after 30 years.

\subsubsection{Managed Forest land and harvest intensity}

Like under KP, Managed Forest Land under regulation 479/2016 will be compared to a forest reference level (FRL). This FRL should be based on a forward looking projection that takes age related forest characteristics into consideration. Although the text in the final decision is watered down, in the projections forest management and wood harvesting should be based on 'sustainable forest management practice' as practices in the period 2000-20009. This intensity relates for instance to the wood removals compared to the amount of wood (or biomass) available for wood supply in a certain forest type or age class during this historic reference period.

The wood harvests considered in the model projections for the reference level depend on the more autonomous development of biomass (or growing stocks) as a result of age dependent growth. If growing stocks are projected to increase during the compliance period, so will be the actual wood harvests projected under the FRL. If growing stocks, however, are projected to decrease during the compliance period, the actual wood harvests projected under the FRL will also decrease.

Actually observed carbon stock changes in managed forests in the periods 2021-2025 and 2026-2030 then will be compared against this FRL. Any increases in carbon removals from Managed Forests that are greater than the FRL will be counted as credits, while decreases in removals from Managed Forests will result in debits.

In the projections of the FRL no planned policies (like expected increasing demand for wood to meet bio-energy needs) are allowed to be taken into consideration. This is different from the approach for the FMRL under KP. Reason for this is that it would result in omitting emissions associated with the wood removals used for bio-energy, an important issue raised by environmental NGO's. If such additional wood harvests from planned policies or expected demand would already be included in the projections of the $\mathrm{FRL}$ and the $\left(\mathrm{CO}_{2}\right)$ removals under this $\mathrm{FRL}$ would decrease. If then these additional 
wood harvests are realised during the compliance period, the associated reduction in $\mathrm{CO}_{2}$ removals is already discounted by the lower FRL. Then, due to the regulations aimed at preventing double counting, using this wood for bioenergy will neither be accounted for in the Energy (ETS) sector.

In general, without additional management measures, the carbon sink in managed forests compared to the FRL is expected to decrease if harvest intensities increase compared to 2000-2009, resulting in debits even if forests are managed sustainably and the harvest is lower than $100 \%$ of the increment. Note, however, that if forest increment is expected to increase, also the absolute harvest amounts could increase at equal harvest intensities. Hence taking into account ageing forests in the FRL could allow higher harvests without generating debits. In some MS, however, the age-class effect may not be sufficient to allow the increase in harvest that is desired, especially in MS that had low harvesting rates in the reference years 2000-2009.

\subsubsection{Accounting of Harvested wood}

Additionally in the Commission proposal the carbon stock changes in the pool of harvested wood products should be included in the reference level. Carbon in HWP are included in the HWP pool, and then depending on the life-times of the end products (paper, wood panels or sawn wood) is released again later in time following a first order decay function ${ }^{6}$. Wood for energy purposes will not be included in the HWP pool and therefore the associated emissions (reduction in removals) will be accounted assuming instantaneous oxidation in the LULUCF sector. On the other hand, the associated reduced emissions due to substitution in the Energy, transport or housing sector will implicitly be accounted in those.

I mported HWP's are not accounted for by the importing country, but by the producing countries (c.f. the IPCC production approach). The commission proposal did not explicitly mention how distribution over HWP categories (paper, wood panels or sawn wood) should be included in the projected FRL, but later amendments indicated that this should consider the proportional historic end-uses, while also maintaining the historic (2000-2009) ratio between solid and energy use of the wood.

\subsubsection{National Forestry Accounting Plan}

Annex IV of the EU LULUCF regulation gives criteria and guidance for a national Forestry accounting plan, containing a member states forest reference level:

Member State forest reference levels shall be determined in accordance with the following criteria:

- '... a constant ratio between solid and energy use of forest biomass as documented in the period from 2000 to 2009 shall be assumed;

- (f) reference levels should be consistent with the objective of contributing to the conservation of biodiversity and the sustainable use of natural resources,'.

The elements for a national forestry accounting plan should a.o. contain

- '. . documentary information on sustainable forest management practices and intensity and adopted national policies;

- (d) information on how harvesting rates are expected to develop under different policy scenarios; .

\subsection{Accounting in relation to woody biomass use}

Most directly influencing the bioenergy use is this : '. . a constant ratio between solid and energy use of forest biomass'. This implies that if for instance in the period 2000-2009 as used for the FRL $10 \%$ of the harvested woody biomass was used for bioenergy and $90 \%$ for other purposes (paper, wood based panels or sawn wood), that also under the projected FRL $10 \%$ of the harvests should be calculated as instantaneous oxidation (IO) and the other $90 \%$ enters the HWP carbon pool. If subsequently during

${ }^{6}$ Default half-life values are 2 years for paper, 25 years for wood panels and 35 years for sawn wood 
the commitment period (2021-2026 or 2026-2030) the share of woody biomass that is used for bioenergy is higher than this $10 \%$ also the amount more than the $10 \%$ is accounted according to 10 , while under the FRL the associated carbon was included in the HWP carbon pool. The resulting smaller C stock gains in the HWP pool compared to the gains in the HWP pool in the reference level will result in debits.

Similarly other changes in end-uses of the HWP will have an effect how actual HWP will compare against the HWP in the FRL. If future wood harvests contribute more to products with shorter halflives than projected in the FRL, these potentially will result in debits (compared to the HWP in the FRL). This also is the case if less wood enters the HWP, for instance if the share of harvested wood used for energy purposes increases.

While increased harvests will potentially result in debits in the LULUCF sector, the use of woody biomass as energy source or wood substituting other more energy intensive materials also prevents emissions. The prevented emissions, however, are accounted in the energy (ETS) and other ESD sectors (see Figure 1 and see Box 1 for a quantitative example). 
Box 1. Example of carbon stock changes associated with the harvest of $1000 \mathrm{~m}^{3}$ round wood and its accounting and substitution effects.

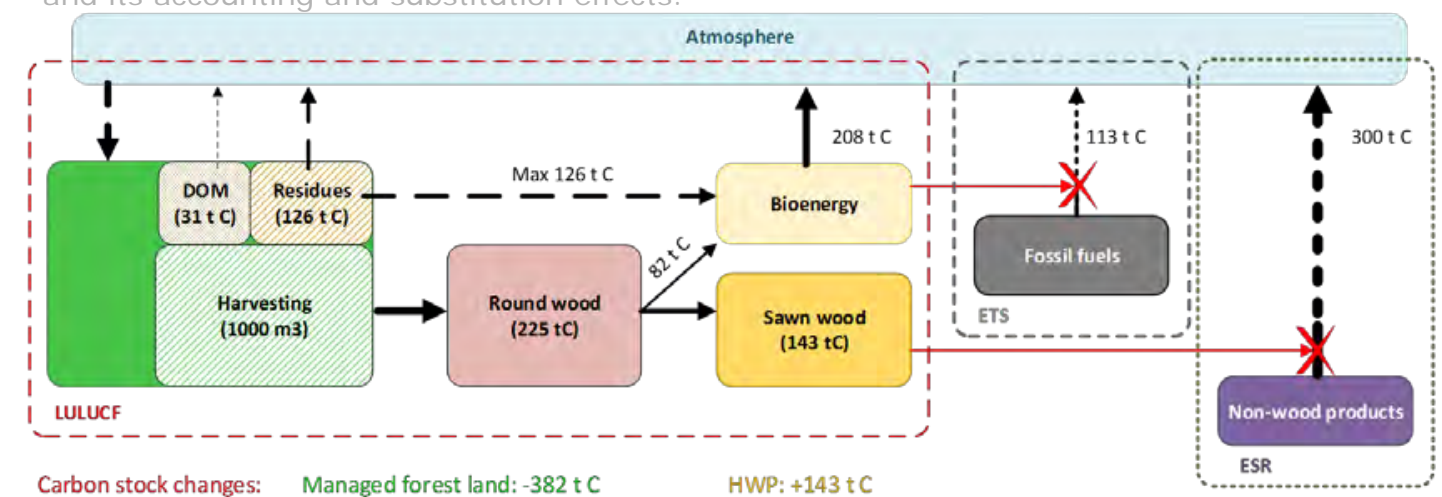

Carbon stock changes: Managed forest land: -382 t C $\quad$ HWP: +143 t C

Accounting: $\quad-239 \mathrm{tC}$ (emission of 877 ton $\mathrm{CO}_{2}$ )

If more than harvest under FRL (+compensation) this will create debits, otherwise it decreases credits in the LULUCF sector

But also decreases emissions in the ETS sector and the Non-ETS sector under the ESR

This box provides an example for the carbon stock changes associated with the harvest of $1000 \mathrm{~m}^{3}$ round wood used to produce sawn wood. In the forest (Managed Forest Land) this will result in a reduction of the carbon stocks in biomass with 382 t C (based on NBI 6 data, see Table 4.2 in Arets et al. (2017): $1 \mathrm{~m}^{3}$ stemwood converts to $764 \mathrm{t}$ dry matter in the trees with dry matter containing $50 \%$ carbon). Assuming a typical wood density of 0.45 and standard carbon content of 0.5 , the $1000 \mathrm{~m}^{3}$ round wood represent $225 \mathrm{t}$ carbon. Hence of the total of $382 \mathrm{t} \mathrm{C}$ felled in the forest $225 \mathrm{t} \mathrm{C}$ ends up in the removed round wood. From the remaining $157 \mathrm{t} \mathrm{C}$ it is assumed that $20 \%, 31$ $\mathrm{t} C$ will end in dead organic matter (like the roots and stumps), and $80 \%$, or $126 \mathrm{t} \mathrm{C}$ in residues (branches, etc). The round wood then may be used to produce sawn wood. Due to losses in the processing of the wood (saw dust, residues) this will on average result in $143 \mathrm{tC}$ in sawn wood and 81 tC in saw residues ( $1.58 \mathrm{~m}^{3}$ round wood needed to produce $1 \mathrm{~m}^{3}$ sawn wood, see Arets et al. (2011)). The 143 tC in Sawn wood will enter the HWP accounting category and will then, using a half-life factor of 35 years, gradually contribute to emissions from HWP, which will be accounted in the future under LULUCF. At the same time when this sawn wood is used to substitute other more energy consuming materials it may substitute the emissions of on average $300 \mathrm{t} \mathrm{C}$ (substitution factor 2.1, see Sathre and O'Connor 2010), thus reducing the emissions in the non-ETS sector under the ESR. Similarly if at the same time the harvest and saw residues are used for bio-energy, these will result in emissions of $208 \mathrm{t} \mathrm{C}$ to be accounted under the LULUCF sector. At the same time this use of bioenergy will substitute the use of fossil energy, reducing the emissions in the ETS sector with $113 \mathrm{t}$ $\mathrm{C}$ (assumed substitution of $0.993 \mathrm{~kg} \mathrm{CO}_{2}$ fossil emission per $\mathrm{kg}$ of biomass used, gives substitution factor of $0.54 \mathrm{t} \mathrm{C}$ per $\mathrm{t} C$ in biomass). The substitution effect strongly depends on the efficiency of the biomass to energy conversions. Application of more efficient techniques would further increase the substitution effect.

If the $1000 \mathrm{~m}^{3}$ of harvested wood would be more than the harvests included under the FRL projections, this will create debits of $239 \mathrm{tC}\left(877\right.$ ton $\left.\mathrm{CO}_{2}\right)$ in the LULUCF sector, while at the same time in this current example it has the potential to decrease emissions in the other sectors with 413 $\mathrm{tC}\left(1514 \mathrm{t} \mathrm{CO}_{2}\right)$.

\subsubsection{Compensation mechanism}

The final regulation leaves the use of FRL and its projection based on historic ${ }^{7}$ management practice and intensity intact under Article 8 (of 479/2016), but also acknowledges that as a result of country specific circumstances and in some member states in order to maintain or even improve the future forest carbon sink, flexibility is needed to temporarily increase harvest intensities. Therefore the regulation includes under article 13 on flexibilities a compensation mechanism for MS that would get debits under accounting of Managed Forest lands. This compensation mechanism entailed a maximum

\footnotetext{
${ }^{7}$ An earlier amendment to change the historic comparison from 1990-2009 to 2000-2009 has remained in place.
} 
amount of debits from forest related accounting categories that may be compensated based on the following principles:

The maximum amount of compensation for 10-year period is given in Annex VII of the regulation:

- MS average forest sink (2000-2009) x compensation factor x 10 .

- Compensation factor to be used in the calculation above: $4 \% ; 8 \% ; 12 \%$ (MS are divided into three groups based on the ratio of forest area/total land area).

Article 13, paragraph 3 and 4 now state:

3. The following shall apply for the amount of compensation:

a. The Member State concerned may only compensate for sink accounted as emissions against their forest reference level.

b. Only up to the maximum amount of compensation for that Member State set out in Annex VII for the period from 2021 to 2030.

4. Finland may compensate up to 10 million tons of $\mathrm{CO} 2$ equivalent emissions provided that the conditions listed in points (a) and (b) of paragraph 2 are met.

For the Netherlands the compensation limit for the period 2021-2030 would be $-0.3 \mathrm{Mt}$ of $\mathrm{CO}_{2}$ equivalents (Figure 13). 


\begin{tabular}{|c|c|c|}
\hline Member State & $\begin{array}{c}\text { Reported average forest } \\
\text { sink } 2000-2009 \text { in million } \\
\text { tonnes } \mathrm{CO}_{2} \text { equivalent } \\
\text { per year }\end{array}$ & $\begin{array}{c}\text { Compensation limit expressed in } \\
\text { million tonnes of } \mathrm{CO}_{2} \text { equivalent for } \\
\text { the period } 2021-2030\end{array}$ \\
\hline Austria & $-5,34$ & $-17,1$ \\
\hline Belgium & $-3,61$ & $-2,2$ \\
\hline Bulgaria & $-9,31$ & $-5,6$ \\
\hline Czech Republic & $-5,14$ & $-3,1$ \\
\hline Cyprus & $-0,15$ & $-0,03$ \\
\hline Germany & $-45,94$ & $-27,6$ \\
\hline Denmark & $-0,56$ & $-0,1$ \\
\hline Estonia & $-3,07$ & $-9,8$ \\
\hline Greece & $-1,75$ & $-1,0$ \\
\hline Spain & $-26,51$ & $-15,9$ \\
\hline Fintand & $-36,79$ & $-44,1$ \\
\hline France & $-51,23$ & $-61,5$ \\
\hline Croatia & $-8,04$ & $-9,6$ \\
\hline Hungary & $-1,58$ & $-0,9$ \\
\hline Ireland & $-0,85$ & $-0,2$ \\
\hline Italy & $-24,17$ & $-14,5$ \\
\hline Lithuania & $-5,71$ & $-3,4$ \\
\hline Luxembourg & $-0,49$ & $-0,3$ \\
\hline Latvia & $-8,01$ & $-25,6$ \\
\hline Malta & 0,00 & 0,0 \\
\hline Netherlands & $-1,72$ & $-0,3$ \\
\hline Poland & $-37,50$ & $-22,5$ \\
\hline Portugal & $-5,13$ & $-6,2$ \\
\hline Romania & $-22,34$ & $-13,4$ \\
\hline Sweden & $-39,55$ & $-47,5$ \\
\hline Slovakia & $-5,42$ & $-6,5$ \\
\hline Slovenia & $-5,38$ & $-17,2$ \\
\hline United Kingdom & $-16,37$ & $-3,3$ \\
\hline
\end{tabular}

Figure 13 Annex VII from regulation with the 10 year maximum amounts of compensation available under the managed forest land flexibility of Article 13 of the LULUCF regulation. 


\section{Effects of the new LULUCF regulation on the production and use of biomass (Task 2 )}

\subsection{Assessment of potential effect of LULUCF regulation on total wood harvest in Europe.}

As explained in Chapter the LULUCF regulation aims for a no debit target, while Managed Forest land will be accounted against a projected reference level. Since the harvesting level very much determines the annual sink, setting a reference level thus determines the allowed harvest (assuming that countries want to avoid debits). Since the discussion between Member States and the Commission was mainly focussed on whether the Regulation would limit the total harvest (if countries indeed don't want a debit), we evaluated for three scenarios the harvest level and interpreted them in the light of future availability of biomass. The sink development under that harvest would be the reference level sink. The absolute value of the sink is not so important here. But a credible methodology for setting the harvest is foremost under attention.

\subsubsection{Methods}

We applied the European Forest Scenario Model (EFISCEN), a forest resource model to calculate 3 scenarios (i.e. interpretations of the LULUCF regulation text). These are:

1. Applying a constant absolute amount of harvest level.

2. Applying a constant harvest intensity.

3. Applying a constant harvest intensity but when the projection of intensity leads to higher harvesting than increment, we limited the ratio between harvest and increment to maximum $90 \%$ of the increment as an interpretation of sustainable management.

Especially scenario 3 is a reflection of how countries may interpret the text in the final LULUCF regulation. Namely Annex IV of WK 14966/2017 INIT (2016/0230 (COD)), states that criteria for determining reference levels are:

'... Including enhancing the potential removals (i.e. sink) by aging forest stocks, which may otherwise show progressively declining sink' and 'consistent with the objective of contributing to the conservation of biodiversity..' and '..constant ratio between solid and energy use of forest biomass as documented in the period from 2000 to 2009 shall be assumed'.

Furthermore the forestry accounting plan shall contain '.. documentary information on sustainable forest management practices and intensity and adopted national policies'

The European Forest Information SCENario Model (EFISCEN) is a large-scale forest model that projects forest resource development on regional to European scale (see efiscen.efi.int and Nabuurs et al. 2007; Sallnäs 1990; Verkerk et al. 2016). It uses national forest inventory data as a main source of input to describe the current structure and composition of European forest resources. EFISCEN is a matrix model, where the state of the forest is represented in matrices as an area distribution over age and volume classes. Aging is simulated as the movement of area to higher age classes, while growth is simulated as the movement of area to higher volume classes. Thinning is simulated as movement of area to a lower volume class, while the difference in volume is assumed to be the volume that has been removed by the thinning. Final felling is simulated by moving the area back to the first volume and age class of the matrix from where it can start growing again. The volume originally present at this area is the volume removed during final felling.

Harvest regimes are specified at two levels in the model. First, a basic management regime defines the age range during which thinnings can take place and a minimum age for final fellings. These 
regimes can be regarded as constraints on the total harvest level. Multiplication of the area available for thinnings and final fellings with the corresponding wood harvest gives the amount of wood that is theoretically available for harvesting. In the second step, the actual demand for wood is specified for thinnings and for final felling separately at the national level. The model calculates which share of the available potential needs to be harvested to satisfy the demand and implements this calculated intensity in the simulation.

\section{Three harvesting scenarios}

In most applications the demand for wood is specified externally, and the required harvest intensity will change per time step to satisfy the demand. This approach is applied in Scenario 1, harvesting a constant amount of wood over time.

In Scenario 2, we calculated the harvest intensity in the first time step (corresponding to the base period 2000-2009) and applied this intensity throughout the rest of the simulation. The amount of wood harvested over time is thus the result of a fixed harvest intensity and changes in the state of the forest over time. This approach is in line with the LULUCF regulation (Figure 14).

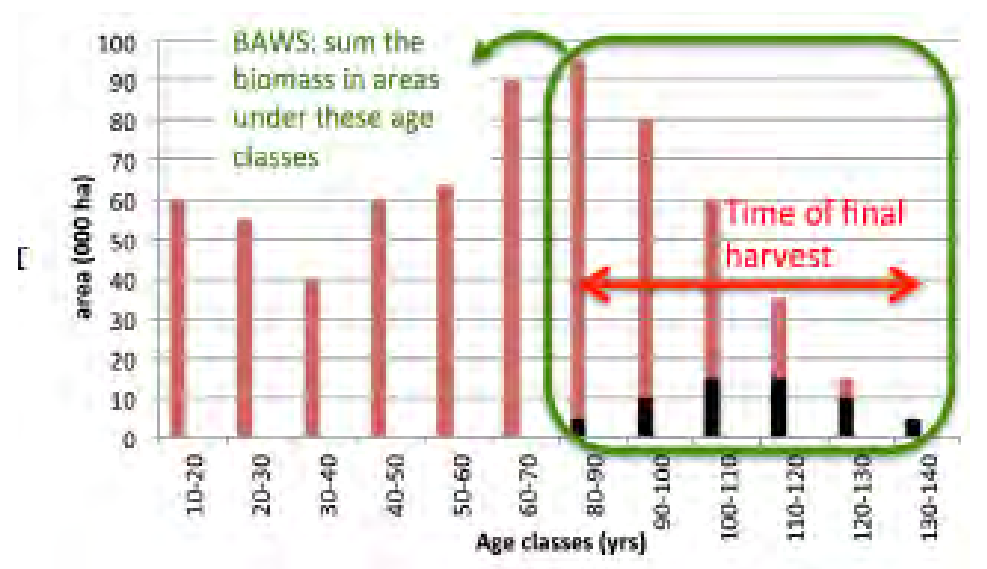

Figure 14 Hypothetical forest age class distribution of a country. The green encircled part are those areas where under the base period harvesting took place. These forest areas are called 'BAWS', biomass available for wood supply. The black part of the bars are those areas that have actually been harvested between 2000-2009. It is these black fractions out of the red bars, that together form the management intensity. This percentage is then used in the projection under 'constant management intensity' (after Grassi and Pilli 2017).

In $\underline{\text { Scenario } 3}$, the amount of wood harvested from scenario 2 is applied as demand, but because a projection of intensity sometimes resulted in high absolute volumes being harvested (more than increment), we limited the total harvest to a maximum of $90 \%$ of the simulated increment in scenario 2.

\subsubsection{Simulations}

The initialisation data are the same as used in the EFSOS II study (UNECE/FAO 2011). Simulations and harvest regimes are based on the EFSOS II baseline scenario, yielding a total net annual increment of 780 million $\mathrm{m}^{3}$ /year. For scenario 1, for the period from start to 2015, the harvest level per time step is derived from the actual wood production as extracted from the FAOSTAT database. For the period 2015-2050 we applied the average harvest as observed in the period 2000-2009. In scenario 2, we applied the average harvest level of the period 2000-2009 to the first time step and calculated the required harvest intensity for each country. This harvest intensity was subsequently applied to all time steps until 2050.

It should be noted that the start year differs among the countries due to different availability of national forest inventory data. In scenario 3, we limited the harvest level as found in scenario 2 to 
$90 \%$ of the simulated increment, on a country-by-country basis. Here we present results for the Netherlands, the EU as a whole (excluding Malta and Cyprus) and some specific countries, not assuming any growth changes due to e.g. climate change or improved forest management.

\subsubsection{Results}

Figure 15 shows the likely harvest under three alternative interpretations of the Regulation text through which a reference level sink would be determined for selected countries in 4 regions in the EU and the Netherlands. Higher harvest than this would result in debits, and depending on credits and debits in other activities would set the compensation mechanism into action. Figure 16 then gives the total EU26 allowable harvest.

Depending on age class structure and historic ( 2000-2009) harvest intensity, most countries, and the EU as a whole, show an increase in absolute harvest potential under continuation of management intensity, following gradual aging of the forest resource over time. I.e. these would be credible harvest levels following the criteria which would set the reference level sink.

Single countries show different patterns over time. The Atlantic example (Figure 15) has planted a lot of forest over the last decades and can expect almost a tripling of its harvest with a constant harvest intensity until 2040. However, harvest levels would temporarily be much higher than the increment, so the sustainable scenario yields a much lower sustainable harvest level. The Baltic example already has a relatively high harvesting intensity, and the sustainability limit would decrease the potential harvest for all projection years. In the Central European example, the sustainable scenario is only lower after 2045. In the Nordic example, the sustainability limit does not affect the simulated potential harvest level. The EU 26 as a whole shows a harvest increase from 420 million $\mathrm{m}^{3}$ in 2000-2009 to 560 million $\mathrm{m}^{3}$ in 2050 , complying to harvest intensity criteria. If we however also set a cut-off to comply to a sustainability criteria as max $90 \%$ of increment to be harvested for each individual country, then the harvest can only increase to 493 million $\mathrm{m}^{3} / \mathrm{year}$. The felling/increment ratio then becomes $80 \%$ for the EU26 as a whole, with values for individual countries ranging between $56 \%$ and $90 \%$. 

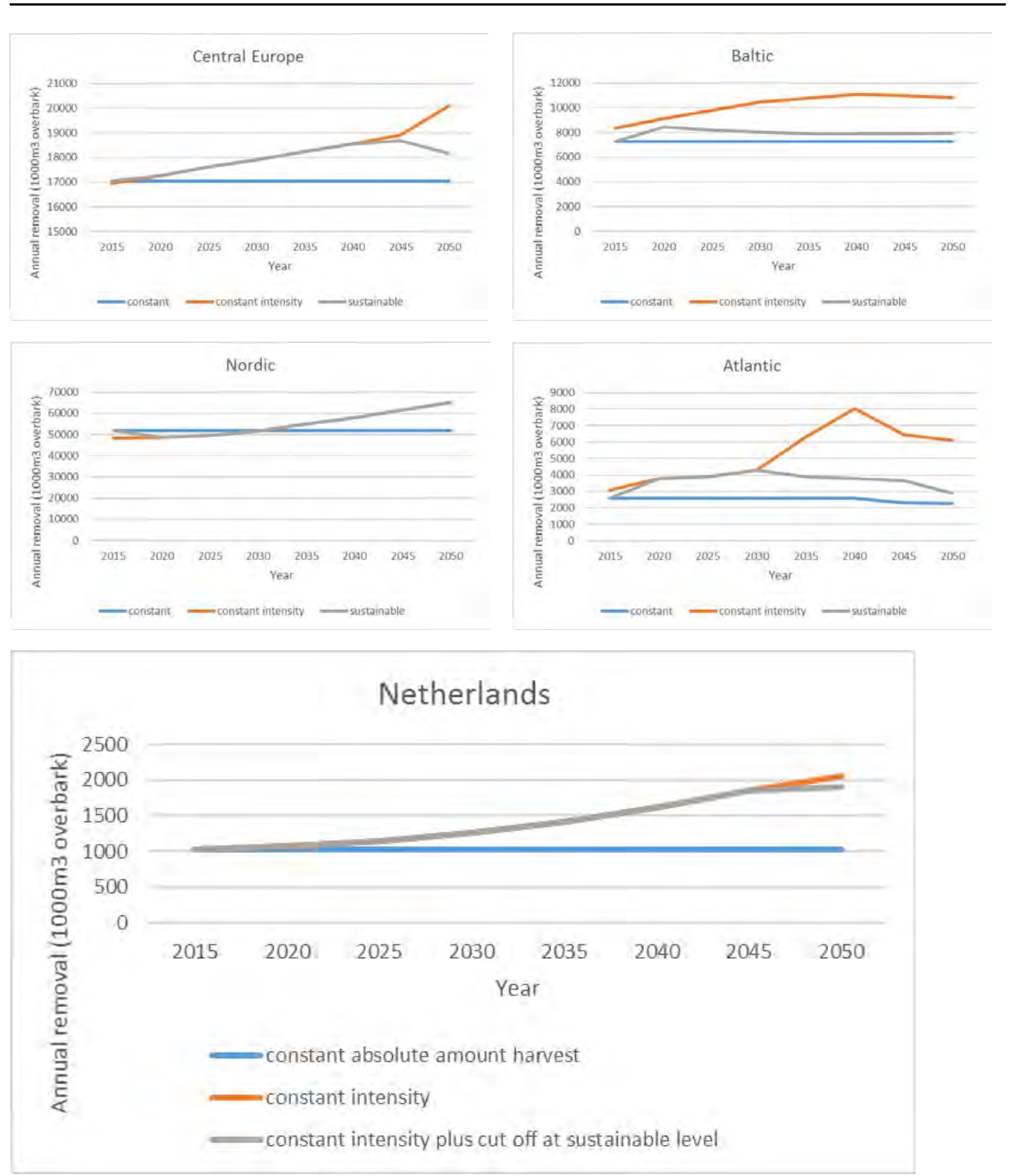

Figure 15 Development of potential annual harvest until 2050 under the Forest Reference Level without creating debits for selected EU countries assuming the three alternative interpretations of the LULUCF regulation text. Above four countries are real countries, but because of sensitivity, the identity is not given. For Netherlands, the identity is given. 


\section{EU28}

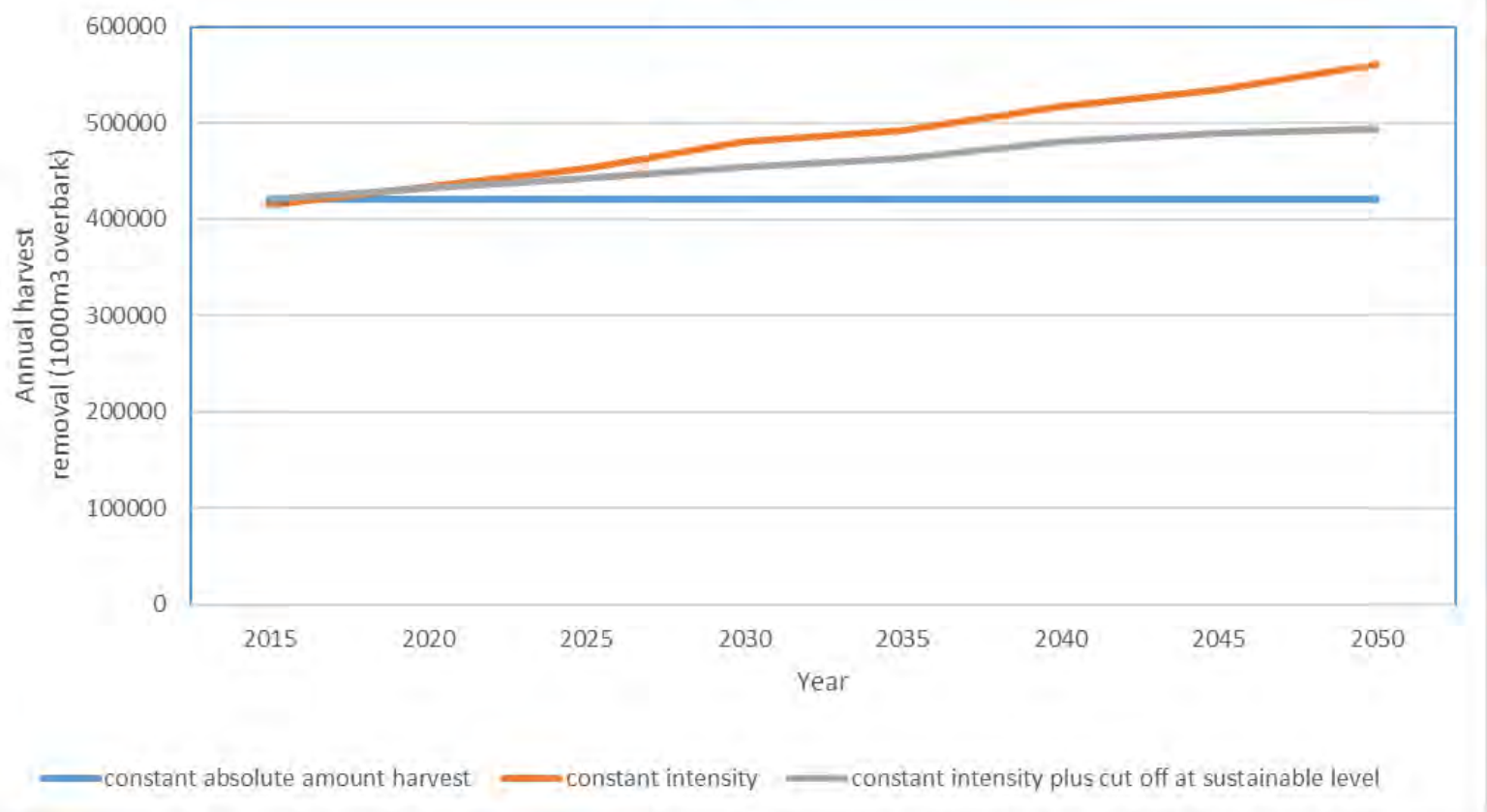

Figure 16 Development of potential annual harvest until 2050 under the Forest Reference Level without creating debits of all EU countries (excluding Malta and Cyprus) under the three alternative interpretations of the LULUCF regulation text.

In Figure 17, the sink development is given for the three scenarios. Under all scenarios the sink declines. The constant intensity, with the highest harvest, shows the most decline. 


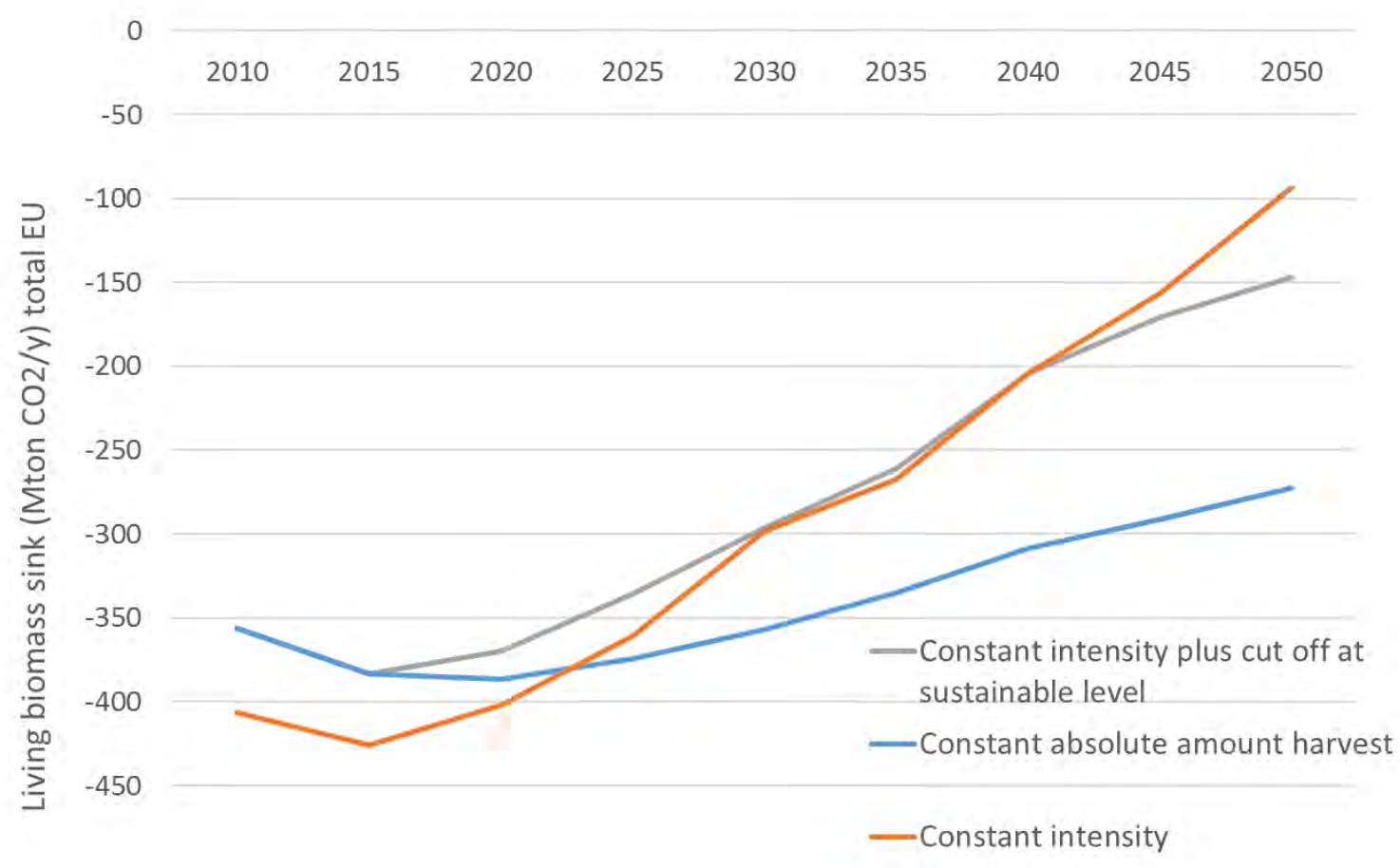

Figure 17 Living biomass sink development for total EU26 forests under the three scenarios.

\subsubsection{Constraints for increasing the harvest level in the Netherlands}

For the Netherlands, about $40 \%$ of the forest has a main management type of nature conservation, while allowing for harvesting in these forests. However, increasing the harvest level in such forests is not very likely. For a recent study for the NEV (Schoots et al. 2017), an EFISCEN setup for the Netherlands was made with the possibility to analyse the forests for nature and production separately. We repeated the analysis above (scenario 2, constant intensity) with this setup. Figure 18 indicates that by the end of the simulation, about 300 thousand $\mathrm{m}^{3}$ extra are harvested in the nature conservation forests. 


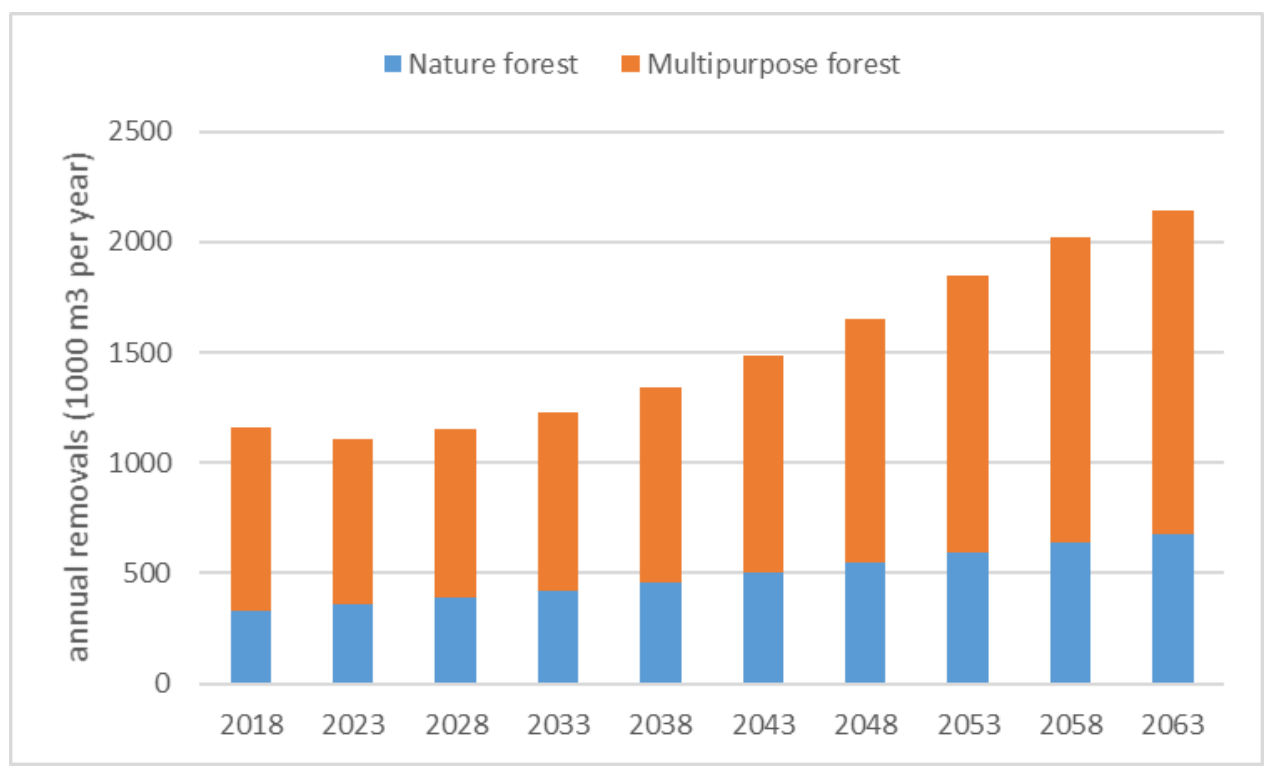

Figure 18 Development of annual harvest removals (in $1000 \mathrm{~m}^{3}$ ) until 2063 of Dutch forests, separated in forest designated for nature conservation (nature forest) and multipurpose forests, assuming a constant harvest intensity

\subsection{Potential effects on agricultural biomass}

For agricultural biomass the proposed EU regulation for including LULUCF in the climate and energy framework will have less and mainly indirect effects compared to forest biomass. First, most carbon in the agricultural biomass is part of the short carbon cycle, and second, the accounting rules for managed cropland and managed grassland are based on net-net accounting relative to the period 2005-2009. This means that a reduction in the emissions from managed cropland or grassland compared to this reference period will result in credits, even if the activity remains a source of emissions, while an increase in emissions compared to this period results in debits.

Most of the agricultural biomass are crops that are grown and harvested within the same year, and therefore belong to the short carbon cycle. This means that the carbon that is sequestered in the crop is released again within a year after consumption of the crop, either for food, feed or energy purposes. This short cycle carbon is not included in the accounting rules, which only consider the changes in the longer term carbon stocks (see also the Chapters on Cropland and Grassland in Arets et al. (2017).

For LULUCF reporting and accounting, the following carbon stock pools are distinguished, living biomass (above and belowground), dead organic matter (litter and dead wood), mineral soils and organic soils. For most arable land and grassland, the carbon pools in the soil are most relevant, as the biomass and dead organic matter pool is small and considered to be equal each year. Only for perennial crops the carbon stock in biomass is relevant. Figure 19 shows that organic soils currently are the main emissions source for cropland and grassland, due to the intensive use and drainage of the peat soils. Mineral soils are a source of carbon for arable land and a sink for grassland.

Managed cropland and managed grassland is included with net-net accounting, which means that emissions during the accounting period are compared to the emissions in the base year. According to the Commission proposal the base year is the average of 2005-2007, but in the proposal by the Member States the average of the period 2005-2009 is proposed as base year. If carbon stocks have increased (removals) during the period or the emissions have decreased (while still being a source), credits will be generated, but if emissions have become higher, debits will occur. If a member state will have strong focus on increasing soil carbon sequestration, this might have an effect on the 
availability of crop residues, as crop residues might be used for the soil, instead of other purposes, such as bioenergy.

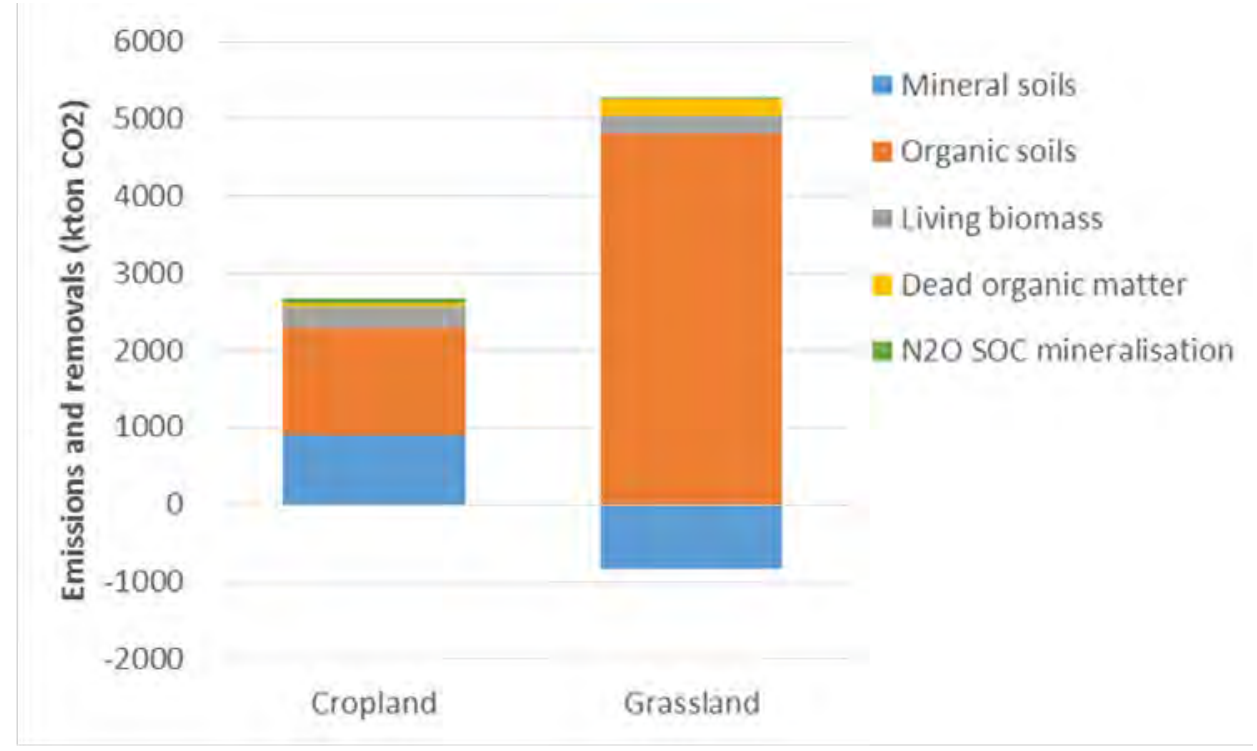

Figure 19 Reported emissions and removals for cropland and grassland for the Netherlands in 2015. Based on data from the NIR 2017 (Arets et al. 2017; Coenen et al. 2017).

In the Netherlands there is also discussion on the fertility of agricultural soils and the loss of organic matter in soils. Although long-term monitoring based on many soil samples does not provide evidence for such a decline, many farmers have a feeling that their soils are becoming less fertile. Probably the problems these farmers experience with their soils are more related to soil structure (soil compaction) and water availability. Nevertheless, this makes that farmers are becoming more aware on maintaining soil fertility and the soil organic matter content.

The Dutch government has set ambitious targets for reducing GHG emissions. In the current policy plans, part of the emission reduction should be obtained in the land use sector (1.5 Mton CO2 for 'slimmer landgebruik'). This will comprise of decreased emissions from cultivated organic soils and increased soil carbon sequestration. Also the agriculture sector is in favour of measures that increase the soil organic carbon content. Increased use of crop residues can have a trade-off on the soil organic matter content, and therefore the potential use of residues for bioenergy will likely be constraint.

\subsection{Assessment of effects of straw use on soil carbon}

To illustrate the trade- off between crop residues for soil carbon or for bioenergy, we used a model simulation to assess the availability of straw for bioenergy, taking the soil carbon effect into account. This analysis was done within the EU project S2BIOM and applied to the EU. The sustainable straw potential for bioenergy is defined as the total straw potential minus the amount of straw required to maintain the SOC balance minus current other use of straw. The sustainable straw potential for bioenergy was calculated according to the following steps:

1. Calculation of the total straw potential based on regional crop yields and the crop specific residues to product ratios from Scarlat et al. (2010).

2. Calculation of the regional SOC balance using RothC soil carbon model for the situation with full straw removal

3. Calculation of the regional SOC balance for the situation without straw removal

4. Assess the potential amount of straw that can be removed without decreasing the SOC stock

5. Subtract the amount of straw currently used for other purposes (i.e. livestock) 
The soil organic carbon balance is the difference between the inputs of carbon to the soil and the carbon outputs. A negative balance, i.e. outputs are larger than the inputs, will reduce the SOC stock and might lead to crop production losses on the long term. To calculate the soil carbon balance at regional (NUTS2 level) we used the MITERRA-Europe model to provide the input data and the RothC model to calculate the soil carbon dynamics. Manure and crop residues are the main carbon inputs that were included. Other inputs such as compost, sludge and sedimentation might be important inputs in certain regions or for certain crops, but in total these inputs are only very small compared to the $\mathrm{C}$ input from manure and crop residues. SOC decomposition has been included as the only carbon output, other possible $\mathrm{C}$ outputs, such as leaching and erosion, are not accounted for.

MITERRA-Europe is an environmental assessment model, which calculates $\mathrm{GHG}\left(\mathrm{CO}_{2}, \mathrm{CH}_{4}\right.$ and $\left.\mathrm{N}_{2} \mathrm{O}\right)$ emissions, SOC stock changes and nitrogen emissions from agriculture on a deterministic and annual basis (de Wit et al. 2014; Lesschen et al. 2011; Velthof et al. 2009). The model comprises about 35 crops and 10 livestock categories. MITERRA-Europe covers the agriculture sector at different spatial scales, e.g. for Europe this consists of EU-27 scale, Member State scale and NUTS2 scale.

The RothC model (Coleman and Jenkinson 1999) was used to calculate the SOC balance. RothC (version 26.3) is a model of the turnover of organic carbon in non-waterlogged soils that allows for the effects of soil type, temperature, moisture content and plant cover on the turnover process. It uses a monthly time step to calculate total organic carbon on a years to centuries timescale (Coleman and Jenkinson, 1999). In RothC model, SOC is split into four active compartments (decomposable plant material, resistant plant material, microbial biomass and humified organic matter) and a small amount of inert organic matter. Each compartment decomposes by a first-order process with its own characteristic rate.

The results of the simulation at EU level is shown in Figure 20. The map shows quite a diverse pattern where some regions have almost no potential, as crop yields are very low (e.g. Mediterranean regions) or the soil carbon content of the soil is very high (e.g. UK), whereas in other regions almost all straw can be harvested, as the inputs from roots and stubbles are sufficient to maintain the soil carbon level. Calculations for the Netherlands indicate that about 700 kton (dry matter) of straw residues is potentially available, mainly coming from barley and wheat. The soil carbon balance calculation shows that about 150 kton is required for maintaining soil carbon, which means that about 600 kton would be available. However, most of this straw is already used in the livestock sectors as fodder and bedding material, which means that the potential of straw for bioenergy is very limited in the Netherlands. 


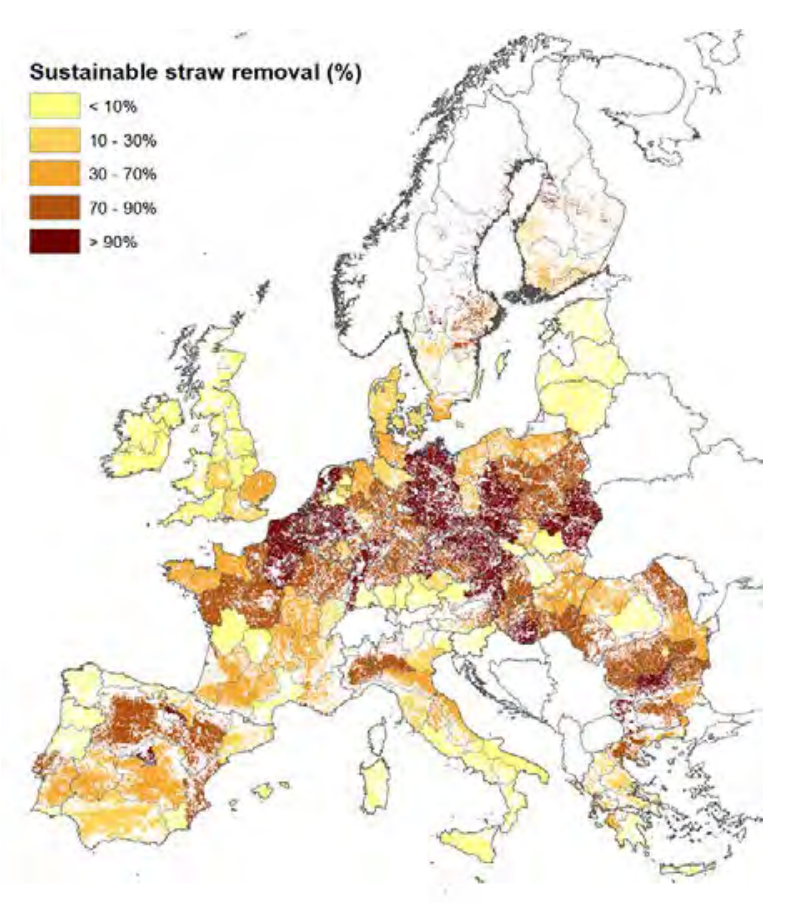

Figure 20 Spatial distribution of the sustainable straw removal rate to maintain the soil carbon level.

We also made an additional calculation with the RothC model for the Netherlands to assess to what extent incorporating crop residues can generate credits under managed cropland. The average soil carbon stock under arable land on mineral soils is 74.7 ton $\mathrm{C} / \mathrm{ha}$. The model results indicate that under a baseline scenario (i.e. no measures and same crop grown each year) the carbon stock declines to 68.5 ton $\mathrm{C} /$ ha. However, for a scenario where all crop residues are left on the field, the soil carbon stock can increase till 76.0 ton $\mathrm{C} / \mathrm{ha}$. If this is scaled up to national level, a maximum amount of credits of about 1 Mton $\mathrm{CO}_{2}$ per year can be obtained over a twenty year period.

\subsection{Use of agricultural biomass for materials and biofuels}

With an evolving bio-economy the demand for biomass for materials is increasing. Also agricultural biomass will be more and more used for bio-based products. Use of crops and residues for fibres is already common, new products are developed every day, and also bio-based plastics are becoming more popular. Many of these bio-based products replace other products that are based on fossil fuels. In this case there is clear mitigation through the substitution effect. However, also carbon is stored in these products, which can be considered as a kind of carbon sequestration. However, for agricultural biomass there is not (yet) a comparable approach as for harvested wood products, which are included in the accounting. Therefore the new LULUCF proposal will have no direct effect of the use of the agricultural biomass and only mitigation through substitution will be accounted for.

Large scale production of biofuels from agricultural crops is not common in the Netherlands, because alternative uses and crops are more profitable. The intensive livestock sector results in a high demand for feed crops and also the high land prices require intensive rotations with high margin crops. Nevertheless, the abolishment of the sugar quota will lead to higher sugar beet yields, and growing sugar beet for biofuels might become profitable. However, an increase in the crop area of sugar beet might lead to further intensification of the crop rotation, and replace other crops. This might lead to lower soil organic carbon stocks, as sugar beet is a crop with relatively low input of carbon to the soils, because the leaves are easily degradable and the roots are harvested. The new LULUCF proposal will not have any direct effect on the choice of crops grown, however, indirectly, potential new national policies that stimulate soil carbon sequestration might lead to other crop choices or crop and soil management. This might limit the possible expansion of the sugar beet area in the Netherlands. 


\subsection{Indirect Land Use Change (ILUC) effects}

Indirect Land Use Change (ILUC) is the process of potential displacement of crop production to previously non-cropland such as grasslands and forests due to the additional demand for biofuels. If land for bioenergy/biofuels is converted from cropland or grassland the production on those land has to be grown somewhere else and this conversion may take place in other countries than where the biofuel is produced. If there is no regulation that this must happen sustainably, this may happen in an unsustainable manner, with potentially high emissions due to land use change. The European Commission recognised this risk and came up with new legislation in 2015, which amend the Renewable Energy Directive and the Fuel Quality Directive, with the aim to reduce the risk of indirect land use change and to prepare the transition towards advanced biofuels. Member states also have to report on the measures they take to reduce the risk on ILUC.

ILUC cannot be seen or measured directly; it is commonly determined by making use of existing (agro-economic) models, which seek to look the global land use change response to increased demand for biofuels. Several economic models have been used to evaluate the ILUC effects of biofuels, but they contain many parameters that are determined by econometric fitting to historical statistical data, with significant uncertainties.

The proposed LULUCF regulation (EC 479/2016) does not have a direct effect on the ILUC discussion, however, indirectly it sets clear rules on full reporting and accounting of emissions and removals in the LULUCF sector, which means that possible emissions due to ILUC will be covered in the reporting at least for the EU member states.

The proposal for the revised Renewable Energy Directive (2016/0382 (COD)) will have more impact, with more strict sustainability criteria and the decision to no longer support first generation biofuels after 2020 and have obligatory lower shares of biofuels from food crops. It will be difficult to predict the exact impact of this proposal, as also some of the biofuel production can be economically attractive without subsidies. The increased support for advanced biofuels from waste and residues might have more impact, and will increase the pressure on the use of crop residues. 


\section{Effects of the LULUCF regulation on views and perceptions of (imported) biomass (Task 3)}

\subsection{Effects on import of biomass}

Under the LULUCF regulation, accounting principles for bioenergy have not changed (i.e. emissions are reported at time of harvest, not at time of burning) compared to the modalities in the Kyoto Protocol. As such the LULUCF regulation does not change the perception towards biomass. However, the FRL and its 'continuation of management intensity' across the EU member states allows (assuming countries don't want debits) only a harvest increase from 420 million $\mathrm{m}^{3}$ now, to 493 million $\mathrm{m}^{3}$ in 2050. The big question is if countries will take this as a ceiling or not. And will it work indirectly as some sort of quota system, still driving up raw material prices even if there is not a real shortage to meet demand? It is impossible to answer these questions now. If there will be a tightened supply from Europe, the current and future bio-economy industry will look at other continents, which thus even favours imports.

The recently presented Tapio study (Kallio et al. 2017) indicates that the potentially limiting effect of the LULUCF regulation on wood harvests, will also have economic effects for the EU forest sector with increasing imports from the rest of the world to meet the EU demand for wood. However, an important assumption in this study is that harvests cannot increase, while the results of our analyses in Chapter 6.1 clearly show that there is still room for increase in the harvests. The assumption that no harvest increases can occur therefor is not valid.

Then there are other articles in the LULUCF regulation that may be seen as first modest indications of incentivising cascading. E.g. a 'constant ratio between solid and energy use of forest biomass' hints in that direction. Currently, the share of wood going directly to energy is already large (non-commercial local fuelwood use amounts to 129 million $\mathrm{m}^{3} / \mathrm{y}$ !). Thus it seems that such a requirement in the forest accounting plan, will not have a large impact.

Maybe a larger impact on imports of biomass are requirements in the RED stating that the country of origin of the biomass must be signatory of the Paris agreement. If not, then supply base assurances that carbon stocks are maintained, must be made. The question is how this will work out for biomass originating from the USA. Most large pellet producers in the USA now have a chain of custody system in place, as well as data on forest management, and Best Management Practices programmes in place in all southern States, but full certification is often not the case.

\subsection{Effects on the Action Plan Forest and Wood and the additional 100,000 ha in the Netherlands}

In the Netherlands a number of civil and governmental parties in 2016 have signed the Action Plan Forest and Wood $^{8}$. The action plan has identified a number of actions aimed at improving the forest resource base in The Netherlands and improving the sustainable utilisation of the wood. Additionally actions are aimed at contributing to climate mitigation solutions. Type of action that were identified include:

1. extending the forest are in the Netherlands by 100,000 ha before 2050 ('more forest'),

\footnotetext{
8 Actieplan Bos en Hout; https://www.staatsbosbeheer.nl/-/media/09-nieuws/actieplan-bos-en-hout. pdf?la=nlnI\&hash=D48D86EA2E6564BEC4A1D93E33831FC93E47C64D
} 
2. developing and implementing climate smart forest management aimed at improve forest growth and wood production of existing forest (more productive and sustainable) forest management ('more with forest'), and

3. improve the sustainable utilisation of wood by using timber and wood products in a broader type of applications with longer use of the wood through innovation and cascading ('more with wood').

The question is whether and how the new LULUCF regulation will potentially affect these objectives?

The accounting for the forest categories, afforestation and forest management in the new LULUCF regulation is very similar to the accounting under the Kyoto protocol (Chapter5 and Annex II).

\section{Afforestation 100,000 ha}

The expected climate effects (in terms of $\mathrm{CO}_{2}$ removals) of these actions indicate that most of them will be incentivised by the LULUCF regulation. Additional planting of forests will directly contribute to increased carbon sequestration. Under the LULUCF regulation this will directly result in net credits because as a result of the gross-net accounting each ton of sequestered $\mathrm{CO}_{2}$ will generate credits. The effect of the afforestation is estimated at removing 0.5 Mton $\mathrm{CO}_{2}$ per year by 2030 , increasing to 1.3 Mton per year by 2050 .

\section{Climate smart forest management}

The climate smart forest management activities will include measures like improved rejuvenation of forest areas, which then are supposed to be planted with faster growing species and improved provenances (aim 120,000 ha) and additionally installing forest reserves in forests are recovered and further will remain unmanaged (27,000 ha).

As a result of these management intervention in the longer term the forest carbon sink is maintained and even improved. However on the shorter term it may decrease the sink compared to the reference situation. Even though these rejuvenated forests still remove $\mathrm{CO}_{2}$, the level is lower than if the forest were allowed to continue growing. Hence, due to the accounting of Managed Forest Land against the forest reference level, on the shorter term this is expected to result in debits. Timing and speed of the implementation will both influence the magnitude of the debits effect on the short term. Also location will have an effect. If rejuvenation is focused on forest that already experience an saturated carbon sink, the effect of a decreased sink after rejuvenation will be smaller.

\section{Sustainable utilization}

The actions focusing on using a larger share of wood in long term and sustainable applications like building will also be supported by the new LULUCF regulation. Harvested wood products are part of the accounting under managed forest land and therefore will also be accounted against the reference level. If a larger share of the harvested wood will end up in more durable applications, the time the carbon will remain in the HWP category will increase and hence will result in credits in the accounting. However, a substitution effect if the wood substitutes other energy demanding raw materials like concrete and steel, will be booked under the ETS and/or the ESD sectors.

Overall it can be expected that the LULUCF regulation will have a positive effect on the action plan. Afforestation and improved sustainability of the utilization of wood will be incentivised by the regulation. The activities envisaged under climate smart forestry will possibly in the shorter term result in debit, but on the longer term the forest sink will be safeguarded and will be increased. Additionally the LULUCF regulation has emphasised the importance of including LULUCF actions in climate mitigation policies. This will likely result in additional attention to enhanced policy support for the Action plan. 


\subsection{Does the new LULUCF regulation result in a change in accounting of the contribution of biomass to $\mathrm{CO}_{2}$ reductions?}

The question is whether the new LULUCF regulation will result in a change in accounting of the contribution of the use of biomass for $\mathrm{CO}_{2}$ reduction.

\section{Wood}

As indicated before in this report, the direct accounting of using woody biomass from forests will not be different to the current accounting under the Kyoto Protocol. Harvest of forest biomass for bioenergy and resulting effects on the carbon stocks in the forest will be accounted under Managed forest land. Potential substitution effects resulting from decreased use of fossil fuels and decreases in the associated emissions will be accounted in the energy (ETS) and transport (under ESD) sectors. The direct emissions from biomass in energy generation are not accounted in those sectors (but in LULUCF).

\section{Agricultural residues}

Biomass from residues from agriculture will be treated a bit different. Under the Kyoto Protocol the emissions and removals from cropland management and grazing land management were only accounted if these voluntary activities had been selected. The Netherlands, however, did not select these activities. Now under the new regulation the accounting of managed cropland and grassland will become compulsory activities for accounting. The harvesting of agricultural biomass or residues will most likely not be directly included in the accounting as no long-term build-up of carbon stocks in biomass is considered. However, changes in soil carbon stocks are included. As a result the removal of residues may affect the carbon inputs into the soil and result in decreased removals from to the soil, or increased emissions from the soils.

\section{Location of accounting}

In the IPCC guidelines (Chapter 12 in IPCC 2006) various approaches are described that can be used to calculate the input of wood into the HWP carbon pools. In order to prevent double counting or omitting emissions or removals associated with the HWP pool, the mandatory methodology under the Kyoto Protocol and also under the new LULUCF regulation is the production approach. Under this production approach, the emissions from woody biomass and decreased removals from using agricultural residues are accounted in the country that produces the biomass.

Potentially other biomass producing countries outside the EU may develop other systems that do not include instantaneous oxidation for biomass for energy or that the systems do not comply with the production approach. As a result there may be a risk of omitting or double counting of emissions and removals. Currently within the EU there is an initiative to propose internationally to have the production approach as the mandatory approach under the UNFCCC reporting.

\subsection{Effects of the LULUCF regulation on application of biomass for energy in comparison to using it in materials or chemicals?}

What is the anticipated effect of the new approaches under the EU LULUCF regulation for price and $\mathrm{CO}_{2}$ mitigation potential for energy and in comparison to other applications like in materials or chemicals. This issue has also been addressed before. This related to the accounting of harvested wood products and possible substitution effects. Longer storage of carbon in wood products will result in a more positive carbon balance in the forest and HWP categories in the LULUCF sector and increases credits or decreases debits in the LULUCF sector. 
Additionally the substitution effects, although not explicitly covered by the LULUCF sector, are an important aspect in the overall climate mitigation effect as well. The quantified example in Box 1, Chapter 5.2 shows that in general the substitution effect potentially is stronger than the losses from the forest, even if harvests result in debits in the LULUCF sector. The exact levels of substitution will depend on the material substituted and techniques used both 


\section{8 \\ LULUCF regulation in relation to Dutch sustainability criteria and the RED (Task 4)}

\subsection{Comparison of text in regulations}

Main question here is what is the relation between the LULUCF regulation, the Dutch sustainability criteria for biomass and the criteria in a new Renewable Energy Directive (RED) ? Will these regulations work in opposite directions, or will they be in line. Note that at the time of designing the ToR for this report, the LULUCF regulation and update of the RED were still in draft. Further, we will look into monitoring requirements. In the context of sustainability criteria, below are some of the most relevant sections from the LULUCF regulation, Dutch sustainability criteria and proposal for an updated RED.

\subsubsection{LULUCF regulation}

The methodology and justification of the forest reference levels should be included in a National Forestry Accounting Plan (NFAP). This NFAP should specifically address a number of criteria and contain elements related to sustainable forest management and sourcing of wood used for energy purposes. This should take into consideration a.o. the following criteria ${ }^{9}$ :

- c) reference levels should ensure a robust and credible accounting, to guarantee that emissions and removals resulting from biomass use are properly accounted for;

- e) a constant ratio between solid and energy use of forest biomass as documented in the period from 2000 to 2009 shall be assumed;

- f) reference levels should be consistent with the objective of contributing to the conservation of biodiversity and the sustainable use of natural resources,...

and should include the following, in this context relevant, elements ${ }^{10}$ :

- c) '..documentary information on sustainable forest management practices and intensity and adopted national policies;

- d) information on how harvesting rates are expected to develop under different policy scenarios;

- e) a description of how each of the following elements were considered in the construction of the reference level:

- (3) forest characteristics, including dynamic age related forests characteristics, increments, rotation length and other information on forest management activities under 'business as usual';

- (4) historical and future harvesting rates disaggregated between energy and non-energy uses.

And in relation to harvested wood products ${ }^{11}$ :

- Member States may, for information purposes only, provide in their submission data on the share of wood used for energy purposes that was imported from outside the Union, and the countries of origin for such wood.

Additionally it has a general statement in preamble that management "be consistent with the objective of contributing to the conservation of biodiversity and the sustainable use of natural resources'.

Even though the LULUCF regulation does not per se limit harvesting, it sets a harvesting regime under which an MS will receive no debits. In chapter 6 , the harvesting levels were given for a few countries and the EU total (see also 7.1). The LULUCF regulation sets no requirements on management as such. It aims to makes sure, however, that the management practices included to project the Forest

\footnotetext{
9 from section A of Annex IV of the LULUCF regulation

10 from section $B$ of Annex IV of the LULUCF regulation

11 from Annex $V$ in the LULUCF regulation on methodological issues relating to HWP
} 
Reference Level are based on sustainable management principles in such a way that if a member state subsequently does not implement sustainable forest management in practice, this will result in debits compared to the projected reference level.

\section{Dutch sustainability criteria (principles only)}

The Dutch sustainability criteria for sustainable biomass include the following principles:

Principle 1: The use of biomass leads to a substantial reduction in greenhouse gas emissions

calculated across the entire chain in comparison with the use of fossil fuels

Principle 2: Soil quality shall be maintained and where possible improved

Principle 3: Production of raw biomass does not result in the destruction of carbon sinks

Principle 4: The use of biomass does not result in a long-term carbon debt

Principle 5. Biomass production does not result in Indirect Land Use Change (ILUC)

Principle 6: Relevant international, national, regional and local laws and regulations are followed

Principle 7: Biodiversity is maintained and where possible enhanced

Principle 8: The regulating effect and the quality, health and vitality of the forest are maintained and where possible enhanced

Principle 9: The production capacity for wood products and relevant non-timber forest products is maintained in order to safeguard the future of the forests

Principle 10: Sustainable forest management is achieved through a management system

Principle 11: Forest management by a group or regional association offers sufficient safeguards for sustainable forest management

Principle 12: A chain of custody system is in place for the biomass, that covers the entire chain from the first actor to the bioenergy producer, that links the source to the material used in the product or product group, and provides greenhouse gas emission data of each individual link

Principle 13: In case of a group management system for the chain of custody the same requirements apply to the group as a whole as to individual businesses

\subsubsection{Renewable Energy Directive}

The Renewable Energy Directive states (in bold are Parliament approved changes of Jan 2018) the following:

5. Biofuels, bioliquids and biomass fuels produced from forest biomass taken into account for the purposes referred to in points (a), (b) and (c) of paragraph 1 shall meet the following requirements to minimise the risk of using unsustainable forest biomass production:

(a) the country in which forest biomass was harvested has national and/or sub-national laws applicable in the area of harvest as well as monitoring and enforcement systems in place ensuring that:

i) harvesting is carried out in accordance to the conditions of the harvesting permit or equivalent proof of the legal right to harvest within the national or regional legally gazetted boundaries;

ii) forest regeneration of harvested areas takes place;

iii) areas designated, by international or national law or by the relevant competent authority, to promote the maintenance of biodiversity or for nature conservation purposes, including in wetlands and peatlands, are protected;

iv) harvesting is carried out considering maintenance of soil quality and biodiversity with the aim of minimising negative impacts; and

v) harvesting maintains or improves the long-term production capacity of the forest at national or regional level

(b) when evidence referred to in the first subparagraph is not available, the biofuels, bioliquids and biomass fuels produced from forest biomass shall be taken into account for the purposes referred to in points (a), (b) and (c) of paragraph 1 if additional information of legality and forest management practices are provided at the supply base level to ensure that:

\section{i) harvesting is carried out in accordance with the conditions of the harvesting permit procedure or equivalent national or regional proof of the legal right to harvest;}

ii) forest regeneration of harvested areas takes place; 
iii) areas designated, by international or national law or by the relevant competent authority, to promote the maintenance of biodiversity or for nature conservation purposes, including in wetlands and peatlands, are protected;

(iv) harvesting is carried out considering maintenance of soil quality and biodiversity; including surrounding areas provided that they are affected by the harvesting activities;

(v) harvesting maintains or improves long-term production capacity of the forest at national or regional level; and

(vi) environmental and nature regulations or measures are in place and in line with the relevant Union environmental and nature standards.

6. Biofuels, bioliquids and biomass fuels produced from forest biomass shall be taken into account for the purposes referred to in points (a), (b) and (c) of paragraph 1 if the country or regional economic integration organisation of origin of the forest biomass meets the following LULUCF requirements:

(i) is a Party to, and has ratified, the Paris agreement;

(ii) has submitted a Nationally Determined Contribution (NDC) to the United Nations Framework Convention on Climate Change (UNFCCC), covering emissions and removals from agriculture, forestry and land use which ensures that either changes in carbon stock associated with biomass harvest are accounted towards the country's commitment to reduce or limit greenhouse gas emissions as specified in the NDC, or there are national or sub-national laws in place, in accordance with Article 5 of the Paris Agreement, and that land sector emissions do not exceed removals, applicable in the area of harvest, to conserve and enhance carbon stocks and sinks;

(iii) has a national system in place for reporting greenhouse gas emissions and removals from land use including forestry and agriculture, which is in accordance with the requirements set out in decisions adopted under the UNFCCC and the Paris agreement;

When evidence referred to in the first subparagraph is not available, the biofuels, bioliquids and biomass fuels produced from forest biomass shall be taken into account for the purposes referred to in points (a), (b) and (c) of paragraph 1 if management systems are in place at supply base level to ensure that carbon stocks and sinks levels in the forest are maintained or increased.

By 1 J anuary 2021, the Commission shall establish the operational evidence for demonstrating compliance with the requirements set out in paragraphs 5 and 6 , by means of implementing acts adopted in accordance with the examination procedure referred to in Article 31(2).

By 31 December 2023, the Commission shall assess, in close collaboration with the Member States, whether the criteria set out in paragraphs 5 and 6 effectively minimise the risk of using unsustainable forest biomass and address LULUCF requirements, on the basis of available data. The Commission shall, if appropriate, present a proposal to modify the requirements laid down in paragraphs 5 and 6 for the period after 2030.

\subsubsection{Comparison of the regulations}

An important limit in the LULUCF regulation is that it only considers and accounts the emissions and removals within the LULUCF sector for which a no debit rule applies. It does not consider possible substitution effects in other sectors. The Dutch sustainability criteria (Principle 1) and the RED in contrast look at emissions in the whole chain from biomass production to its use in energy production compared to a reference level for fossil fuels. These latter two are also much more specific in their demands for environmental integrity. While the LULUCF regulation does not demand this explicitly, its inclusion in the reference level will result in debits in the accounting if the Member State in practice fails to implement sustainable forest management. 
Another important difference between the LULUCF regulation and the other two is that a Member States' LULUCF accounting is on the basis of domestic production of biomass and is not affected by importing biomass, while the Dutch sustainability criteria for biomass and the proposed update of the RED address sustainability of all biomass used for energy production including imported biomass. Any distinction would probably not be allowed under the WTO agreements.

An extensive comparison of these texts was outside the scope of this report. But from a overview perspective, it can be concluded that the Dutch criteria are much more strict and elaborate than the RED criteria. As such the Dutch criteria can be seen as a national elaboration of an EU minimum. However, on one point, the EU criteria are specific 'country of origin has to be a signatory of the Paris agreement'. If this is not the case, a supply base analyses has to be made that assures maintenance of carbon stocks.

Overall, the LULUCF regulation and the RED or Dutch criteria do not seem to work in opposing directions. The LULUCF does not strongly incentivise $\mathrm{CO}_{2}$ storage in the ecosystem nor does it strongly incentivise mobilisation of wood. LULUCF allows some increase in harvest without creating immediate debits. Most likely the LULUCF regulation will not incentivise much action in any direction, but as stated before, may have an impact on total harvesTable amounts ad on share of the wood that can be sued for energy purposes. Therefore, we can conclude that LULUCF and RED in general seem to complement each other.

\subsection{How Member States can show compliance with criteria}

Here we look into a few of the criteria of the RED on monitoring and enforcing the compliance with the criteria. The RED e.g. states: has national and/or subnational laws .... as well as monitoring and enforcement'. To what degree will countries be able to comply with?

All EU countries have a forest policy document. This could be for example a 'forest strategy', 'forest policy' etc. These exist in all EU countries. Many were further developed in the context of National Forest Programme processes and/or are endorsed at a high political level. The forest laws currently in force in most EU countries are less than five years old. Many have amended their legal and regulatory frameworks since 2011. The most frequent amendments in the legal/regulatory frameworks address issues concerning the governance of land use change. With regard to international commitments, the majority reported domestic policy and legal changes in the follow-up to international commitments such as the EU's Timber Regulation and FOREST EUROPE's Oslo Ministerial Decision and Resolutions (see Table 2).

For the US, there is no national (Federal) forest law, but governance is regulated at State level. Forest area as such is not protected (private land owners are allowed to convert to agriculture), but a species protection act and water protection act and several support schemes aim at sustainable management. Although in some regions deforestation occurs (due to urban sprawl) this is compensated by afforestation elsewhere. The forest department in every state manages the State forests according to the regulations and supports private owners. See e.g.

http://dof.virginia.gov/stateforest/index.htm

Canada's provinces and territories have jurisdiction over the vast majority of the country's forests, and develop and enforce laws, regulations and policies related to forests. Those laws, regulations and policies differ from one jurisdiction to another but they are all: based on sustainable forest management principles, developed in consultation with the public, industries and other interested parties, grounded in scientific research and analysis.

The forest code of Russia also provides for a national law that sets the regulation of management and the designation of protected areas. Naturally enforcement is a challenge in Russia

http:// www. fire.uni-freiburg.de/GlobalNetworks/BalticRegion/ForestCode-3rdReading-061108-eng. pdf. 
Table 2 Overview of EU national forest laws.

\begin{tabular}{|c|c|c|c|c|}
\hline \multirow[b]{2}{*}{ Country } & \multicolumn{4}{|c|}{ Main forest and SFM related legal/regulatory act with national scope (e.g. Forest law, act or code) } \\
\hline & Name and reference to legal document & Main changes from previous legal act & Date of enactment & Date of latest amendment \\
\hline Austria & Austrian Forest Act 1975 & No major changes & 1975 & 2013 \\
\hline Bulgaria & $\begin{array}{l}\text { Law on Forests publ. SJ } 19 \text { from 08.03.2011, in force since } \\
09.04 .2011 \text {, last amm. SJ } 61 \text { since 25.07.2014 } \\
\text { http://iag.bg/docs/lang/1/cat/1/index }\end{array}$ & see comments & 09.04 .2011 & 25.07 .2014 \\
\hline Croatia & $\begin{array}{l}\text { Act of Forest (Official Gazette 140/05, 82/06, 129/08, } \\
80 / 10,124 / 10,145 / 11,25 / 12,68 / 12,148 / 13 \text { and } 94 / 14 \text { ) }\end{array}$ & $\begin{array}{l}\text { Established Extension service*. Allows the construction of golf } \\
\text { courses and camps. *Amendments on Forest Law (OG 124/10) } \\
\text { Forestry Extension Service merged with the company "Croatian } \\
\text { Forests" Ltd. }\end{array}$ & 28.11.2005. (OG 140/05) & 8.8.2014 \\
\hline Cyprus & $\begin{array}{l}\text { The Forest Law 2012. (L.25(I)/2012. Official Gazette Annex } \\
\text { (1), 30.3.2012) }\end{array}$ & A totally new forest legislation that replaces the previous one. & $30 / 3 / 2012$ & $\begin{array}{l}\text { No amendments on the basic } \\
\text { Law. A minor amendment on } \\
\text { Forest Regulations (legal } \\
\text { document) for the control of } \\
\text { the disposal and use of state } \\
\text { forest land. }\end{array}$ \\
\hline Czech Republic & $\begin{array}{l}\text { The Forest Act No. } 289 / 1995 \text { has been valid since Jan. } 1 \text {, } \\
\text { 1996. It replaced the former law No. } 77 / 1977 \text { and its main } \\
\text { aim was to react on the change of the socio-economic } \\
\text { conditions in the country after 1989. During the time some }\end{array}$ & $\begin{array}{l}\text { Reaction on the change of economic system after } 1989 \text { (creation of } \\
\text { private sector). Prohibition of lease and sub-lease of state forests } \\
\text { for the purpose of forest management (Â§ 5); etc. No change since } \\
2007 .\end{array}$ & Nov. 3, 1995 & $\begin{array}{l}1.5 .2014 \text { (minor changes due to } \\
\text { consistency with the act on } \\
\text { inspection (general)) }\end{array}$ \\
\hline Finland & Forest Act & $\begin{array}{l}\text { The amendments to the Forest Act increase the freedom of choice } \\
\text { of forest owners in managing their own forest property, improve } \\
\text { the profitability of forestry and operating conditions of wood- } \\
\text { producing industry, and enhance the biodiversity of forests. One } \\
\text { important objective in the reform was to have less detailed } \\
\text { regulation on the treatment of forests and to clarify the legislation. } \\
\text { The most important changes include allowing uneven-aged forest } \\
\text { stands, abolition of age and diameter limits in regeneration, more } \\
\text { diverse range of tree species, and increase the spectrum of habitats } \\
\text { of special importance. }\end{array}$ & 1.1.1997 & 20.12 .2013 \\
\hline France & Code forestier (Forest code) & & 1827 & $\begin{array}{l}2012 \text { (restructuration and } \\
\text { rewritting) July } 2014 \text { (forest act) }\end{array}$ \\
\hline \multicolumn{5}{|c|}{ 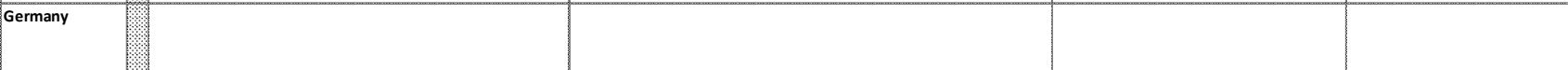 } \\
\hline Greece & $\begin{array}{l}\text { Presidential Decree 86/1969 "Forest Code" Law 998/1979 } \\
\text { "about the protection of forests and forests areas of the } \\
\text { country" Law } 3208 / 2003 \text { "protection of forest ecosystems, } \\
\text { establishment of forest cadastre, regulation of legal rights } \\
\text { on forests and forest areas and other provisions" }\end{array}$ & & & $\begin{array}{l}8 \text { August 2014, publication of } \\
\text { law 4280/2014. }\end{array}$ \\
\hline Hungary & $\begin{array}{l}\text { Act no. XXXVII/ } 2009 \text { on Forests, Protection of Forests and } \\
\text { Forest Managemen }\end{array}$ & & 10072009 & \\
\hline Italy & $\begin{array}{l}\text { Decree of Goverment } \mathrm{n} \text {. } 227 \text { of } 18 \text { th May } 2001 \text { on } \\
\text { modernization of the Forest Sector. - Law n. 296, } \\
27 / 12 / 2006 \text { (National Financial Law } 2007 \text { â } \epsilon^{\text {“ paragraphs }} \\
1082 \text { and } 1084 \text { ). .- Decree } 16 / 06 / 2005 \text { of the Ministry of } \\
\text { Environment on guidelines on forest programmes }\end{array}$ & Not significant & & \\
\hline Latvia & Forest Law & Forest Law was legal basis for implementation of Forest Policy & 17.03 .2000 & $\begin{array}{l}\text { Major amendments done on } \\
\text { 13.10.2011 }\end{array}$ \\
\hline
\end{tabular}


Table 2 (continued)

\begin{tabular}{|c|c|c|c|c|}
\hline Luxembourg & $\begin{array}{l}\text { Loi du } 8 \text { octobre } 1920 \text { concernant l'amÃ } \odot \text { nagement des } \\
\text { bois administrã } \cong \text { s. Loi du } 30 \text { janvier } 1951 \text { ayant pour objet } \\
\text { la protection des bois. Loi du } 19 \text { janvier } 2004 \text { concernant la }\end{array}$ & $\begin{array}{l}\text { Implementation of the EU FLEGT regulations. Softening of the } \\
\text { planning obligations for small properties. }\end{array}$ & 21.7.2014 8.4.2014 & 8.4 .2014 \\
\hline Poland & $\begin{array}{l}\text { Act on Forests; Journal of Laws of the Republic of Poland - } \\
\text { Dz.U. 1991.101.444, with amendments }\end{array}$ & $\begin{array}{l}\text { They were described in } 2004 \text { report. Since then no significant } \\
\text { changes. }\end{array}$ & January 1st 1992 & June 10th 2014 \\
\hline Portugal & 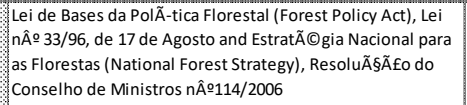 & & 1996 and 2006 (respectively) & $\begin{array}{l}\text { National Forest Strategy is } \\
\text { currently being updated }\end{array}$ \\
\hline Romania & Law 46/2008 Forest Code & 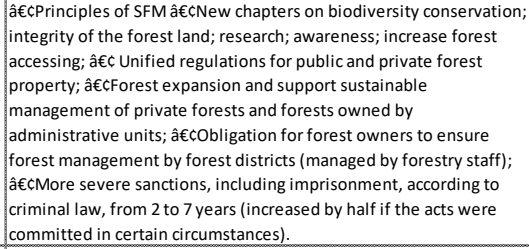 & ; 27.03.2008 & 01.02 .2014 \\
\hline Slovak Republic & Act No 326/2005 of the Coll. on Forests as amended & Only minor changes were taken & $\begin{array}{l}\text { Date of adoption: } 23 \text { June } 2005 \text { Valid } \\
\text { from: } 22 \text { July } 2005 \text { Effective from: } 1 \\
\text { September } 2005\end{array}$ & $\begin{array}{l}\text { The last amendment by Act No } \\
\text { 182/2014 of the Coll. Date of } \\
\text { adoption: } 27 \text { May } 2014 \text { Effective } \\
\text { from: } 11 \text { July } 2014\end{array}$ \\
\hline Slovenia & Act on Forest & $\begin{array}{l}\text { According to this act, forests are managed by forest owners and not } \\
\text { by forest enterprises as was the case in socialist period. }\end{array}$ & 10.6.1993 & 7.3.2014 \\
\hline Spain & $\begin{array}{l}\text { National Forest Law } 43 / 2003 \text { of } 21 \text { st november, amended } \\
\text { by the Law 10/2006. (consolidated text can be found under } \\
\text { http://www.boe.es/buscar/act.php?id=BOE-A-2003- } \\
\text { 21339). }\end{array}$ & $\begin{array}{l}\text { They were not made over the } 2009-2014 \text { period. An upcoming } \\
\text { amendment of this law is envisaged by } 2015 \text {. This review has } \\
\text { already been undergone a participatory process } \\
\text { (http://www.magrama.gob.es/es/desarrollo-rural/participacion- } \\
\text { publica/anteproyecto-ley-modificacion-ley-montes.aspx) and is } \\
\text { expected to be approved by the Spanish Council of Ministers in } \\
\text { September } 2014 \text { and then discussed by the Spanish Parliament. }\end{array}$ & 21 November 2003 & 29 April 2006 \\
\hline Sweden & $\begin{array}{l}\text { The Forestry Act (SkogsvÃ ¥rdslagen) } \\
\text { (www.notisum.se/rnp/ss//lag/19790429.HTM) or } \\
\text { (http://www.skogsstyrelsen.se/en/forestry/The-Forestry- } \\
\text { Act/) }\end{array}$ & $\begin{array}{l}\text { Main changes between } 1979 \text { and today: Wood production is of } \\
\text { equal importance as conservation of biodiversity. Forest as a } \\
\text { renewable resource is highlighted in the first article of the Forestry } \\
\text { act. The definition of forest is adapted to international (FAO) } \\
\text { definitions including Other woodeed land. The requirement on } \\
\text { forest owners about documentation of the state of the forest as } \\
\text { well as information about nature and cultural values on their forest } \\
\text { estate is taken out. The required information in the notification } \\
\text { that has to be sent to the authority prior to final felling is clearified. }\end{array}$ & 1979 (major revision in 1993) & $\begin{array}{l}1 \text { September } 2014 \text { (no major } \\
\text { changes) }\end{array}$ \\
\hline Switzerland & $\begin{array}{l}\text { Federal Law on Forests of } 1991 \text { (SR 921.0) } \\
\text { http://www.admin.ch/opc/en/classified- } \\
\text { compilation/19910255/index.html }\end{array}$ & & $\begin{array}{l}\text { Parliament decision of } 4 \text { October 1991, in } \\
\text { force since } 1 \text { January } 1993\end{array}$ & (1 July 2013 \\
\hline United Kingdom & $\begin{array}{l}\text { Forestry Act } 1967 \text { (as amended), the Plant Health Act } 1967 . \\
\text { www.legislation.gov.uk/nia/2010/10/pdfs/nia_20100010_e } \\
\text { n.pdf }\end{array}$ & & 19672010 & \\
\hline
\end{tabular}

\section{Monitoring:}

All EU countries have a national forest inventory in place. Although they differ in detail of the exact assessment, they produce at national level reliable results. However they cannot serve to pinpoint what exactly happens at the local level, because a) the sampling design is usually $1 \times 1$ or $2 \times 2 \mathrm{~km}, \mathrm{~b}$ ) raw (local) data are not available, c) results are 3-4 years old by the time they are published. 


\begin{tabular}{|c|c|c|c|c|c|c|c|}
\hline Country & $\begin{array}{l}\text { Systematic grid spacing for plots } \\
\text { or clusters of plots }(\mathrm{km} \times \mathrm{km})\end{array}$ & $\begin{array}{l}\text { Strata criteria for } \\
\text { stratified sampling }\end{array}$ & $\begin{array}{l}\text { Random } \\
\text { component in plot } \\
\text { location }\end{array}$ & $\begin{array}{l}\text { Number of field } \\
\text { plots per cluster }\end{array}$ & $\begin{array}{l}\text { Permanent plots } \\
\text { (proportion of all } \\
\text { plots) }\end{array}$ & $\begin{array}{l}\text { Last NFI } \\
\text { cycle }\end{array}$ & $\begin{array}{l}\text { Current/ } \\
\text { future NFI } \\
\text { cycle }\end{array}$ \\
\hline $\begin{array}{l}\text { Belgium } \\
\text { (Walloon } \\
\text { Region) }\end{array}$ & $1 \times 0.5$ & - & - & 1 & 1.00 & $1994-2008$ & 2008-2018 \\
\hline China & - & - & - & 1 & 1.00 & $2004-2008$ & - \\
\hline Cyprus & - & - & - & 1 & 1.00 & $2001-2005$ & - \\
\hline $\begin{array}{l}\text { Czech } \\
\text { Republic }\end{array}$ & $2 \times 2$ & - & $\begin{array}{l}\text { Within } 300 \mathrm{~m} \text { of } \\
\text { grid point }\end{array}$ & 1 & 1.00 & 2001-2004 & - \\
\hline Denmark & $2 \times 2$ & - & - & 4 & Approximately 0.33 & $2002-2006$ & $2007-2011$ \\
\hline Estonia & $5 \times 5$ & - & - & 16 & $0.25-0.50$ & $2004-2008$ & 2009-2013 \\
\hline Great Britain & - & Forest type & Within polygons & 1 & - & 1995-1999 & 2009-2013 \\
\hline Iceland & $0.5 \times 1$ to $1.5 \times 3$ & $\begin{array}{l}\text { Plantation and } \\
\text { birch }\end{array}$ & - & 1 & 1.00 & - & 2005-2009 \\
\hline Ireland & $2 \times 2$ & - & $\begin{array}{l}\text { Within } 100 \mathrm{~m} \text { of } \\
\text { grid point }\end{array}$ & 1 & 1.00 & $2004-2006$ & - \\
\hline Italy & $1 \times 1$ & $\begin{array}{l}\text { Administrative } \\
\text { region and land } \\
\text { cover }\end{array}$ & - & 1 & $0.00^{\mathrm{b}}$ & 2003-2007 & - \\
\hline Japan & $4 \times 4$ & - & - & 1 & 1.00 & $2004-2008$ & - \\
\hline Korea & $4 \times 4$ & - & - & 4 & 1.00 & 1996-2005 & $2006-2010$ \\
\hline Latvia & $2 \times 2$ to $4 \times 4$ & - & - & 1 & 1.00 & $2004-2008$ & 2009-2013 \\
\hline Lithuania & $4 \times 4$ & - & - & 1 & 0.75 & $2003-2007$ & $2008-2012$ \\
\hline Luxembourg & $1 \times 0.5$ & - & - & 1 & 1.00 & $1999-2001$ & $2008-2010$ \\
\hline Slovenia & $4 \times 4$ & & & 5 & 1.00 & 2007 & \\
\hline Spain & $1 \times 1$ & & & 1 & 1.00 & $1997-2007$ & $2008-2018$ \\
\hline Sweden & varying & & & $4-12$ & Approximately 0.60 & 1993-2002 & 2003-2012 \\
\hline Switzerland & $1.41 \times 1.41$ & & & 1 & 1.00 & $2004-2006$ & \\
\hline USA & $\begin{array}{l}2,400 \text { ha systematic hexagonal } \\
\text { tessellation }\end{array}$ & & $\begin{array}{l}\text { Within } 2,400 \text { ha } \\
\text { hexagon }\end{array}$ & 4 & 1.00 & $2004-2008$ & 2009-2013 \\
\hline
\end{tabular}

${ }^{\mathrm{a}}$ Percent non-productive forest land, volume, cumulative day-time temperature.

${ }^{b}$ All plots marked for possibility of future measurement.

Figure 21 Overview of forest inventory meta data (from Lawrence et al. 2010).

However, for monitoring new satellite derived assessments are coming available. A good example is the Swedish Skogsstyrelsen that makes use of Sentinel 2 data, less than one week old to monitor the clearcut areas. Thus, national level monitoring exists that would show that on item ii) regeneration, iii) areas of high conservation value are protected, and v) harvesting does not exceed long term productivity are assured.

Some examples:

www. bundeswaldinventur.de

http://inventaire-forestier.ign.fr

http://www.sumari.hr/biblio/pdf/11405.pdf

http://stat. gov.pl/en/topics/agriculture-forestry/forestry/forestry-2016,1,7.html

\section{Enforcement}

The term 'Enforcement' can be interpreted in different ways. Is a very low staffing sufficient to enforce and to check that forest management is carried out according to the regulations? Is enforcement sufficient when only national and sub-nationally the trends are checked and followed. There are certainly trends in the enforcement. Compared to 2011 only in a few eastern European countries, additional measures are implemented and enforced. Mostly the trend is of less regulation and less support to private owners. In Finland the 'Finnish Forest Centre' commenced operations in early 2012; its activities include the promotion of forestry and related livelihoods, advising landowners on how to care for and benefit from their forests and the ecosystems they contain, the collection and sharing of 
data related to Finland's forests, and the enforcement of the forestry legislation. Overall the number of public staff is decreasing in most countries (Figure 22). Thus, precise enforcement will be a challenge for most countries.

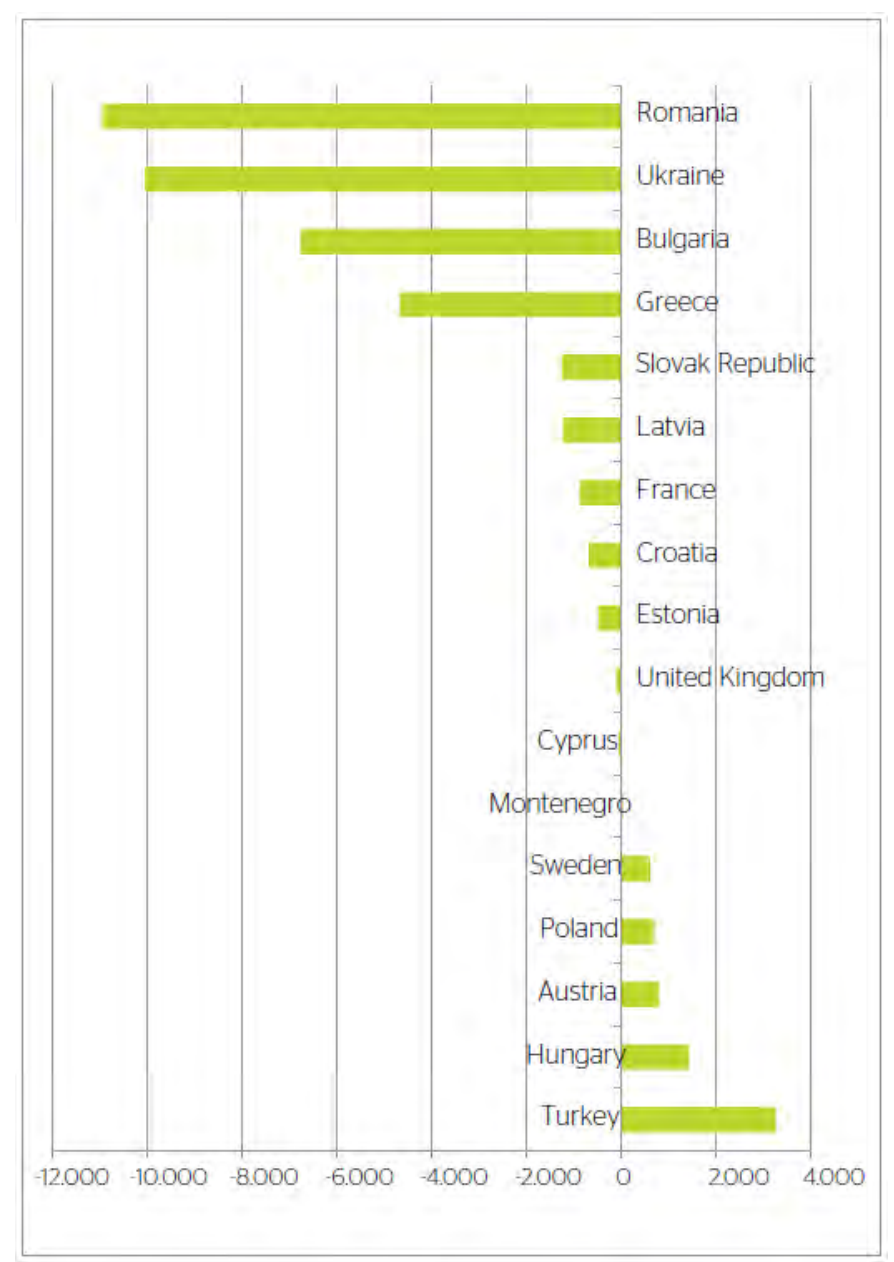

Figure 22 Change in number of FTE public staff per country (Forest Europe 2015).

\section{ii How to demonstrate that 'forest regeneration of harvested areas takes place'?}

Every EU country has a national forest inventory (NFI). These inventories are carried out on a sample base, whereby on every $1 \times 1$ or $2 \times 2 \mathrm{~km}$ grid a plot of roughly 25 trees is measured. These inventories are carried out every 5-10 years. Disadvantages are that they are different between countries, raw data are (often) not given out, and by the time reports come out, the data are $\sim 3-4$ years old. For several countries, the latest inventory results are by now close to 10 years old.

Inventories thus are not a good information source to 'assure' that a specific harvested area has been regenerated. $\mathrm{NFIs}$ do give the possibility to trace certain inventory plots that had been harvested before the previous inventory, regarding its regeneration status in the current inventory. As such NFIs can help to demonstrate that e.g. all harvested inventory plots from the previous inventory are regenerated at the time of the new inventory.

As a risk based approach (demonstrate), the inventory of sample plots will tell if all harvested plots were regenerated by the time the next inventory is carried out. E.g. a 100\% regeneration of all plots which were a clearcut in previous inventory, should be achieved by the time of current inventory. This can be seen as a national level risk based approach sufficient to demonstrate, although results will come quite late. 
Furthermore, the sample scheme of a national forest inventory is always determined based on latest aerial photos. These aerial photos are used to determine the forest area (and land use in general). The aerial photo interpretation is a very good way to assure the maintenance of forest area and regeneration of clearcuts.

Newer possibilities based on Landsat or Sentinel are given in Figure 23 and 25.

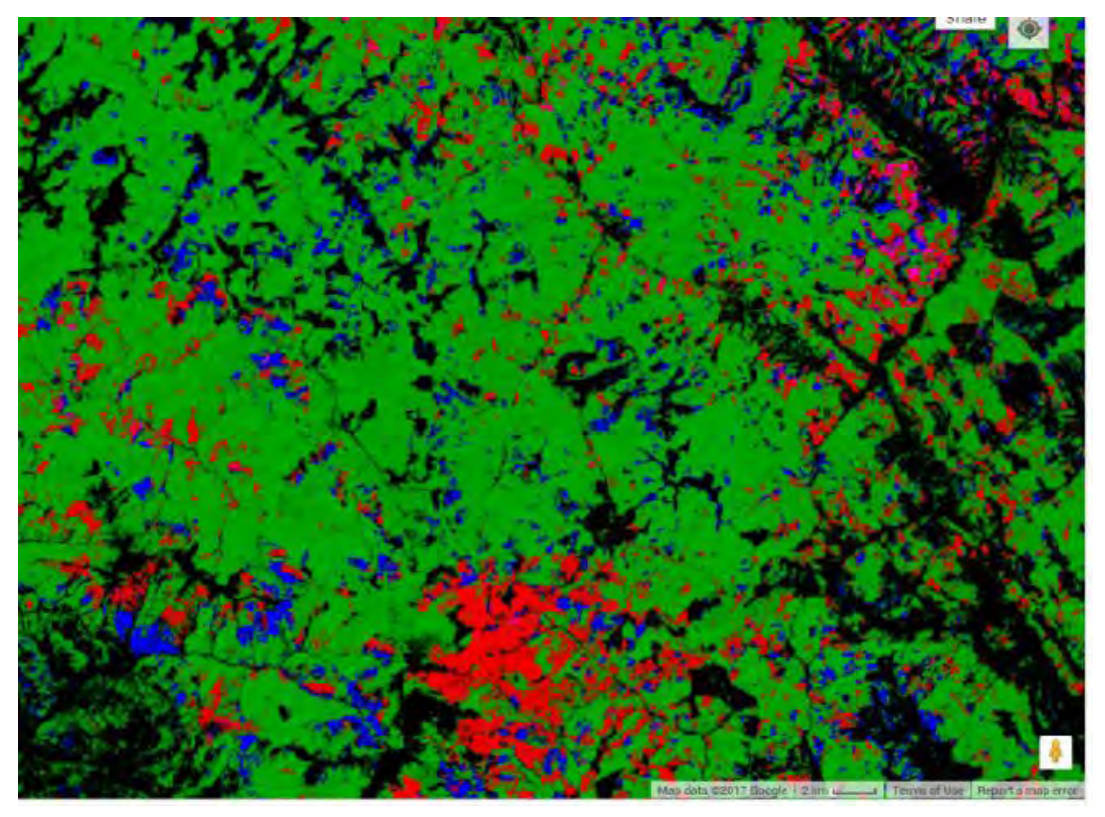

Figure 23 Landsat image analyses (Hansen et al. 2013) for a small part of Northern Carpathians. At $25 \times 25$ m resolution, the losses (red) and gains (blue) of forest cover can be seen for the period 2000-2013. Also annual comparisons are possible.

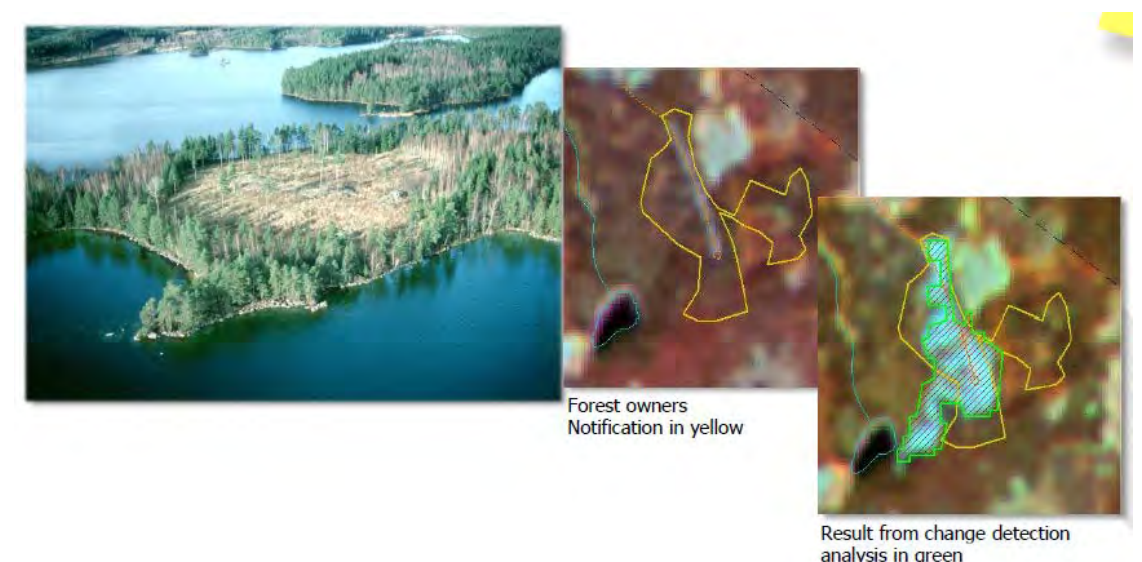

Figure 24 Skogsstyrelsen (The Swedish forestry Board) tracks every harvest permit which has been given, and can provide weekly updates of regenerated areas

\section{iii How to demonstrate that 'areas of high conservation value, including wetlands and peatlands, are protected'}

All countries have their own system of strict reserves, landscape parks, national parks etc. These have been identified and delineated in all EU countries and also in Canada, Russia and USA. On top the EU has its Natura2000 network mapped and implemented in national legislation. 
However, these delineations do not assure that no harvesting takes place in high conservation value sites. In the lower levels of protection (IUCN classes 1.2 - 3) harvesting can still take place, but at moderate levels and taking into account the site specifics.

But these delineated areas can demonstrate that a country has a system in place to sufficiently protect high conservation sites. See Figure 25. In addition a major pellet producer in the USA (Enviva) has an online system where the location and type of wood bought can be traced (Figure 26). This would be relatively easy to set up in most countries as all sold and bought wood is accompanied by tract papers anyway.
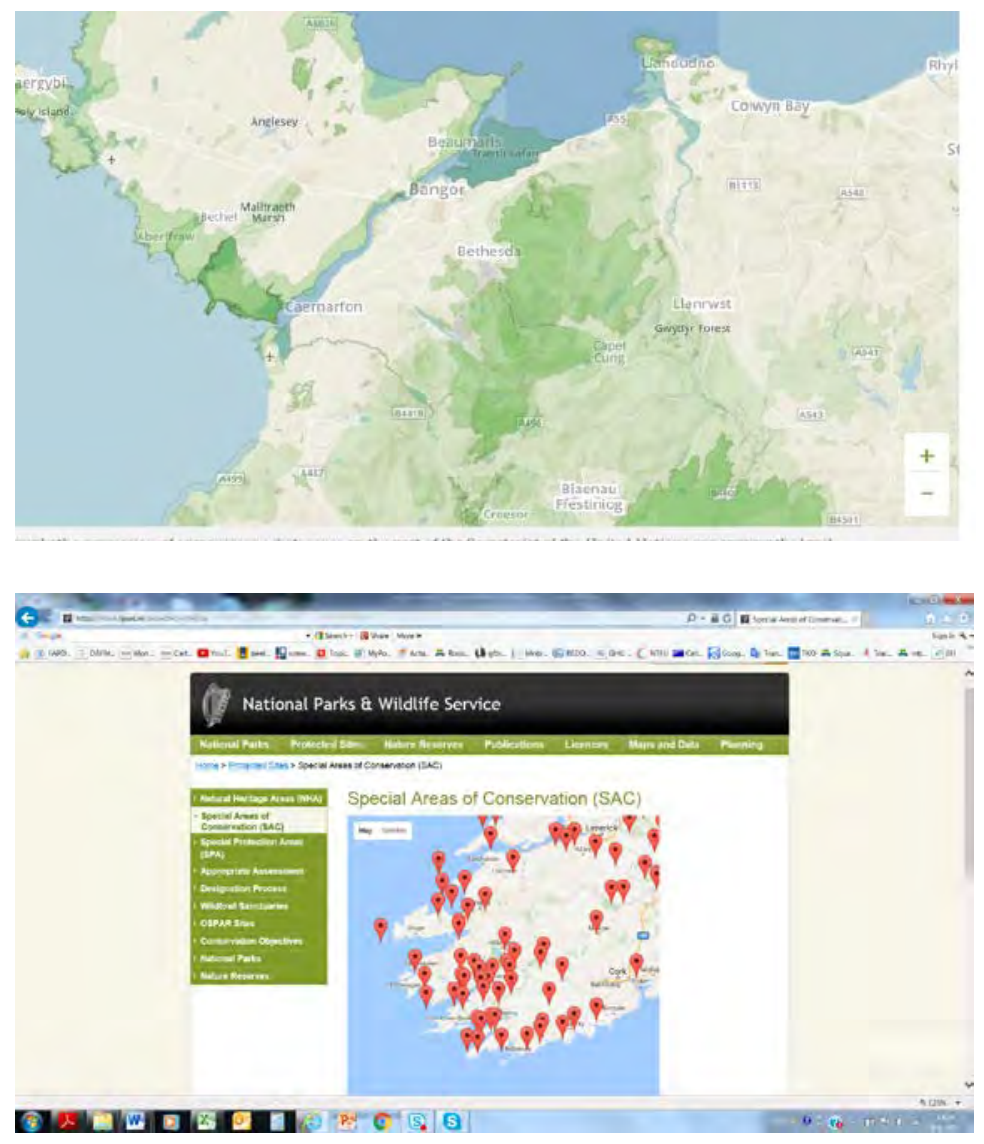

Figure 25 (top). Example of delineation of various levels of protection status, here around Snowdon national park, UK. Intensities of green indicate different protection statuses. Still, harvesting would be allowed on many IUCN categories. Especially on medium quality sites for biodiversity, unclear situations may occur. Source: IUCN https://www.protectedplanet.net/. Bottom: Irish systems of 'areas of conservation' and 'Special Protection Areas'. 


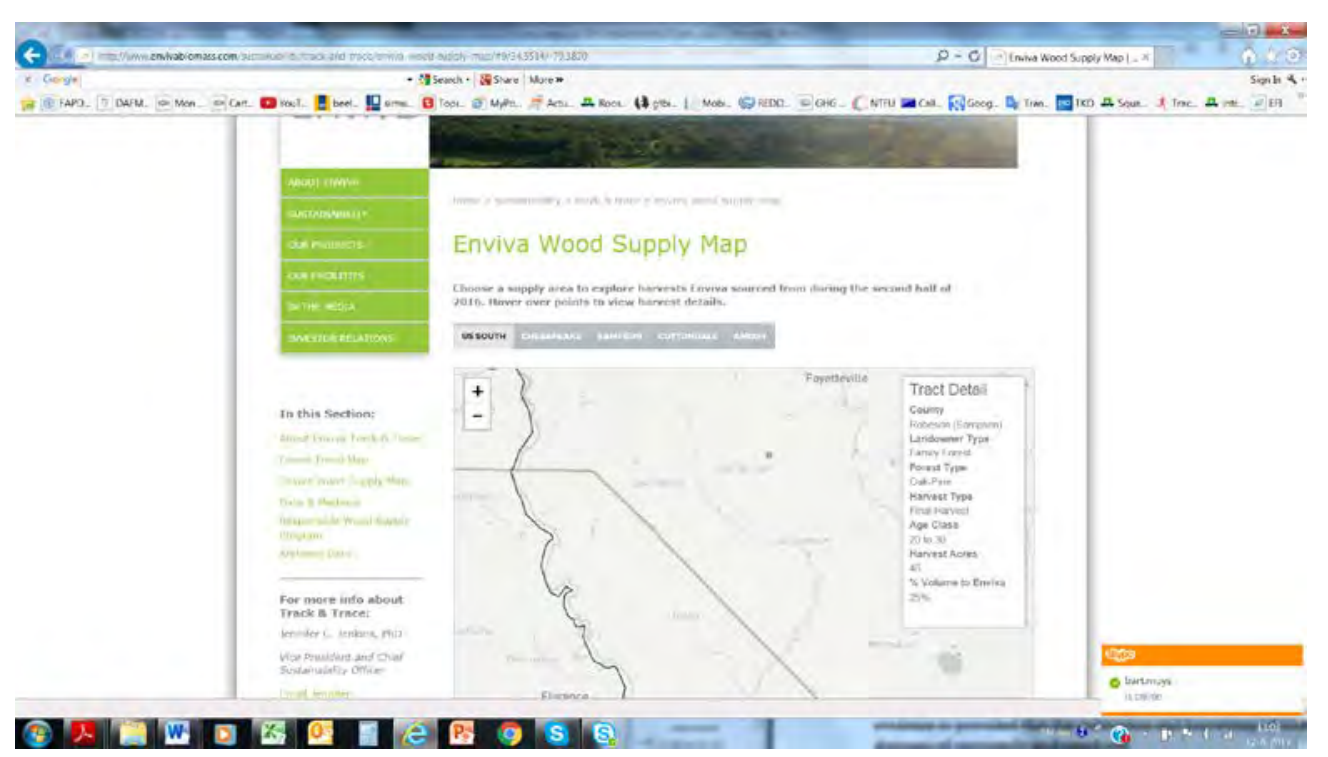

Figure 26 Enviva's track \& trace system. Every single harvest from which Enviva has bought wood, can be traced here. Here a small part of North Carolina is shown and one tract detail is given from Robeson county.

Also wetland and peatlands have been mapped as well and are often part of the above mentioned designated areas of high nature value, certainly for pristine peatlands in Europe. Large tracts of peatlands in Canada and Russia are often not designated as valuable in terms of biodiversity. There is a risk on those countries.

Drained and managed peatlands should not be regulated in this policy (and thus distinguished), often they have been subjected to past times drainage and planted with forest in Finland, Sweden, Scotland and I reland These are often 'normal' productive forests and should be distinguished somehow from pristine peatlands. Restrictions on these trivial production forests are not motivated by the objectives of this article.

If wetlands and peatlands are specifically addressed, there needs to be a distinction between trivial and valuable peatlands.

\section{iv How to demonstrate that 'the impacts of forest harvesting on soil quality and biodiversity are minimised'?}

This is probably the most difficult to interpret/implement in practice. No country has a good system in place that monitors soil quality. Even the term 'soil quality' is vague. Does it encompass physical quality, or also nutrient provision. Extraction of biomass as tops and branches would extract more nutrients than under conventional management. But it is hardly known how much nutrients are extracted and what is sustainable on various soil types. A country could demonstrate that it avoids harvesting on vulnerable soils (wet soils, steep slopes). These can be identified and delineated in countries where this has not been done yet. Some enforcement systems (like the one from Skogsstyrelsen) keep very good track of river sides, vulnerable soils, steep slopes, wetlands and would prevent harvesting, but these systems are rare. 


\section{Conclusions}

This report covers several supporting tasks for the Dutch Executive Agency RVO. A main share of the work was to increase awareness within RVO about the present state of LULUCF accounting, reporting, and the LULUCF regulation and Renewable Energy Directive itself. This is documented in chapters 3, 4 and 5 .

I mportant conclusion to make is that the LULUCF regulation does not change the manner in which harvested wood for bioenergy is accounted. If wood products are used to produce bioenergy the emissions which are the result of the burning of the wood are still reported and accounted at the time and the country of harvesting. To prevent double counting of the emissions at the point of burning the wood, emissions are counted as 0 , provided criteria of Sustainable Forest Management are met. . This means the burning of the wood at the energy producer is still counted as carbon neutral. Related carbon emissions are accounted in the LULUCF regulation.

\section{Woody biomass provision}

The new LULUCF regulations projects the forest sink into the future under a Forest Reference Level (FRL) (comparable to Kyoto Commitment period 2). This continued projected sink will not be accounted as an achievement of the Paris goals. Only small changes in the sink compared to the FRL, will create debits or credits for the Paris goals and this sink is strongly impacted by harvesting level. The future harvest level thus has a great impact on the FRL, which MS have to set.

The annual increment in the EU is $780 \mathrm{Mm} 3$ and this would theoretically be the maximum amount that can be harvested. However, the criteria for sustainable harvesting as negotiated reduce this potential. We quantified this harvesting possibilities under the LULUCF regulation, provided a country does not want to generate debits. The simulations showed that the EU 26 as a whole may have a harvest increase from 420 million $\mathrm{m}^{3}$ in 2000-2009 to 560 million $\mathrm{m}^{3}$ in 2050, complying to harvest intensity criteria, without creating debits compared to Forest Reference Level. If we however set a cutoff to comply to a sustainability criteria as $\max 90 \%$ of increment to be harvested for each individual country, then the harvest can only increase to $\mathbf{4 9 3} \mathbf{m i l l i o n} \mathbf{~ m}^{\mathbf{3}} / \mathbf{y}$. The felling/increment ratio then becomes $80 \%$ for the EU26 as a whole, with values for individual countries ranging between $56 \%$ and $90 \%$. It also shows that the increase of the harvest is limited and can increase only by $20 \%$ to 560 $\mathrm{Mm} 3$.

In the Netherlands the present annual growth is 2.7 Mm3. Simulations have shown that in the Netherlands the annual removal can increase from the $1 \mathrm{Mm} 3$ in 2000-2009 to $2 \mathrm{Mm} 3$ in 2050. So for the Netherlands the harvest could be doubled over the next decades within the constraints of the LULUCF regulation.

The big question is if countries will take harvesting under the forest reference Level as some sort of quota system, still driving up raw material prices even if there is not a real shortage to meet demand? If there will be a tightened supply from Europe, the current and future bio-economy industry will look at other continents. Thus favour imports. Then there are other articles in the LULUCF that may be seen as indications of cascading. E.g. a 'constant ratio between solid and energy use of forest biomass' hints in that direction. Currently, the share of wood going directly to energy is already large (noncommercial local fuelwood use amounts to $129 \mathrm{Mm} 3 / \mathrm{y}$ ). Thus it seems that such a requirement in the forest accounting plan, will not have a large impact. Maybe a larger impact on imports of biomass are requirements in the RED stating that the country of origin of the biomass must be signatory of the Paris agreement. If not, then supply base assurances that carbon stocks are maintained, must be made. The question is how this will work out for biomass originating from the USA.

\section{Agricultural biomass provision}

The sustainable straw potential for bioenergy was quantified. Calculations for the Netherlands indicate that about 700 kton (dry matter) of straw residues is potentially available, mainly coming from barley and wheat. The soil carbon balance calculation shows that about 150 kton is required for maintaining 
soil carbon, which means that about 600 kton would be available. However, most of this straw is already used in the livestock sectors as fodder and bedding material, which means that the potential of straw for bioenergy is very limited in the Netherlands.

In the new EU LULUCF regulation managed cropland and managed grassland become obligatory accounting categories. This incentives, together with the flexibility mechanism of the Effort Sharing Regulation, the measures that stimulate carbon sequestration and reduction of emissions from organic soils on agricultural land. The legislation might have indirect effects through increased competition between biomass for energy use and biomass for soil carbon sequestration.

\section{Action Plan Forest and Wood and criteria}

The accounting rules in the new LUUCF regulation are not very different from the earlier Kyoto accounting. As such the views on using biomass for bioenergy, or the accounting of afforestation and changes in forest management will hardly change. New policies designed and implemented after 2009 to stimulate afforestation and better forest management will still be accounted (up to a maximum number of credits) as was the case under Kyoto Protocol. Only the setting of the Forest reference level is more bound to rules, including a share of wood used for energy.

Only touched upon rather briefly in this report, the biomass criteria do not seem to conflict with the LULUCF regulation; the biomass criteria can help to avoid risk of carbon debt. The LULUCF may have some impact on total harvesTable amounts. Also the enforced forest policies and the available information systems to monitor and enforce are briefly reviewed and seem at first glance adequate. 


\section{References}

Arets, E. J. M. M., J. W. H. van der Kolk, G. M. Hengeveld, J. P. Lesschen, H. Kramer, P. J. Kuikman and M. J. Schelhaas. (2017). Greenhouse gas reporting of the LULUCF sector in the Netherlands. Methodological background, update 2017. WOt Technical report 95. Statutory Research Tasks Unit for Nature \& the Environment (WOT Natuur \& Milieu), Wageningen UR, Wageningen, The Netherlands. http://edepot.wur.nl/418559.

Arets, E. J. M. M., P. J. van der Meer, C. C. Verwer, G. J. Nabuurs, G. M. Hengeveld, G. W. Tolkamp and M. van Oorschot. (2011). Global wood production: Assessment of industrial round wood supply from different management systems in different global regions. Alterra Report 1808. Alterra, Wageningen UR, Wageningen, The Netherlands. http://edepot. wur. nl/196265.

Coenen, P. W. H. G., C. W. M. Maas, P. J. Zijlema, E. J. M. M. Arets, K. Baas, A. C. W. M. van den Berghe, E. P. van Huis, G. Geilenkirchen, M. Hoogsteen, J. Spijker, R. te Molder, R. Dröge, J. A. Montfoort, C. J. Peek, J. Vonk, S. Oude Voshaar and S. Dellaert. (2017). Greenhouse gas emissions in the Netherlands 1990-2015. National Inventory Report 2017. RIVM; National Institute for Public Health and Environment, Bilthoven, The Netherlands. http://dx.doi.org/10.21945/RIVM-2017-0033.

Coleman, K. and D. S. Jenkinson. (1999). RothC-26.3 - A Model for the turnover of carbon in soil : Model description and windows users guide. Rothamsted Research, Harpenden, UK.

Daamen, W. and G. M. Dirkse. (2005). Veldinstructie. Meetnet FunctieVervulling 2005

de Wit, M. P., J. P. Lesschen, M. H. M. Londo and A. P. C. Faaij. (2014). Greenhouse gas mitigation effects of integrating biomass production into European agriculture. Biofuels, Bioproducts and Biorefining 8:374-390.

Dirkse, G. M., W. P. Daamen, H. Schoonderwoerd, M. Japink, M. van Jole, R. van Moorsel, W. J. Schnitger and M. Vocks. (2007). Meetnet Functievervulling bos 2001-2005. Vijfde Nederlandse Bosstatistiek. Directie Kennis, Ministerie van Landbouw, Natuur en Voedselkwaliteit.

European Commission 2016a. Proposal for a REGULATION OF THE EUROPEAN PARLIAMENT AND OF THE COUNCIL on the inclusion of greenhouse gas emissions and removals from land use, land use change and forestry into the 2030 climate and energy framework and amending Regulation No $525 / 2013$ of the European Parliament and the Council on a mechanism for monitoring and reporting greenhouse gas emissions and other information relevant to climate change. Brussels, 20.7.2016 $\operatorname{COM(2016)~} 479$ final 2016/0230 (COD). 37 p.

European Commission 2016b. Proposal for a Regulation of the European Parliament and of the Council on the inclusion of greenhouse gas emissions and removals from land use, land use change and forestry into the 2030 climate and energy framework and amending Regulation No $525 / 2013$ of the European Parliament and the Council on a mechanism for monitoring and reporting greenhouse gas emissions (First reading). 11494/16 - COM(2016) 479 Final . Interinstitutional file. $42 \mathrm{p}$.

European Council. 2017. Proposal for a Regulation of the European Parliament and of the Council on the Inclusion of Greenhouse Gas Emissions and Removals from Land Use, Land Use Change and Forestry into the 2030 Climate and Energy Framework and Amending Regulation No 525/2013 of the European Parliament and the Council on

a Mechanism for Monitoring and Reporting Greenhouse Gas Emissions; European Council: Brussels, Belgium, 2017; 42p.

Ellison, D., M. Lundblad and H. Petersson. (2014). Reforming the EU approach to LULUCF and the climate policy framework. Environmental Science \& Policy 40:1-15.

Fingerman, K. R., G. J. Nabuurs, L. I riarte, U. R. Fritsche, I. Staritsky, L. Visser, T. Mai-Moulin and M. Junginger. (2017). Opportunities and risks for sustainable biomass export from the south-eastern United States to Europe. Biofuels, Bioproducts and Biorefining 0.

Forest Europe. (2015). State of Europe's Forests 2015. Ministerial Conference on the Protection of Forests in Europe, Forest Europe Liaison Unit Madrid, Madrid, Spain. 
Grassi, G. and R. Pilli. (2017). Projecting the EU forest carbon net emissions in line with the 'continuation of forest management': the JRC method. Publications office of the European Union, Luxemburg.

Hansen, M. C., P. V. Potapov, R. Moore, M. Hancher, S. A. Turubanova, A. Tyukavina, D. Thau, S. V. Stehman, S. J. Goetz, T. R. Loveland, A. Kommareddy, A. Egorov, L. Chini, C. O. Justice and J. R. G. Townshend. (2013). High-Resolution Global Maps of 21st-Century Forest Cover Change. Science 342:850-853.

IPCC. (2006). 2006 IPCC Guidelines for National Greenhouse Gas Inventories, Volume 4, Agriculture, Forestry and Other Land Use. IPCC National Greenhouse Gas I nventories Programme. Published by the Institute for Global Environmental Strategies (IGES), Kanagawa, Japan.

Kallio, M., B. Solberg, L. Käär and R. Päivinen. (2017). Economic impacts of the potential EU forest carbon sink policies on the forest-based sectors. Tapio, Helsinki, Finland, Presented 6 September 2017 in Brussels.

Lawrence, M., R. E. McRoberts, E. Tomppo, T. Gschwantner and K. Gabler. (2010). Comparisons of National Forest Inventories. Pages 19-32 in E. Tomppo, T. Gschwantner, M. Lawrence, and R. E. McRoberts, editors. National Forest Inventories: Pathways for Common Reporting. Springer Netherlands, Dordrecht.

Lesschen, J. P., M. van den Berg, H. J. Westhoek, H. P. Witzke and O. Oenema. (2011). Greenhouse gas emission profiles of European livestock sectors. Animal Feed Science and Technology 166167: 16-28.

Nabuurs, G.-J ., M. Lindner, P. J. Verkerk, K. Gunia, P. Deda, R. Michalak and G. Grassi. (2013). First signs of carbon sink saturation in European forest biomass. Nature Climate Change 3: 792-796.

Nabuurs, G. J., P. Delacote, D. Ellison, M. Hanewinkel, M. Lindner, M. Nesbit, M. Ollikainen and A. Savaresi. (2015). A new role for forests and the forest sector in the EU post-2020 climate targets. European Forest Institute http://edepot. wur.nl/371799.

Nabuurs, G. J., A. Pussinen, J. v. Brusselen and M. J. Schelhaas. (2007). Future harvesting pressure on European forests. European Journal of Forest Research 126:391-400.

Pretzsch, H., P. Biber, G. Schütze, E. Uhl and T. Rötzer. (2014). Forest stand growth dynamics in Central Europe have accelerated since 1870. Nature Communications 5:4967.

Sallnäs, O. (1990). A matrix growth model of the Swedish forest. Studia Forestalia Suecica 183.

Sathre, R. and J. O'Connor. (2010). Meta-analysis of greenhouse gas displacement factors of wood product substitution. Environmental Science \& Policy 13:104-114.

Scarlat, N., M. Martinov and J.-F. Dallemand. (2010). Assessment of the availability of agricultural crop residues in the European Union: Potential and limitations for bioenergy use. Waste Management 30: 1889-1897.

Schelhaas, M., A. P. P. M. Clerkx, W. P. Daamen, J. F. Oldenburger, G. Velema, P. Schnitger, H. Schoonderwoerd and H. Kramer. (2014). Zesde Nederlandse bosinventarisatie : methoden en basisresultaten. Alterra-rapport 2545. Alterra Wageningen UR, Wageningen, The Netherlands. http://edepot. wur.nl/307709.

Schoonderwoerd, H. and W. P. Daamen. (1999). Houtoogst en bosontwikkeling in het Nederlandse bos: 1984-1997. Reeks: HOSP, Bosdata nr 3. Stichting Bosdata, Wageningen, The Netherlands.

Schoots, K., M. Hekkenberg and P. Hammingh, editors (2017). Nationale Energieverkenning 2017. Energieonderzoek Centrum Nederland (ECN), with PBL Netherlands Environmental Assessment Agency, Statistics Netherlands (CBS) and Netherlands Enterprise Agency (RVO), Petten, The Netherlands.

Strange Olesen, A., J. P. Lesschen, M. Rayment, N. Ebrahim, P. Weiss, E. J. M. M. Arets, A. FrelihLarsen, N. Sikirica, G. J. Nabuurs and M. Schelhaas. (2016). Agriculture and LULUCF in the 2030 Framework. European Union, Luxembourg. http://edepot.wur.nl/405796.

UNECE/FAO. (2011). The European Forest Sector Outlook Study II. United Nations Economic Commission for Europe (UNECE) and Food and Agriculture Organisation of the United Nations (FAO), Geneva, Switzerland.

Velthof, G. L., D. Oudendag, H. R. Witzke, W. A. H. Asman, Z. Klimont and O. Oenema. (2009). Integrated Assessment of Nitrogen Losses from Agriculture in EU-27 using MITERRA-EUROPE. Journal of Environmental Quality 38:402-417.

Verkerk, P. J., M. J. Schelhaas, V. Immonen, G. M. Hengeveld, J. Kiljunen, M. Lindner, G. J. Nabuurs, T. Suominen and S. Zudin. (2016). Manual for the European Forest Information Scenario model (EFISCEN 4.1). EFI Technical Report 99. European Forest Institute http://edepot. wur.nl/403059. 


\section{Annex 1 Glossary}

Activity-based. starting point of this accounting is the carbon stock change attribuTable to designated LULUCF activities. First, each applicable activity's impact on carbon stocks is determined per unit area. This impact is multiplied by the area on which each activity occurs. This equation may also include adjustments to reflect policy decisions by the Parties. Aggregate emissions or removals are calculated by summing across applicable activities. Potentially, a given area of land could be counted more than once if it is subject to multiple activities. This potential double-counting could result in inaccurate accounting if the effects of activities are not additive

\section{Afforestation}

Planting of new forests on lands that historically have not contained forests. For a discussion of the term forest and related terms such as afforestation, reforestation and deforestation, see the IPCC Special Report on Land Use, Land-Use Change, and Forestry (IPCC, 2000b). See also information provided by the United Nations Framework Convention on Climate Change (UNFCCC, 2013) and the report on Definitions and Methodological Options to Inventory Emissions from Direct Human-induced Degradation of Forests and Devegetation of Other Vegetation Types (IPCC, 2003, WGI, III).

AFOLU Agriculture, Forestry and Other Land Use (AFOLU) is a term from the 2006 Intergovernmental Panel on Climate Change (IPCC) Guidelines describing a category of activities which contribute to anthropogenic greenhouse gas emissions. Used in national greenhouse gas inventories, the AFOLU category combines two previously distinct sectors LULUCF (Land Use, Land Use Change and Forestry) and Agriculture (i.e. the animals of Agriculture, incl N2O and $\mathrm{CH} 4$ ).

Carbon accounting refers generally to processes undertaken to 'measure' amounts of carbon dioxide equivalents emitted/sequestered by an entity as compared to a target emission or sink. It is used by nation states, corporations, individuals - to create the carbon credit commodity. Correspondingly, examples for products based upon forms of carbon accounting can be found in national inventories, corporate environmental reports or carbon footprint calculators.

\section{Carbon Flux}

Transfer of carbon from one carbon pool to another in units of measurement of mass per unit area and time (e.g., t C ha-1 y-1).

\section{Carbon Pool}

A reservoir. A system which has the capacity to accumulate or release carbon. Examples of carbon pools are forest biomass, wood products, soils, and atmosphere. The units are mass (e.g., t C).

\section{Carbon budget}

The balance of the exchanges of carbon between carbon pools or within one specific loop (e.g., atmosphere - biosphere) of the carbon cycle.

\section{Carbon dioxide equivalent}

A measure used to compare different greenhouse gases based on their contribution to radiative forcing. The

UNFCCC currently (2005) uses global warming potentials (GWPs) as factors to calculate carbon dioxide equivalent (see below).

\section{Carbon Stock}

The absolute quantity of carbon held within a pool at a specified time. 


\section{Emission factor}

A coefficient that quantifies the emissions or removals of a gas per unit activity. Emission factors are often based on a sample of measurement data, averaged to develop a representative rate of emission for a given activity level under a given set of operating conditions

Global warming potential A factor used to calculate the cumulative radiative forcing impact of multiple specific (GWP) GHGs in a comparable way. 10

Indirect land-use change When the demand for a specific land use induces a carbon stock change on other lands.

Land use categories Forest land, cropland, grassland, wetlands, settlements and other lands. 11 Land-use change Occurs when the demand for a specific land use results in a change in carbon stocks on that land, due to either a conversion from one land-use category to another or a conversion within a land-use category.

Land-use change impacts Emissions and removals due to land-use change.

LULUCF: Land use, Land use change and forest sector. LULUCF stands for Land Use, Land Use Change and Forestry. It is one of the sectors under the United Nations Framework on Climate Change that measures and accounts for emissions and removals of $\mathrm{CO}_{2}$ from land and forests. It is an essential part of EU climate policy which aims to reduce EU greenhouse gas emissions to at least 40 per cent below 1990 levels by 2030. LULUCF is an unusual sector in that it measures not just carbon releases, but also carbon removals. This is because when a tree grows it temporarily sequesters $\mathrm{CO}_{2}$, and when it dies or is removed, it releases the $\mathrm{CO}_{2}$ back into the atmosphere. Across the EU, LULUCF presently removes more carbon from the atmosphere than it releases. This means it is a carbon sink.

\section{Mitigation ( of climate change)}

A human intervention to reduce the sources or enhance the sinks of greenhouse gases (GHGs). This report also assesses human interventions to reduce the sources of other substances which may contribute directly or indirectly to limiting climate change, including, for example, the reduction of particulate matter emissions that can directly alter the radiation balance (e.g., black carbon) or measures that control emissions of carbon monoxide, nitrogen oxides, Volatile Organic Compounds and other pollutants that can alter the concentration of tropospheric ozone which has an indirect effect on the climate. (WGI, II, III)

\section{Reforestation}

Planting of forests on lands that have previously contained forests but that have been converted to some other use. For a discussion of the term forest and related terms such as afforestation, reforestation and deforestation, see the IPCC Special Report on Land Use, Land-Use Change, and Forestry (IPCC, 2000b). See also information provided by the United Nations Framework Convention on Climate Change (UNFCCC, 2013). See also the Report on Definitions and Methodological Options to Inventory Emissions from Direct Human-induced Degradation of Forests and Devegetation of Other Vegetation Types (IPCC, 2003, WGI, II, III)

\section{Reporting}

The process of providing results of the inventory, as complete and precise as possible as the atmosphere sees it. (see also carbon accounting). e.g. a person weighs 80 kilo in year 0 , and 77 kilos after 5 years. Then 80 and 77 are reported. But he may have had goal of going to 70 kilos. Then he has underachieved with 7 kilo. In accounting 7 kilos debit would be accounted.

\section{Sequestration}

The process of increasing the carbon content of a carbon pool other than the atmosphere.

Silviculture is the practice of controlling the establishment, growth, composition, health, and quality of forests to meet diverse needs and values. The name comes from the Latin silvi- (forest) + culture (as in growing). 


\section{Source}

Opposite of sink. A carbon pool (reservoir) can be a source of carbon to the atmosphere if less carbon is flowing into it than is flowing out of it.

\section{Wood Products}

Products derived from the harvested wood from a forest, including fuelwood and logs and the products derived from them such as sawn timber, plywood, wood pulp, paper, etc. 


\section{Annex 2 Accounting principles for EU forests before 2020}

Besides the reporting under the climate convention (UNFCCC), until 2020 emissions and removals are accounted under the Kyoto Protocol (KP), under which parties have agreed specific targets on emission reductions compared to a base year, which for most parties, and emission sectors is 1990 .

For LULUCF accounting under the Kyoto Protocol three different ways of accounting are considered:

1. Gross-net accounting: This implies that the full emissions and removals in a given year are included in the accounted quantity.

2. Net-net accounting compared to a base-year: The emissions in the accounting year are compared against the emissions and removals in the base-year (eg.1990).

3. Net-net accounting against a reference level: The emissions or removals in the accounting year are compared against projected emissions and removals for the same year providing an estimate for the expected emissions and removals in that year under certain policy and management assumptions.

In order to focus more on the human induced emissions and removals the accounting under KP is not based on the land categories as used under the UNFCCC, but rather on related activities:

afforestation/reforestation, deforestation, forest management, cropland management, grazing land management, etc. (Figure A1). Under the KP in the second commitment period (CP2, 2013-2020) afforestation and reforestation, deforestation and forest management are the mandatory activities for accounting, while the other activities can be accounted by parties voluntarily (if decided to do so before the start of the period). The Netherlands has chosen to only account the mandatory activities.

\begin{tabular}{|c|c|c|c|c|}
\hline UNFCCC & KP (CP2) & & 479/2016/EU & \\
\hline Reporting & Reporting & Accounting & Reporting & Accounting \\
\hline $\begin{array}{l}\text { CL Cropland }\left(\mathrm{CO}_{2}\right) \\
\text { (GL Grassland }\left(\mathrm{CO}_{2}\right) \\
\text { WL Wetland } \\
\text { (5) Settlements } \\
\text { O Other }\end{array}$ & $\begin{array}{l}\text { GHG only from direct } \\
\text { human induced } \\
\text { activities } \\
\text { AR Aff/Reforestation } \\
\text { D Deforestation } \\
\text { FM Forest Management } \\
\frac{ \pm \text { HWP }}{\text { AM Cropland manag. }} \\
\text { GM Grazing land manag. } \\
\text { ND: Wetland drain./rewet. } \\
\text { RV Revegetation }\end{array}$ & $\begin{array}{l}\text { Mandatory, gross- } \\
\text { net } \\
\text { Mandatory, ref level } \\
\text { +cap } \\
\\
\text { Voluntary, net-net } \\
\text { (relative to 1990) }\end{array}$ & $\begin{array}{l}\text { GHG only from managed } \\
\text { land } \\
\text { activities } \\
\text { AR Afforested land } \\
\text { (D) Deforested land } \\
\text { FM Managed Forest Land } \\
\text { +HWP } \\
\text { CM Managed Cropland } \\
\text { GM Managed Grassland } \\
\text { WM Managed wetland }\end{array}$ & $\begin{array}{l}\text {-Mandatory, gross-net } \\
\text { - Mandatory, ref level } \\
\text { +cap (-compensation) } \\
\text { - Mandatory, net-net rel. } \\
\text { to base period } \\
\text { - Voluntary, net-net rel. } \\
\text { to base period }\end{array}$ \\
\hline
\end{tabular}

Figure A1 Overview of reporting under UNFCCC, reporting and accounting under KP (CP2) and the proposed accounting under 479/2016/EU. 


\section{Afforestation/ reforestation}

Units of land subject Afforestation and Reforestation (AR) are defined as units of land that did not comply with the forest definition on 1 January 1990 and do so at any moment (that can be measured) before 31 December of the reporting year. Land is classified as AR as long as it complies with the forest definition. Afforestation and Reforestation are accounted gross-net, i.e. all net emissions or removals in a given year will be accounted for this activity.

\section{Deforestation}

Units of land subject to Deforestation are defined as units of land that did comply with the forest definition at any moment in time on or after 1 January 1990, and ceased to comply with this forest definition at any moment in time (that can be measured) after $1 \mathrm{~J}$ anuary 1990. Once land is classified as deforested, it remains in this category, even if it is reforested and thus complies with the forest definition again later in time. Deforestation is also accounted gross-net, i.e. all net emissions or removals in a given year will be accounted for this activity.

\section{Forest Management}

Units of land subject to Article 3.4 Forest Management are units of land meeting the definition of forest that is managed for stewardship and use of forest land since 1 J anuary 1990 up until the reporting year. For this the Netherlands applies the broad interpretation of Forest Management. As a result all forest land under the UNFCCC that is not classified as AR or D land will be classified as FM. Further, since all forest land in the Netherlands is considered to be managed land, and conversions from other land uses to forest land are always human induced, such conversions to forest land will always be reported under AR.

Ever since the discussions towards the Kyoto Protocol in the early nineties, the paradigm has been that many countries in the Northern Hemisphere already had substantial amounts of new (replanted) forests on their territory, with a significant sink caused by earlier activities. Since this is a long living ecosystem, the reasoning was that countries should not simply be granted a substantial sink (=credit) because they already had those forests. The fear was also that countries would simply tick off the sink as an achievement towards emission reduction goals.

Thus, only those parts of the sink for which additional efforts were made were to be credited. The basic principle of the KP accounting rules until 2020 has been that countries rather independently project their sink into the future (using age class distributions and foreseen management and harvest intensities based on current and planned policies) and that would be set as the 'forest management reference level' (FMRL). There is no unified approach given for this.

Under this net-net accounting compared to the FMRL only the additional carbon sink on top of this FMRL can be credited, i.e. used to achieve the emission reduction target. But also this additional carbon sink above the reference level has a maximum; it is 'capped' at 3.5\% of the countries' base year emissions. As a result the room to include credits from Forest Management differs between countries.

The guidelines for setting the FMRL are flexible for implementing different approaches. The FMRL's for the CP2 had to be submitted to the UNFCCC in 2009. Based on the synthesis report of the technical assessments of the forest management reference level ${ }^{12}$ :

1. Projections of 'business-as-usual' based on policy and economic scenarios and models:

a. Country specific approaches (10 MS)

b. Common approach developed by the JRC (14 MS)

2. Average removals during the historical time series (1MS)

3. Linear extrapolation of historical emission data (2 MS)

Now being half-way the KP CP2, analysis of the reported Forest Management sink compared to the FMRL by the EU28 Member States shows a large gap between these two, potentially leading to relatively large amounts of credits (depending on the cap for the different MS). It appears that especially by using policy scenarios for FMRL projections, future harvesting has been overestimated for MS that applied this approach. The projections for the FMRL were mostly made in the course of 2009

\footnotetext{
${ }^{12}$ http://unfccc.int/resource/docs/2011/awg16/eng/inf02.pdf
} 
and included policies and economic information up to April 2009. This was in a time that the full scope and duration of the economic crisis that started in 2008 was not yet known. It is likely therefore that the projections for wood demand and thus the harvest rates in the FMRL projections were strongly overestimated. This in turn resulted in an underestimation of the net $\mathrm{CO}_{2}$ removals in the FMRL. For a more detailed analysis see Strange Olesen et al. (2016).

To avoid double counting of emissions and emission reductions under the KP the decisions and guidelines provide guidance on which emissions are reported under which sector. As a result of this the possible emissions resulting from the removal of biomass are accounted for in the LULUCF sector. At the same time in the energy sector the use of biomass for energy purposes is considered climate neutral and does not generate additional emissions. Potential substitution effects of e.g. bioenergy therefore become implicitly visible in the energy sector as reduced fossil fuel use. Thus this effect is not accounted explicitly.

For the same reason of preventing double counting of emissions or removals there are guidelines on accounting of carbon stock changes in harvested wood products (HWP). These are accounted in the producing country, which is referred to as the production approach. This means that wood that for instance is harvested in Finland and then exported to the Netherlands will be accounted in the HWP category by Finland. Possible implicit substitution effects of using this wood to replace other more energy intensive materials like concrete or steel will then contribute to the reduction of the emissions in those sectors in the Netherlands. Wood that is used for energy purposes has to be accounted assuming instantaneous oxidation, meaning that all carbon in the wood is emitted instantaneous. For this the same rules are in place. The producing country will need to include these instantaneous emissions in its accounting, while an importing country using the wood will benefit from reduced emissions in the energy sector.

If importing fuel wood from a country that is not a party under the Kyoto Protocol, the emissions from HWP, which should be accounted for in the producing country, will not be included in KP accounting. The importing country will consider this wood fuel as climate neutral in its own accounting. As a result there will an accounting gap. For instance emissions associated with wood imported from the USA will not be accounted under the KP. Nevertheless, the USA being an Annex I party under the UNFCCC should report these emissions in its UNFCCC reporting. 
Wageningen Environmental Research

\section{P.O. Box 47}

6700 AA Wageningen

The Netherlands

$\mathrm{T}+31(0) 317480700$

www.wur.nl/environmental-research

Wageningen Environmental Research

Report 2886

ISSN 1566-7197
The mission of Wageningen University \& Research is 'To explore the potential of nature to improve the quality of life'. Under the banner Wageningen University \& Research, Wageningen University and the specialised research institutes of the Wageningen Research Foundation have joined forces in contributing to finding solutions to important questions in the domain of healthy food and living environment. With its roughly 30 branches, 5,000 employees and 10,000 students, Wageningen University \& Research is one of the leading organisations in its domain. The unique Wageningen approach lies in its integrated approach to issues and the collaboration between different disciplines.

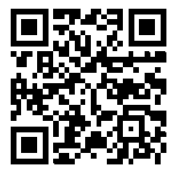





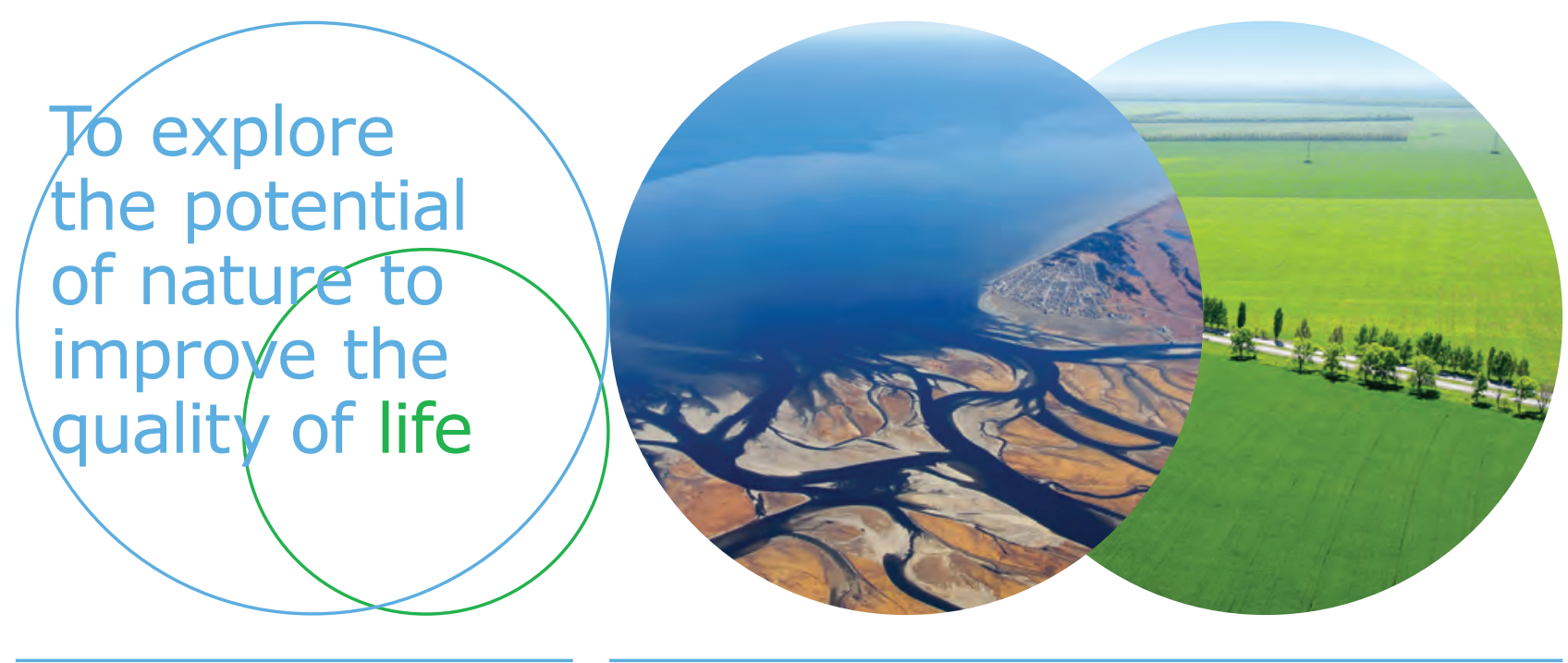

Wageningen Environmental Research P.O. Box 47

$6700 \mathrm{AB}$ Wageningen

The Netherlands

$T+31(0) 317480700$

www.wur.eu/environmental-research

Report 2886

ISSN 1566-7197
The mission of Wageningen University \& Research is "To explore the potential of nature to improve the quality of life". Under the banner Wageningen University $\&$ Research, Wageningen University and the specialised research institutes of the Wageningen Research Foundation have joined forces in contributing to inding solutions to important questions in the domain of healthy food and living environment. With its roughly 30 branches, 5,000 employees and 10,000 students, Wageningen University \& Research is one of the leading organisations in its domain. The unique Wageningen approach lies in its integrated approach to issues and the collaboration between different disciplines. 